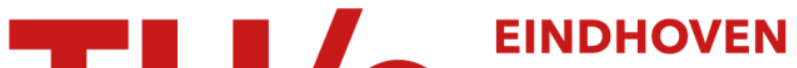 UNIVERSITY OF TECHNOLOGY
}

\section{Liquid phase oxidation chemistry in continuous-flow microreactors}

\section{Citation for published version (APA):}

Gemoets, H. P. L., Su, Y., Shang, M., Hessel, V., Luque, R., \& Noel, T. (2016). Liquid phase oxidation chemistry in continuous-flow microreactors. Chemical Society Reviews, 45(1), 83-117. https://doi.org/10.1039/c5cs00447k

DOI:

10.1039/c5cs00447k

Document status and date:

Published: 01/01/2016

\section{Document Version:}

Accepted manuscript including changes made at the peer-review stage

\section{Please check the document version of this publication:}

- A submitted manuscript is the version of the article upon submission and before peer-review. There can be important differences between the submitted version and the official published version of record. People interested in the research are advised to contact the author for the final version of the publication, or visit the $\mathrm{DOI}$ to the publisher's website.

- The final author version and the galley proof are versions of the publication after peer review.

- The final published version features the final layout of the paper including the volume, issue and page numbers.

Link to publication

\section{General rights}

Copyright and moral rights for the publications made accessible in the public portal are retained by the authors and/or other copyright owners and it is a condition of accessing publications that users recognise and abide by the legal requirements associated with these rights.

- Users may download and print one copy of any publication from the public portal for the purpose of private study or research.

- You may not further distribute the material or use it for any profit-making activity or commercial gain

- You may freely distribute the URL identifying the publication in the public portal.

If the publication is distributed under the terms of Article $25 \mathrm{fa}$ of the Dutch Copyright Act, indicated by the "Taverne" license above, please follow below link for the End User Agreement:

www.tue.nl/taverne

Take down policy

If you believe that this document breaches copyright please contact us at:

openaccess@tue.nl

providing details and we will investigate your claim. 


\section{Chem Soc Rev}

\section{Critical Review}

\section{Liquid phase oxidation chemistry in continuous-flow microreactors}

O0Received 00th January 20xx, Accepted 00th January 20xx

DOI: $10.1039 / \times 0 \times x 00000 x$

www.rsc.org/

\author{
Hannes P. L. Gemoets ${ }^{a}$, Yuanhai Sua , Minjing Shanga, Volker Hessela, Rafael Luque $^{b}$ and Timothy \\ Noël*a,c
}

\begin{abstract}
Continuous-flow liquid phase oxidation chemistry in microreactors receives a lot of attention as the reactor provides enhanced heat and mass transfer characteristics, safe use of hazardous oxidants, high interfacial areas, and scale-up potential. In this review, an up-to-date overview of both technological and chemical aspects of liquid phase oxidation chemistry in continuous-flow microreactors is given. A description of mass and heat transfer phenomena is provided and fundamental principles are deduced which can be used to make a judicious choice for a suitable reactor. In addition, the safety aspects of continuous-flow technology are discussed. Next, oxidation chemistry in flow is discussed, including the use of oxygen, hydrogen peroxide, ozone and other oxidants in flow. Finally, the scale-up potential for continuous-flow reactors is described.
\end{abstract}

\section{Introduction}

Liquid phase oxidation processes are one of main pathways to convert petroleum-based hydrocarbon raw materials into important commodity chemicals used in the fine chemical industry. ${ }^{1-3}$ Throughout the years, there have been some wellknown liquid phase oxidations realized in an industrial setting, such as the preparation of terephthalic acid, cumene peroxide, adipic acid, acetaldehyde, propylene oxide. Despite these landmark achievements from the past, new reaction routines and techniques are still highly required due to increasingly stringent government regulations concerning the emission of organic and inorganic wastes and the related environmental and safety impact. ${ }^{4}$

Several issues are associated with liquid phase oxidation chemistry. Hydrocarbon molecules possess several reactive sites, and thus various products/by-products can be formed in liquid oxidation processes. These selectivity issues are one of the main reasons why aerobic oxidation chemistry is often avoided in the pharmaceutical industry. Thus, the design of new and improved catalysts and oxidants to increase the selectivity remains a vigorous research discipline. ${ }^{5-11}$ Furthermore, reaction mechanisms are often complex for oxidation processes. ${ }^{12-15}$ The complexity is further aggravated by complex mass transport processes in e.g., multiphase oxidation processes using oxidants such as oxygen, ozone or

\footnotetext{
a. Department of Chemical Engineering and Chemistry, Micro Flow Chemistry \& Process Technology, Eindhoven University of Technology, Den Dolech 2, $5612 \mathrm{AZ}$ Eindhoven, The Netherlands

E-mail:t.noel@tue.nl

b. Departamento de Quimica Organica, Universidad de Cordoba, Edificio Marie Curie (C-3), Campus de Rabanales, Ctra. Nnal. IV-A, Km 396, E14014 Cordoba, Spain.

c. Department of Organic Chemistry, Ghent University, Krijgslaan 281 (S4), 9000 Ghent, Belgium.
}

hydrogen peroxide. ${ }^{16-18}$ This is more pronounced in fast oxidations as the reaction rate is in such cases greatly influenced by the mass transfer rate. Unclear reaction mechanisms and complex transport phenomena make modelling of the reactor and the process control design very

Conventional batch or semi-batch reactors, such as agitator bubbling reactors, bubble columns, trickle-bed reactors, gaslift and loop reactors, multi-stage trayed column reactors, are widely applied for liquid phase oxidations. However, these reactor types are often avoided at large scale production sites due to several reasons, including insufficient heat- and mass transfer rates, low interfacial areas, back mixing of the liquid phase and potential safety issues. Especially, aerobic oxidations pose the process engineer particular challenges to develop a safe and reliable process. In particular, strict handling protocols of the oxidant-organic reactant mixtures are required to ensure process safety. For example, one should make sure that the oxygen concentration in the gas-liquid disengagement zone, or any other open space existing in the reactor system, is kept below the flammability limit when designing a specific multiphase reactor for liquid phase oxidations with oxygen as an oxidant.

The limitations on process control, reactor scale-up and safety may be overcome by utilizing microreactor technology. ${ }^{19-34}$ This technology has experienced a spectacular development as one of the most important process intensification technologies on the market. ${ }^{35-38}$ The advantages of this reactor design for chemical production are in general the potential to work under a continuous operational mode, well-defined flow properties, large surfaceto-volume ratios, enhanced heat- and mass transfer, excellent process safety and the ease of increasing throughput by numbering-up. The extremely small characteristic dimensions challenging. 
of microreactors provide a low liquid holdup, which is beneficial to avoid many safety risks associated with the use of hazardous oxidants.

It is the goal of this review to provide a comprehensive overview of the potential and the use of microreactor technology for liquid phase oxidation chemistry. A detailed description of the engineering aspects associated with this topic is given. Hereby, we focused on mass- and heat-transfer aspects which are of importance when designing a suitable oxidation protocol. In addition, process safety aspects associated with this chemistry are vital for a reliable design and are discussed as well. Next, we survey the different oxidation chemistries, which have been performed in continuous-flow microreactors. This includes important fields such as aerobic oxidations, hydrogen peroxide oxidations, and ozonolysis. The results in flow are compared with their batch counterparts where possible. Finally, different scale-up strategies are described. For gas-solid catalytic oxidation chemistry, which is of great importance for the development of micro fuel processors, we guide the reader to some specialist reviews. ${ }^{39-42}$ Oxidations in supercritical media are not included in this discussion. ${ }^{43-50}$

\section{Fundamental engineering aspects}

\subsection{Mass transfer limitations in liquid phase oxidations}

Many oxidation processes consist of multiphase reaction mixtures (e.g., gas-liquid, liquid-liquid, liquid-solid, and combinations thereof). Herein, it is important to maximize the interfacial area which causes a reduction of the transport distances. Consequently, the yield of the target compound can be maximized by careful selection of a proper reactor design and a suitable catalyst. ${ }^{51-55}$ The overall performance of the oxidation reaction is mainly determined by intrinsic kinetics and transport properties inside reactors. The intrinsic reaction rate of liquid phase oxidation can be slow (e.g., toluene oxidation) or fast (e.g., $\beta$-isophorone oxidation), mainly depending on the catalytic system and operational conditions. ${ }^{56-58}$ For fast liquid phase oxidation processes, the reaction rate and the selectivity are significantly influenced by the mass transfer rate, and the key to increase the production rate is to facilitate mass transfer by increasing the interfacial area. ${ }^{59-62}$ Classical reactors, such as mechanically agitated reactors, bubble columns, trickle-bed reactors, result in poorly defined interfacial contact areas. The scale-up of such reactors for a large-scale production is not trivial considering the safety hazards associated with oxidation chemistry. ${ }^{63-65}$ In addition, insufficient heat and mass transfer in these reactors further complicates the scalability. ${ }^{66,67}$ In contrast, micro-structured reactors can provide higher surface-to-volume ratios and thus higher heat and mass transfer rates for multiphase reaction processes. ${ }^{18,68-74}$ With known mass transfer characteristics and reaction kinetics in hand, one can judge whether it is justified to use microreactors for a specific liquid phase oxidation process and which microreactor type should be selected. ${ }^{75-78}$
The mass transfer in multiphase liquid phase oxidations can be described using a two-film model (Figure 1). A gaseous component (A, e.g., oxygen) is transferred from the gas to the liquid phase where it can be consumed in the reaction to form products (Equation 1). The driving force for the gas-liquid mass transfer of $A$ is the concentration gradient, which is governed by thermodynamic and chemical equilibriums. In the film theory, the interface zone between the gas and liquid phases can be represented by two stagnant films (i.e., a gas layer and a liquid layer). In this interface zone, a vapor-liquid equilibrium with thickness $\delta_{\text {int }}$ is established. The bulk of the gas and liquid is considered to be well mixed. For only a few absorptionreaction systems, the mass transfer resistance in the gas film should be considered. In these systems, either the liquid phase has a very high solubility for the gaseous reactants or the diffusivity of the gaseous reactants in the gas phase is quite small. For a Taylor flow (slug flow or segmented flow) regime in microreactors, application of the film theory for the calculation of mass transfer coefficient $\left(k_{L}\right)$ is highly feasible. Taylor flow is a very uniform flow pattern and is characterized by gas bubbles, which are separated by liquid slugs and a thin liquid film on the channel walls. In the liquid and gas bubble, internal circulations are established, which arise from the interfacial friction and the slip velocity. This internal circulation results in homogeneous mixing and facilitates a fast mass transfer between the two phases. ${ }^{79-82}$ Interestingly, a microreactor operating in the Taylor flow regime shows minimal axial dispersion and provides an excellent residence time distribution, making it behave as an ideal plug flow reactor. ${ }^{82-87}$

$$
\mathrm{A}(\mathrm{g}) \stackrel{\text { mass transfer }}{\longrightarrow} \mathrm{A}(\mathrm{l}) \stackrel{\text { organic molecules }}{\text { oxidation }} \text { products }
$$

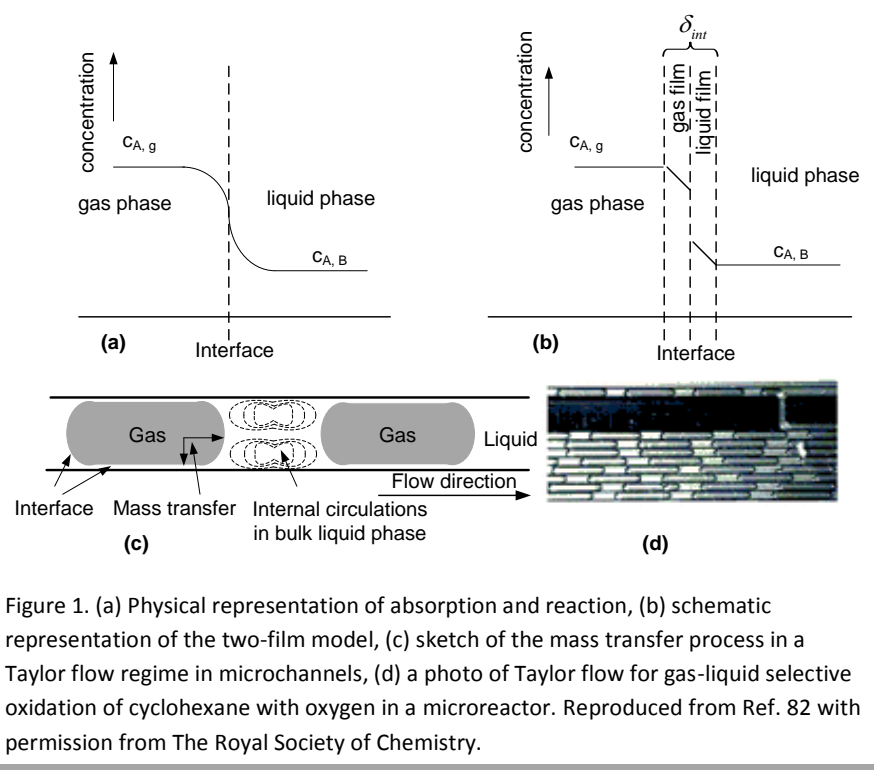

In literature, a large number of investigations can be found on the description of the gas-liquid and liquid-liquid mass transfer performance in microreactors under various operational conditions ${ }^{18,69,73,80,88-90}$ The mass transfer performance is 
frequently represented by a liquid side volumetric mass transfer coefficient $\left(k_{L} a\right)$, which is a product of the mass transfer coefficient $\left(k_{L}\right)$ and the effective interfacial area $(a)$.The liquid side volumetric mass transfer coefficient can be easily obtained through physical or chemical experiments, while the effective interfacial area can be obtained by measurement of the geometrical area. ${ }^{91}$ The liquid side volumetric mass transfer coefficient and the effective interfacial area in microchannels can respectively reach $21 \mathrm{~s}^{-1}$ and $9000 \mathrm{~m}^{2} / \mathrm{m}^{3}$, which are at least one or two orders of magnitude higher than those obtained in conventional gasliquid contactors. ${ }^{80}$ With the known liquid side volumetric mass transfer coefficient and the effective interfacial area, the value of the liquid side mass transfer coefficient can be acquired $\left(k_{L}=\left(k_{L} a\right) / a\right)$. In addition, its value can be obtained through the film model:

$$
k_{L}=D_{A} / \delta_{i n t}
$$

where $D_{A}$ is the molecular diffusivity of gaseous reactant in the liquid phase. $\delta_{i n t}$ is the hypothetical interfacial film thickness and can be considered to be equal to the thickness of liquid films around the gas bubbles $(\delta)$ in a simplified way. Correlations for the liquid film thickness within gas-liquid Taylor flow can be found in literature. ${ }^{92}$ It should be noted that many liquid oxidation processes take place at elevated temperatures and pressures. Therefore, the effects of these operational parameters on the mass transfer performance should be taken into account. ${ }^{85,93}$

The selection of a suitable reactor for liquid phase oxidation processes is also highly dependent on the characteristics of the intrinsic reaction kinetics. A detailed description of the kinetics and mechanisms of liquid phase oxidations has been reviewed. ${ }^{94-97}$ Most liquid phase oxidations involve a free radical chain mechanism, which includes four elemental steps, i.e., initiation, propagation, branching and termination. The intrinsic reaction rate constant $\left(k_{r}\right)$ is dependent on the initiation rate constant, the propagation rate constant and the termination rate constant. With both specific parameters of mass transfer and reaction kinetics in hand, the Hatta number can be calculated and allows to evaluate the extent of mass transfer limitations:98

$$
H a=\frac{\sqrt{\frac{2}{m+1} k_{r}\left(c_{A, i n}\right)^{m-1}\left(c_{s u b, L}\right)^{n} D_{A}}}{k_{L}}
$$

Where $m$ and $n$ are the reaction orders for gaseous reactants and substrates, respectively. Equation 2 can be transformed to the following equation (Equation 3 ) if the reaction orders for gaseous reactants and substrates are respectively 2 and $0 .{ }^{99}$

$$
H a=\frac{\sqrt{k_{r} c_{A, l}^{*}}}{k_{L}}
$$

Where $c_{A, l}^{*}$ is the saturated concentration of gaseous reactant in the liquid phase. Equation 3 clearly shows that the value of $\mathrm{Ha}$ is inversely proportional to the liquid side mass transfer coefficient. The dependence of the Hatta number on the mass transfer coefficient for the uncatalyzed selective aerobic oxidation of liquid cyclohexane can be found in Figure 2.99 Figure 2 indicates that there are no mass transfer limitations when conducting this reaction in a capillary microreactor $(\mathrm{Ha}<$ 0.3). This means that the reaction process occurs inside the bulk phase due to the fast supply of oxidant from the gas to the liquid phase. However, mass transfer limitations still occur when bubble column reactors are used. Recently, Noël et al. reported that the value of $\mathrm{Ha}$ could be even as low as 0.06 in the fast photo catalytic aerobic oxidation of thiols using a capillary microreactor and a Taylor flow regime. ${ }^{100}$ The low values of $\mathrm{Ha}$ demonstrate the advantages of using microreactors for the measurement of intrinsic reaction kinetics as one can avoid mass transfer limitations.

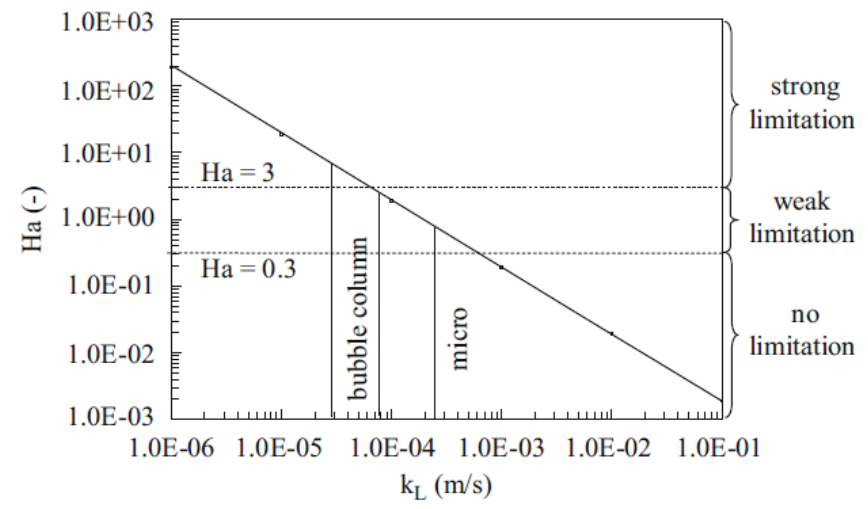

Figure 2. Hatta number versus mass transfer coefficient with $\mathrm{kr}=9.49 \times 10-1 / \mathrm{s}, \mathrm{D}=$ $3.08 \times 10-8 \mathrm{~m} 2 / \mathrm{s}$, $\mathrm{kL}$ for bubble columns in range of $3.7 \times 10-5 \mathrm{~m} / \mathrm{s}-8.2 \times 10-5 \mathrm{~m} / \mathrm{s}$, and $\mathrm{kL}$ for capillary microreactors larger than $2.5 \times 10-4 \mathrm{~m} / \mathrm{s}$. Reproduced from Ref. 99 with permission from Elsevier.

For catalyzed liquid phase oxidations and gas-liquid-solid catalyzed oxidations, mechanisms, such as Mars-van Krevelen mechanism and classical Langmuir-Hinshelwood mechanism, can be applied to describe the reaction rate expression. In these cases, the calculation of intrinsic reaction rate constant is different from those reactions with a free radical chain mechanism. A full description of these catalyzed reaction mechanisms is outside the focus of this review and we direct the reader to some relevant references for more details. ${ }^{101}$

\subsection{Heat transfer in liquid phase oxidations}

Any chemical reaction can be fully characterized by its reaction mechanism, thermal (exothermic/endothermic) properties, thermodynamic equilibrium and chemical kinetic equilibrium. Many liquid phase oxidation reactions are highly exothermic and thus inefficient heat management in a reactor possibly leads to a low selectivity and yield. Moreover, some intermediates/products of oxidation reactions are highly thermally unstable (e.g., peroxides) and can undergo vigorous decomposition at elevated temperatures. ${ }^{101}$ In conventional 
reactors, explosive mixtures can be easily produced in the reactor head space due to volatilization. When heat dissipation is insufficient, local hot spots are formed which can cause an ignition of the explosive mixtures. In contrast to conventional reactors, heat management in microreactors is better due to the high surface to volume ratio. This allows a wider operational zone providing higher selectivity and yield. ${ }^{19,102-104}$

For exothermic reactions, the heat equilibrium in a reaction system is dependent on several factors including the rate of heat generated from the reaction, the heat absorption rate by the reaction mixture and the rate of heat removed from the reactor wall through conduction or convection. In order to increase the heat transfer rate in microreactors for reaction processes, one can reduce the reactor dimensions to get a higher specific interfacial area, place active heat exchange or mixing elements (e.g., heat pin-fins, channel curvature and static mixers) and use materials or heatexchange fluids with high heat conductivity.

To improve heat transfer in microchannels it is crucial to understand the theoretical basis behind it. It should be noted that the literature on heat transfer phenomena in microchannels is contradictory. This is due to the high complexity as there is a strong correlation between heat transport phenomena and microchannel characteristics. Scaling effects (e.g., entrance effect, surface roughness, channel geometry), which are negligible on a macro-scale, cannot be ignored on a micro-scale. A complete description is beyond the scope of this review and is discussed in great detail in the following references. ${ }^{105-107}$ In this review, we provide some general trends and guidelines which can help the reader to understand the underlying principles of heat transfer.

The classical energy balance equation can be used to describe any heat transfer process without considering the effect of axial dispersion:

$$
\frac{d T}{d V}=\frac{d T}{S \cdot d z}=\frac{r \cdot\left(-\Delta H_{R}\right)}{m C_{P}}-\frac{U \cdot a \cdot\left(T-T_{c}\right)}{m C_{P}}
$$

Where $T$ is the temperature of reaction mixture, $V$ is the reactor volume, $S$ is the cross-sectional area, $z$ is the reactor length along the flow direction, $a$ is the specific heat-exchange surface, $\Delta H_{R}$ is the reaction enthalpy, $C_{P}$ is the mean specific heat capacity of the reaction mixture, and $U$ is the global heattransfer coefficient. The item on the left side of this equation is the temperature variation rate of the reaction mixture along the flow direction. The first item on the right side of this equation is the rate of heat produced due to the reaction, while the second item is the rate of heat removed through the microchannel using a coolant with temperature $T_{c}$. Assuming that the cross section is constant and the specific heatexchange surface is equal to $4 / d_{h}\left(d_{h}\right.$ is the hydraulic diameter of microreactors), equation 4 can be rewritten to: ${ }^{108}$

$$
\frac{d T}{d z}=\frac{1}{\rho u C_{P}}\left[r \Delta H_{R}-\frac{4 U\left(T-T_{c}\right)}{d_{h}}\right]
$$

This equation cannot be solved analytically because the reaction rate $(r)$ is controlled by the reaction temperature according to the Arrhenius equation. Only a numerical solution can be obtained for the temperature profile taking the concentration profiles of substrates and products into account (Figure 3). ${ }^{109}$

Furthermore, the adiabatic temperature rise can be calculated according to the following equation:

$$
\Delta T_{a d}=\frac{c_{\mathrm{s}, 0}\left(-\Delta H_{R}\right)}{\rho C_{p}}
$$

where $c_{s, O}$ is the inlet concentration of the substrate and $\rho$ is the mean density of the reaction mixture. The adiabatic temperature rise $\left(\Delta T_{a d}\right)$ constitutes the increase in reaction temperature as a result of an exothermic chemical reaction, when there is no heat transfer to or from the environment. In other words, this is the worst case scenario of heat generation and $\Delta T_{a d}$ is an important design parameter when selecting a suitable chemical reactor. In reality, the temperature profile along the flow direction under non-adiabatic conditions strongly depends on the global heat-transfer coefficient that includes all the effects of heat transfer resistances. The global heat-transfer coefficient can be expressed as follows: ${ }^{110}$

$$
\frac{1}{U}=\frac{1}{h_{\text {in }}}+\left(\frac{d_{\text {out }}-d_{h}}{2 \lambda_{\text {wall }}}\right) \frac{a}{a_{m}}+\frac{1}{h_{\text {out }}} \frac{a}{a_{\text {out }}}
$$

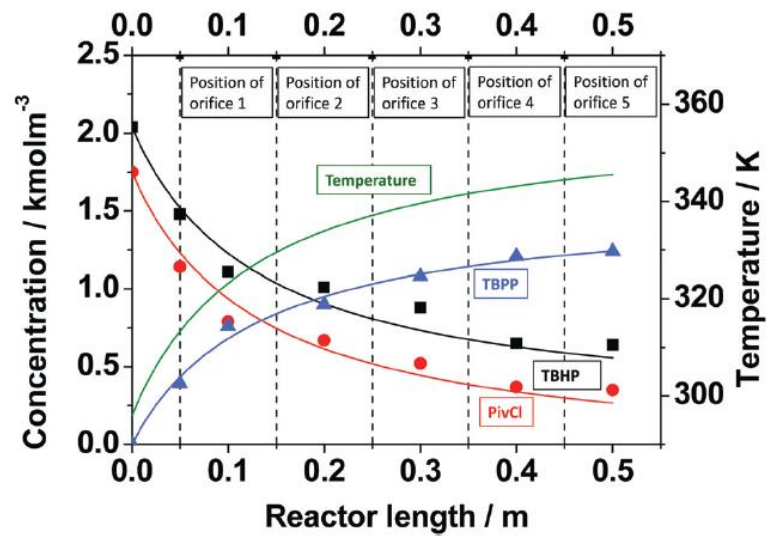

Figure 3. Experimental and simulated adiabatic temperature and concentration profiles in a microchannel reactor with five orifices as transport intensification units for exothermic biphasic synthesis of tert-butyl peroxypivalate (experimental data is indicated using a point diagram; simulated data is indicated with a solid line; the position of each orifice is marked with a dashed line; Pivaloylchloride (PivCl); tertbutylhydroperoxide (TBHP); tert-butylperoxide (KTBP)). Reproduced from Ref. 109 with permission from The Royal Society of Chemistry.

In the right side of Equation 7, the first item represents the resistance between channel wall and reaction mixture, the second item represents the resistance of channel wall, and the third item represents the resistance located between the outer wall and the cooling fluid. The convective heat-transfer coefficients ( $h_{\text {in }}$ and $h_{\text {out }}$ ) are related to the hydrodynamics and the hydraulic diameter of reactors, which can be calculated through the Nusselt number $(\mathrm{Nu}) .{ }^{111,112}$ 


$$
h_{i n}=N u \cdot \lambda_{\text {fluid }} / d_{h}=\left[3.65+\frac{0.19\left(\operatorname{Re} \cdot \operatorname{Pr} \cdot d_{h}\right)^{0.8}}{1+0.117\left(\operatorname{Re} \cdot \operatorname{Pr} \cdot d_{h}\right)^{0.467}}\right] \cdot \lambda_{\text {fluid }} / d_{h}
$$

According to this correlation, a reduction of the channel diameter will lead to a higher convective heat-transfer coefficient when keeping other parameters constant. This explains the advantage of using microreactors for exothermic reactions. In addition, higher conductivities of channel materials will result in a higher global heat-transfer coefficient (Table 1), which is beneficial for reaching a smooth temperature profile along the flow direction.

In order to perform reactions under near isothermal conditions and to avoid exothermal runaways, it is necessary to ensure that the heat removal rate is at least equal to the heat generation rate. That is, the ratio of heat generation rate to the heat removal rate should be lower than 1 . This principle can be applied to the heat management in microreactors. ${ }^{75,113}$

$$
\beta=\frac{\text { heatgeneration rate }}{\text { heatremovalrate }}=\frac{-r \Delta H_{R} d_{h}}{6 \Delta T_{a d} h_{i n}} \leq 1
$$

Table 1. Thermal conductivity of some materials commonly employed for the fabrication of microreactors.

\begin{tabular}{cc}
\hline Material & $\begin{array}{c}\text { Thermal Conductivity } \\
(k) \\
{\left[\mathrm{W} \mathrm{m}^{-1} \mathrm{~K}^{-1}\right]}\end{array}$ \\
\hline PFA & 0.195 \\
FEP & $0.19-0.24$ \\
Glass & 1 \\
Stainless Steel & $12-45$ \\
Silicon & 149 \\
Aluminium (pure) & 237 \\
Aluminium (alloy) & $120-180$ \\
Silicon Carbide & $120-490$ \\
Copper & 401 \\
\hline
\end{tabular}

The importance of good heat management is convincingly demonstrated in the highly exothermic preparation of tertbutyl peroxypivalate. In batch, a large amount of solvent is required to provide a sufficient temperature buffer to control the reaction temperature and to avoid thermal runaway. $4,75,114,115$ In flow, a compact microreactor assembly consisting of a microchannel with orifices and a heat exchanger plate was employed (Figure 4a). ${ }^{109,116}$ This reactor design allows for the two-step synthesis of tert-butyl peroxypivalate without adding additional solvents as a temperature buffer. The first step constitutes a nearly isothermal deprotonation step, while the second step involves a strongly exothermic reaction between potassium tertbutylperoxide and pivaloylchloride. The temperature profile was measured in situ by using an infrared camera. As can be seen from Figure $4 \mathrm{~b}$, the temperature profile in the absence of cooling fluid showed a very steep temperature rise $(\Delta T=63 \mathrm{~K})$ in the section where the second reaction takes place. In the presence of active cooling, smooth temperature profiles along the microreactor could be obtained (Figure 4c-d).

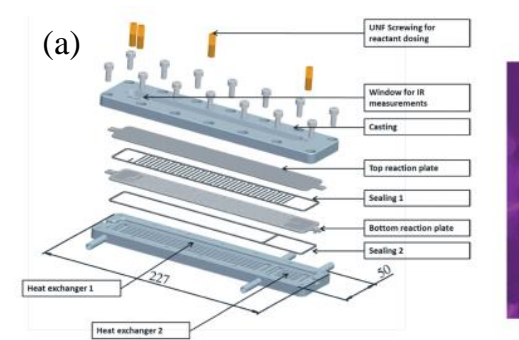

(c)

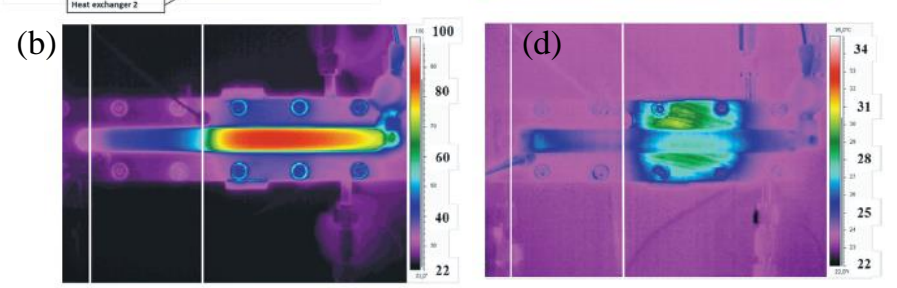

Figure 4. (a) Exploded view of the microreactor assembly consisting of an orifice microchannel and a heat exchanger plate for exothermic biphasic synthesis of tertbutyl peroxypivalate, and infrared pictures indicating the in-line temperature in the reaction plate (flow rate of reaction mixture is $18.5 \mathrm{~mL} / \mathrm{min}$ ) using different flow rates of the cooling fluid: (b) $0 \mathrm{~mL} / \mathrm{min}$, (c) $21 \mathrm{~mL} / \mathrm{min}$ and (d) $9 \mathrm{~mL} / \mathrm{min}$. Reproduced from Ref. 109 with permission from The Royal Society of Chemistry.

\subsection{Safety aspects in liquid phase oxidations}

Liquid phase oxidations often combine highly reactive species (e.g., oxygen, ozone, peroxide) with organic solvents which can lead to combustion. ${ }^{117-119}$ Ignition of explosive reaction mixtures result in a significant increase in temperature and pressure inside the reactor, possibly leading to rupture of the reactor and explosions. Therefore, pure oxygen or oxygenenriched air is rarely used even though it is known that the reaction rate and selectivity can be enhanced significantly with increasing oxygen concentrations. Typically, nitrogen diluted oxygen mixtures are used, which are well below the limiting oxygen concentration (LOC) of organic solvents or reagents. The LOC is defined as the limiting concentration of oxygen below which combustion of gas mixtures is impossible. Table 2 shows an overview of LOC data for frequently applied organic solvents in the pharmaceutical industry. The use of inert gas largely increases the process complexity in conventional reactors. For example, it is necessary to continuously refresh the gas mixture in bubble columns to reach full conversion. ${ }^{120}$

The power of an explosion is proportional to the mass of the explosive mixture with the power of $1 / 3 .{ }^{121,122}$ This relation immediately explains why microreactors are safe to use when employing hazardous reaction conditions. ${ }^{123}$ However, while the total amount of volume of a microreactor is small and thus contains only small amounts of potentially explosive material, one should take great care that the explosion is not propagated to nearby storage vessels, containing larger amounts of flammable starting materials or products. ${ }^{124,125}$ Hereto, it is important that the reaction is immediately quenched upon exiting the microreactor, so that explosion propagation is avoided. Continuous-flow processing also allows to generate hazardous intermediates in situ, which are subsequently reacted away in a follow-up reaction. This allows to minimize the total amount of hazardous material holdup in the laboratory or chemical plant. 
Table 2. Summary of limiting oxygen concentration data for frequently applied organic solvents. ${ }^{120}$

\begin{tabular}{ccccc}
\hline & \multicolumn{5}{c}{ limiting oxygen concentration (vol. \%) } \\
solvent & $T\left({ }^{\circ} \mathrm{C}\right)$ & 1 bar & 10 bar & 20 bar \\
\hline acetic acid & 200 & 10.6 & - & 9.6 \\
NMP & 200 & 8.1 & - & 7.6 \\
DMSO & 200 & 3.9 & - & - \\
DMSO & 100 & 6.4 & - & - \\
tert-amyl alcohol & 100 & 9.6 & - & 10.1 \\
ethyl acetate & 100 & 9.4 & - & 9.9 \\
2-MeTHF & 100 & 9.4 & - & 9.1 \\
methanol & 100 & 7.6 & - & 6.9 \\
acetonitrile & 100 & - & 12.1 & 11.9 \\
toluene & 100 & 10.4 & 10.3 & 9.9 \\
methanol & 25 & 8.6 & - & - \\
acetonitrile & 25 & 12.7 & - & - \\
toluene & 25 & 11.6 & - & - \\
\hline
\end{tabular}

The safety issues in liquid phase oxidation processes are also highly associated with the hydrodynamics and transport phenomena in the reactors. The occurrence of local hot spots due to insufficient heat and mass transfer rates serves as an ignition source for explosive reaction mixtures (thermal explosions). Safety problems may be avoided by transforming the batch process to a continuous-flow protocol. Siccama and Westerterp have investigated via experimental and numerical methods the ignition of ethylene-air mixtures inside a tube (50 $\mathrm{mm}$ ID) using a hot surface. ${ }^{126,127}$ It was found that the explosion region was reduced under continuous-flow conditions as compared to batch processing (Figure 5). Higher oxygen concentrations can be used in flow when gas is flowing at a higher flow rate, thus avoiding the occurrence of dead zones which are often the cause of the actual explosion. The explosion limits for reactive gas mixtures in flow were found to be influenced by many parameters such as flow rate, pressure and temperature, but also by the shape and the size of the tube and by the characteristics of the ignition source. In general, an increase in the flow rate and a decrease in the pressure or the temperature will increase the minimum critical oxygen concentration above which flame propagation becomes possible. Continuous-flow processing lowers these upper explosion limits and thus widens the operational zone for liquid phase oxidations with a higher reliability than batch processing. ${ }^{128}$

The high surface-to-volume ratios encountered in microreactor technology make that the reactor material is an important design parameter. ${ }^{129}$ We have already demonstrated the importance of the conductivity of the material for efficient heat dissipation in exothermic oxidation processes (so-called thermal quenching of the reaction). In addition, the material itself can play a catalytic role. For example, stainless steel reactors can catalyze the decomposition and isomerization of organic peroxides. ${ }^{130,131}$ Moreover, a steel reactor wall can initiate the radical formation of hydroperoxide intermediates in the oxidation of saturated hydrocarbons using molecular oxygen as the terminal oxidant and acetaldehyde as sacrificial coreductant. ${ }^{132}$ This demonstrates the heterogeneous initiation effect of steel for the production of radicals. In addition, Veser has described an interesting radical quenching effect in the platinum-catalyzed oxidation of hydrogen. ${ }^{133}$ Kinetic explosions can occur in such situations when radical species are uncontrollably formed. Quenching of the explosion can be achieved by radical chain termination, in which two radicals combine to give one stable molecule. This occurs typically at the catalytic reactor walls. Given the large surface-to-volume ratios in microreactors, reactants can diffuse rapidly to the reactor walls, which quenches efficiently the potential kinetic explosion and thus increases the explosion limit. This effect allows one to utilize higher reaction temperatures in microreactors. As an example, explosive behavior was observed at $420^{\circ} \mathrm{C}$ and atmospheric pressure in a conventional reactor with a $1 \mathrm{~m}$ diameter, while higher temperatures (up $750^{\circ} \mathrm{C}$ ) were feasible in a microreactor with a diameter of $1 \mathrm{~mm}$.

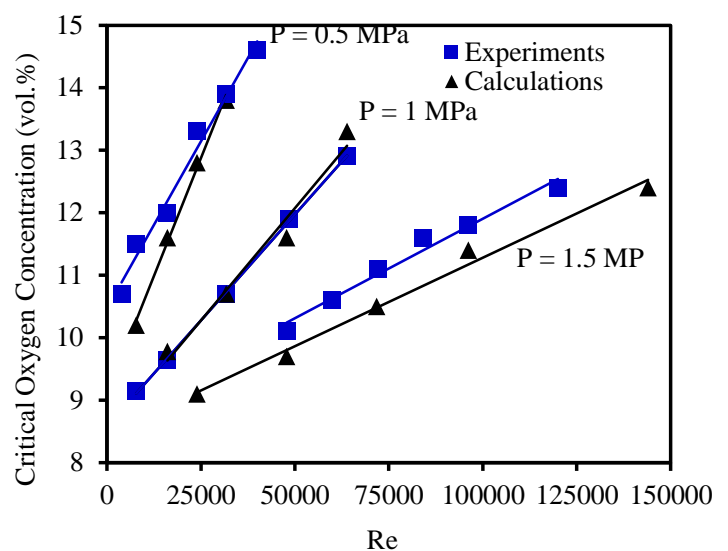

Figure 5. Critical oxygen concentration in the explosion point in the 50-mm tube. Reproduced from Ref. 128 with permission from John Wiley and Sons.

The choice of reactor materials and reactor types also depends on the operational conditions. Especially at high temperatures and elevated pressures, one should carefully select the reactor material in order to withstand these harsh conditions. Stainless steel microreactors can resist high temperature and high pressure, and provide a high heat conductivity. ${ }^{134,135}$ However, stainless steel is not compatible with acidic media except for those with special surface treatments. PFA, FEP or PTFE microreactors have the advantages of easy fabrication, low cost and high flexibility. They can resist strong acidic and alkaline media at low to moderate temperatures and pressures. Such polymeric materials are transparent which allows one to study the hydrodynamics inside the microchannel. This is beneficial for improving the reactor design and the overall process. ${ }^{77} \mathrm{~A}$ high transparency is also crucial for photochemical processes (e.g., singlet oxygen generation); PFA and FEP are transparent for both UV and visible light. Nevertheless, PFA microreactors cannot resist high temperatures and the limiting pressure decreases significantly with increasing temperatures. Importantly, these polymers have a low thermal conductivity, which can be a problem for highly exothermic reactions. 
Silicon microreactors have similar transparency properties and better thermal conductivity than polymer-based reactors. It can withstand high temperatures and high pressures, and provide chemical resistance to a broad range of chemicals. ${ }^{136}$ However, they are not always resistant to strong alkaline reaction mixtures, especially at elevated temperatures. Surface treatments can help to overcome this limitation. ${ }^{137}$ Silicon carbide has an even higher thermal conductivity and combines it with an exceptional chemical stability. However, this material is quite expensive and is also brittle.

\section{Aerobic oxidation processes in continuous flow}

In this section, aerobic oxidations processes carried out in continuous-flow microreactors, are discussed. The chapter is divided into five sub-chapters according to the catalysis mode.

\subsection{Transition metal-catalyzed aerobic oxidation processes in continuous flow}

Transition metal-catalyzed oxidation reactions are known as one of the fundamental transformations in chemistry. Its ability to enable mild and selective chemistry is what makes this topic appealing for today's applications. In oxidative transformations, the use of oxygen is of high interest, since molecular oxygen is completely ecological, highly abundant and the cheapest source of oxidant. Moreover, because of its gaseous nature, work up procedures are made effortless and allow the use of super-stoichiometric amounts to boost reaction rates. In recent years, the use of microreactors has become increasingly popular for aerobic oxidations, since microreactors offer superior mass transfer characteristics under biphasic reaction conditions and safeguard high reproducibility and safety over the process.

Heterogeneous catalysis. Plucinski et al. reported several papers about the application of microreactors for the selective aerobic oxidation of liquid organic feedstock. ${ }^{138-140}$ A threephase micro packed-bed reactor was constructed, which consisted out of 5 parallel micro channels with respective square cross-sections of $2 \times 2,3 \times 3$ and $5 \times 5 \mathrm{~mm}^{2}$. Each channel was $10 \mathrm{~cm}$ long. $\mathrm{Ru} / \mathrm{Al}_{2} \mathrm{O}_{3}$ was immobilized on the reactor walls. The aerobic oxidation of benzyl alcohol to benzaldehyde was used as a model reaction (Table 3, Entry 1). Yields up to 55\% (selectivity 99\%) were achieved for a single pass reaction. Notably, it was shown that the microreactor could be operated at isothermal conditions, despite significant heat formation of the exothermic reaction (TOF $=300 \mathrm{~h}^{-1}, \Delta \mathrm{H}^{\circ}$ r $=-183,7 \mathrm{~kJ} \cdot \mathrm{mol}^{-1}$ ).

A continuous-flow aerobic oxidation of benzyl alcohol by supported tetrapropylammonium perruthenate (TRAP) in a silicon-glass micro packed-bed reactor (MPBR) $(0.6 \mathrm{~mm} \times 0.3$ $\mathrm{mm}, \mathrm{V}=26 \mu \mathrm{L}$ ) was reported by Gavriilidis et al. ${ }^{141}$ For the multiphase (gas-liquid-solid) reaction, a conversion up to $40 \%$ was obtained within a residence time of approximately $1 \mathrm{~min}$ (Table 3, Entry 2). The same group reported a solvent free aerobic oxidation process of benzyl alcohol with pure oxygen. ${ }^{142}$ A similar silicon-glass MPBR $(0.6 \mathrm{~mm} \times 0.3 \mathrm{~mm}, \mathrm{~V}=$ $34 \mu \mathrm{L}$ ) was used, packed with $1 \%(\mathrm{Au}-\mathrm{Pd}) / \mathrm{TiO}_{2}$ catalyst. The reaction progress was monitored with in situ Raman spectroscopy. A conversion of $95 \%$ was measured with a selectivity of $78 \%$ to benzaldehyde, for optimized conditions (catalyst particles: $53-63 \mu \mathrm{m}, 120^{\circ} \mathrm{C}$ and 5 bar) (Table 3, Entry 3).

\begin{tabular}{|c|c|c|c|c|}
\hline Entry & $\begin{array}{c}\text { Reference } \\
\text { (publication year) }\end{array}$ & Microreactor design & Reaction conditions & $\begin{array}{c}\text { Conversion }(\mathrm{X}) \\
\text { Selectivity }(\mathrm{S})\end{array}$ \\
\hline 1 & $\begin{array}{l}\text { Plucinski et al. }{ }^{138-140} \\
(2005)\end{array}$ & $\begin{array}{l}\text { Stainless steel multichannel micro packed-bed reactor } \\
\qquad-5 \text { parallel channels } \\
\qquad-V=900 \mu \mathrm{L}(3 \mathrm{~mm} \times 3 \mathrm{~mm}) \text { per channel }\end{array}$ & $\begin{array}{c}\mathrm{Ru} / \mathrm{Al}_{2} \mathrm{O}_{3}(0.9 \mathrm{wt} \% \mathrm{Ru}) \\
\mathrm{c}=1 \mathrm{M}, \mathrm{T}=115^{\circ} \mathrm{C}, \mathrm{p}_{\mathrm{O} 2}=8 \mathrm{bar}\end{array}$ & $\begin{array}{l}X=55 \% \\
S=99 \%\end{array}$ \\
\hline 2 & $\begin{array}{l}\text { Gavriilidis et al. }{ }^{141} \\
\quad(2006)\end{array}$ & $\begin{array}{l}\text { Silicon-glass micro packed-bed reactor (MPBR) } \\
\text { - single serpentine shaped channel } \\
-\mathrm{V}=26 \mu \mathrm{L}(0.6 \mathrm{~mm} \times 0.3 \mathrm{~mm})\end{array}$ & $\begin{array}{c}\text { TRAP } / \mathrm{Al}_{2} \mathrm{O}_{3}(2 \mathrm{wt} \% \mathrm{TRAP}) \\
\text { Particle size: } 50-90 \mu \mathrm{m} \\
\mathrm{c}=0.24 \mathrm{M}, \mathrm{T}=75^{\circ} \mathrm{C}, \mathrm{p}_{\mathrm{O} 2}=\mathrm{atm}\end{array}$ & $X=40 \%$ \\
\hline 3 & $\begin{array}{l}\text { Gavriilidis et al. }{ }^{142} \\
\text { (2011) }\end{array}$ & $\begin{array}{l}\text { Silicon-glass micro packed-bed reactor (MPBR) } \\
\text { - single serpentine shaped channel } \\
-\mathrm{V}=34 \mu \mathrm{L}(0.6 \mathrm{~mm} \times 0.3 \mathrm{~mm})\end{array}$ & $\begin{array}{c}(\mathrm{Au}-\mathrm{Pd}) / \mathrm{TiO}_{2}(1 \mathrm{wt} \% \mathrm{Au}-\mathrm{Pd}, \text { molar } \\
\text { ratio } 1: 1) \\
\text { particle size: } 53-63 \mu \mathrm{m} \\
\text { neat }, \mathrm{T}=120^{\circ} \mathrm{C}, \mathrm{p}_{\mathrm{o} 2}=5 \mathrm{bar}\end{array}$ & $\begin{array}{l}X=95 \% \\
S=78 \%\end{array}$ \\
\hline 4 & $\begin{array}{l}\text { Kappe et al. }{ }^{143} \\
\quad(2013)\end{array}$ & $\begin{array}{c}\mathrm{H} \text {-Cube Pro }{ }^{\mathrm{TM}} \text { microreactor } \\
-\mathrm{V}=500 \mu \mathrm{L} \text { (catalyst cartridge) }\end{array}$ & $\begin{array}{c}\text { Fe/Al-SBA15 }(1 \mathrm{wt} \% \mathrm{Fe}) \\
\text { Particle size: } 1-2 \mu \mathrm{m} \\
\mathrm{c}=0.1 \mathrm{M}, \mathrm{T}=140^{\circ} \mathrm{C}, \text { po2 }=25 \mathrm{bar}\end{array}$ & $\begin{array}{l}X=100 \% \\
S=95 \% \\
\text { recirculation }\end{array}$ \\
\hline
\end{tabular}




$5 \quad$ Gavriilidis et al. ${ }^{144}$

(2015)
Teflon AF-2400 tube-in-tube microreactor

$$
-\mathrm{V}=150 \mu \mathrm{L}
$$

- inner tube: Teflon AF-2400 (ID $=0.8 \mathrm{~mm}, \mathrm{OD}=1.0 \mathrm{~mm}$ )
(Au-Pd)/TiO $(1 \mathrm{wt} \% \mathrm{Au}-\mathrm{Pd}, 1: 19$ )

particle size: $63-75 \mu \mathrm{m}$

neat, $\mathrm{T}=120^{\circ} \mathrm{C}, \mathrm{p}_{\mathrm{O} 2}=7 \mathrm{bar}$
$X=44 \%$

$S=73 \%$
In a later study, the disproportionation of benzyl alcohol to toluene was confirmed experimentally using $1 \%(\mathrm{Au}-\mathrm{Pd}) / \mathrm{TiO} 2$ and $1 \%$ (Au-Pd)/MgO as supported catalysts. ${ }^{145}$

The use of first-row transition metals for catalysis is of great interest as these metals are abundant and cheap. Kappe et al. demonstrated that the aerobic oxidation of benzyl alcohol to benzaldehyde could be carried out with heterogeneous iron nanoparticles in micro flow. ${ }^{143}$ Iron oxide $\left(\mathrm{Fe}_{2} \mathrm{O}_{3}\right)$ nanoparticles were covalently bound to an aluminosilicate support (AI-SBA15). The Fe/AI-SBA15 (1wt\% Fe) catalyst was diluted with silica gel and loaded into a cartridge. A commercially available $\mathrm{H}$-Cube Pro $^{\mathrm{TM}}$ module microreactor was used. With 2,2,6,6-tertramethylpiperidine-1-oxyl (TEMPO) as co-catalyst, a yield of $42 \%$ was acquired for a single pass reaction. Full conversion was achieved (95\% selectivity) by recirculation of the reaction mixture through the microreactor (Table 3, Entry 4). In addition, no leaching of catalyst was detected.

The tube-in-tube reactor developed by the Ley group is an operationally simple membrane microreactor concept consisting out of two concentric capillaries. ${ }^{146,147}$ The inner capillary functions as a semipermeable membrane (Teflon AF2400) and allows gas diffusion from the gas channel to the liquid channel. Recently, Gavriilidis et al. demonstrated the use of this reactor for the solvent-free aerobic heterogeneous oxidation of benzyl alcohol. ${ }^{144}$ The continuous supply of oxygen through the reactor wall offered significant improvement in both conversion and selectivity as compared to a non-permeable reactor design with a pre-saturated feed. The highest conversion achieved was $44 \%$ with $73 \%$ selectivity to benzaldehyde (Table 3, Entry 5).

The continuous-flow oxidation of vanillyl alcohol to vanillin was reported by Semenov et al. ${ }^{148}$ Yields up to $98 \%$ were obtained within the first hour of run time (Scheme 1). The mesoreactor consisted of quartz tubing ( $7 \mathrm{~mm}$ diameter, $1 \mathrm{~mL}$ ) and was loaded with palladium catalyst on Subunit (a commercially available supporting matrix). The catalyst retained activity up to 100 hours of run time and could be regenerated.

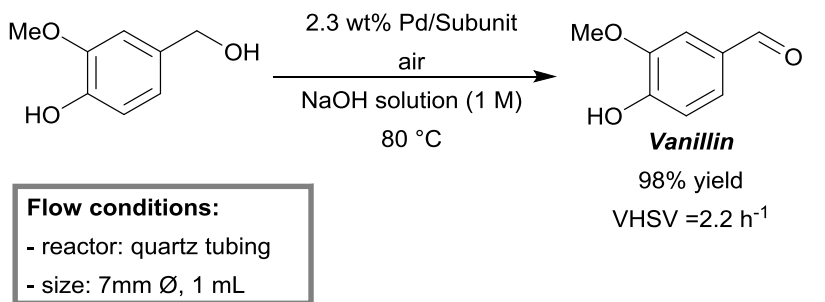

Scheme 1. Oxidation of vanillyl alcohol to vanillin under flow reaction conditions. ${ }^{148}$

Kobayashi et al. described the first quantitative aerobic oxidation process of both primary and secondary alcohols to its respective aldehydes and ketones in a microreactor. ${ }^{149}, 150$
The reactor consisted out of a wall coated, gold-immobilized, capillary column. The three-phase system proved to be highly applicable for a wide scope of benzylic, aliphatic and allylic alcohols. Yields ranged between $89-99 \%$ and up to $92 \%$ in the case of benzyl alcohol using a bimetallic Au/Pd-immobilized column (Scheme 2). No leaching of gold was observed after four days of continuous running.

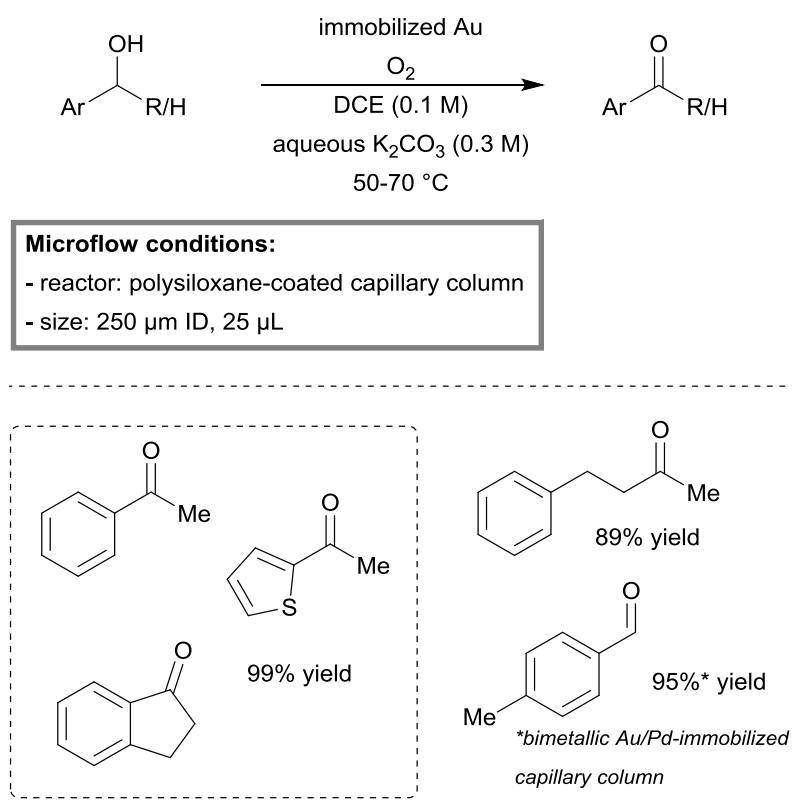

Scheme 2. Oxidation of alcohols with molecular oxygen in a gold-immobilized capillary microreactor. ${ }^{149}$

Hii et al. reported a highly practical process for the aerobic oxidation of alcohols to aldehydes or ketones. ${ }^{151} \mathrm{~A}$ commercially available XCube ${ }^{\mathrm{TM}}$ flow reactor was used. The cartridge was packed with readily available $\mathrm{Ru} / \mathrm{Al}_{2} \mathrm{O}_{3}$. Recirculation of reaction mixture was maintained until full conversion was reached. The system proved to be highly selective (>95\%) in the case of allylic and (hetero)benzylic alcohols, including substrates with bulky substituents and/or heteroatoms at the ortho-position. Primary and secondary aliphatic alcohols proved to be more challenging (conversion $64-78 \%$ ). However, by the addition of a desiccant cartridge $\left(\mathrm{MgSO}_{4}\right)$, activity of catalyst could be retained, and in case of 2-hexanone, the yield could be improved significantly from 75 up to $91 \%$ (Scheme 3 ). 


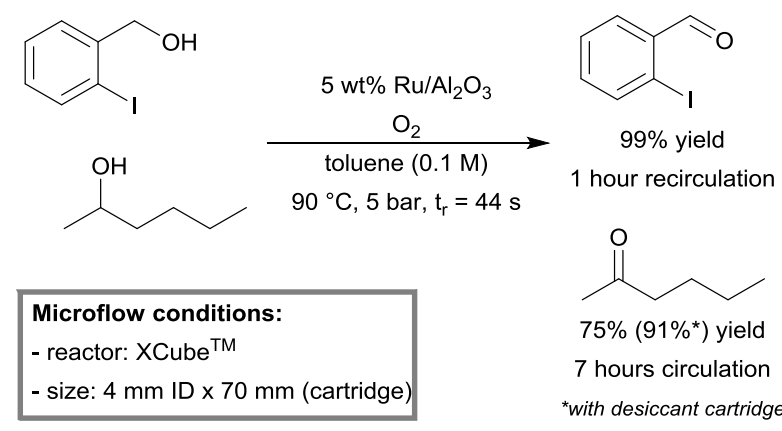

Scheme 3. Aerobic oxidation of alcohols in a XCube ${ }^{\mathrm{TM}}$ microreactor. ${ }^{151}$

A multistep synthesis of amides from alcohols and amines using a continuous-flow microreactor system was reported by Jensen et al. ${ }^{135}$ The reaction system consisted out of three sections: 1) a packed-bed microreactor for the heterogeneous aerobic oxidation of alcohols, 2) a membrane separator for the removal of residual $\mathrm{O}_{2}$ and 3) a spiral-channel microreactor for the oxidative amidation reaction. For the first step, $\mathrm{Ru} / \mathrm{Al}_{2} \mathrm{O}_{3}(5$ wt\% Ru) was found to be the most efficient heterogeneous catalyst. As oxidants, molecular oxygen and urea hydrogen peroxide (UHP) are used for the first and third section respectively. The integrated setup was suitable for a wide scope of benzylic (69-94\%) and heterocyclic aromatic alcohols (79-97\%), displaying good to excellent yields (Error! Reference source not found.). In addition, this process can be applied to secondary amines, including piperidine (81\%), pyrrolidine (81\%) and 1,2,3,4-tetrahydroisoquinoline (69\%). However, aliphatic alcohols were not reactive within this system.
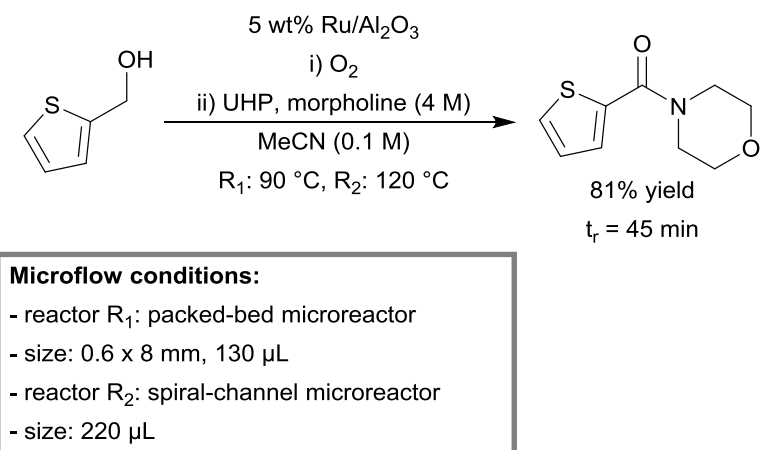

Scheme 4. Multistep synthesis of amides from benzylic or heterocyclic aromatic alcohols and secondary amines in continuous flow. ${ }^{135}$

Stahl et al. reported a continuous-flow setup for the aerobic oxidation of diverse benzylic and heterobenzylic alcohols. ${ }^{152}$ The mesoscale reactor was constructed out of stainless steel tubing (6 mm OD, $76 \mathrm{~mm}$ length) and was packed with commercially available $\mathrm{Ru}(\mathrm{OH})_{\times} / \mathrm{Al}_{2} \mathrm{O}_{3}(2.3 \mathrm{wt} \%$ $\mathrm{Ru})$ catalyst. A diluted source of oxygen ( $8 \%$ in $\left.\mathrm{N}_{2}\right)$ was used as oxidant to stay below the flammability threshold of the solvent. The packed-bed reactor was operated in an up-flow orientation to ensure optimal liquid-solid interaction and was submerged in a heating bath. Partial deactivation of the catalyst was noticed during initial benzyl alcohol oxidation. Accumulation of trace amounts of benzoic acid were found to poison the active sites of the catalyst. However, after more than 50 turnovers, the activity stabilized, which allowed steady-state operation. High to excellent yields (88-99\%) for single pass runs were obtained for a variety of substrates. In addition, a continuous 72 hour run, with 2(hydroxymethyl)thiophene as a substrate, was conducted (Scheme 5). Steady state yields of 2-thiophene carboxaldehyde remained $>99 \%$ throughout the whole run and minimal leaching of catalyst was detected (5 ppm). Further, the flow system also promoted the oxidative dehydrogenation of indoline, yielding $95 \%$ indole. Asao et al. also employed a similar continuous-flow mesoreactor for the aerobic oxidation of various alcohols with a nanoporous gold catalyst. ${ }^{153}$
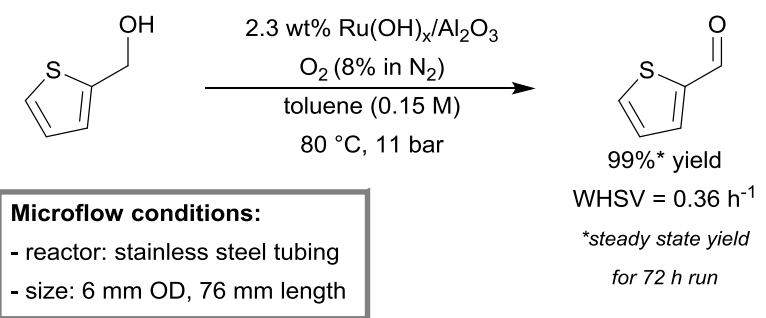

Scheme 5. Continuous flow aerobic alcohol oxidation using $\mathrm{Ru}(\mathrm{OH}) \mathrm{x} / \mathrm{Al} 2 \mathrm{O} 3$ as catalyst and $\mathrm{O} 2$ ( $8 \%$ in $\mathrm{N} 2)$ as source of oxidant. ${ }^{152}$

One major advantage of microreactors (compared to batch) is the increased heat-transfer characteristics. ${ }^{19,154,155}$ This is attributed to the high surface-to-volume ratios of microchannels. The conventional way of heating microreactors is done by convectional heating instruments (e.g., oil baths). Alternatively, more efficient heating can be achieved by direct heating methods, such as microwave heating and induction.

Inductive heating was demonstrated by Kirschning et al. for the continuous-flow oxidation of both allylic an benzylic alcohols. ${ }^{156}$ The magnetic particles were packed into a mesofluidic PEEK (polyether ether ketone) reactor $(3 \mathrm{~mL})$ and diluted with MAGSILICA $^{\circledR}$ to facilitate inductive heating. A medium frequency $(25 \mathrm{kHz})$ external inductor was used to rapidly heat the magnetic particles. A Teflon AF-2400 tube-intube reactor $(0.8 \mathrm{~mm} \mathrm{AD}, 0.6 \mathrm{~mm}$ ID) was placed in front of the inductively heated PEEK reactor in order to saturate the reaction mixture with molecular oxygen. A scope of both primary and secondary alcohols was investigated. In almost all cases, full conversion was observed in a single pass reaction, providing a good to excellent yields (63-98\%). In order to demonstrate the practicality of this catalytic system, a scale-up study was conducted; 4-bromobenzyl alcohol could successfully be oxidized to its corresponding aldehyde (96\%) on gram scale (Scheme 6). 


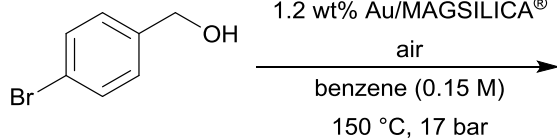

Microflow conditions:

- reactor: PEEK packed-bed mesoreactor

- size: $9 \mathrm{~mm}$ ID, $3 \mathrm{~mL}$

- inductor: medium frequency $(25 \mathrm{kHz})$

Scheme 6. Aerobic oxidation of allylic and benzylic alcohols under inductively-heated flow conditions with gold-doped superparamagnetic nanostructured particles. ${ }^{156}$

Recently, Uozumi et al. developed a highly practical, fast and clean continuous-flow procedure for the aqueous aerobic flow oxidation of primary and secondary alcohols to their corresponding carboxylic acids and ketones. ${ }^{157}$ Platinum nanoparticles dispersed on an amphilic polystyrenepoly(ethylene glycol) resin (APR-Pt) were used as an active heterogeneous catalyst. The catalyst was loaded into a cartridge $(4 \mathrm{~mm} I D \times 70 \mathrm{~mm}$ ) and fitted to a commercial $\mathrm{XCube}^{\mathrm{TM}}$. A broad scope of alcohols, including aliphatic, aromatic and heteroaromatic alcohols were efficiently oxidized (63-99\%) within a short contact time (44 to 73 seconds). Further, benzyl alcohol could be partially oxidized to benzaldehyde $(90 \%)$ in the presence of triethylamine $\left(\mathrm{Et}_{3} \mathrm{~N}\right)$. In addition, a gram-scale production of surfactants (dodecyl\{oligo(oxyethylene)\}acetic acids) was performed by the oxidation of a mixture of oligo(ethylene glycol) monododecyl ethers in the aqueous continuous-flow setup (Scheme 7). These results show that the flow setup is robust for long duration processing (113 hour runtime).
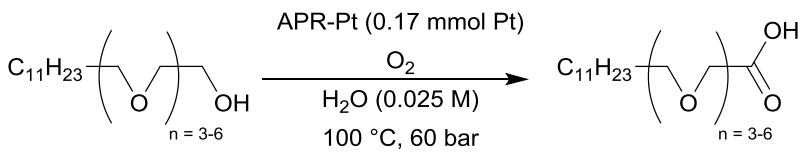

$100 \%$ conversion

Microflow conditions:
- reactor: $X C$ Cube ${ }^{T M}$
- size: $4 \mathrm{~mm}$ ID $\times 70 \mathrm{~mm}$ ( $2 \times$ cartridge)

$$
\mathrm{t}_{\mathrm{r}}=55 \mathrm{~s}
$$

$57 \mathrm{~g}$ on $113 \mathrm{~h}$ run $T O N=890$

Scheme 7. Aerobic oxidation off oligo(ethylene glycol) ethers to the desired surfactant carboxylic acid in an aqueous continuous-flow procedure. ${ }^{157}$

Homogeneous catalysis. Another way of optimizing reaction conditions is by the implementation of a genetic algorithm (GA). ${ }^{158-161}$ This method allows for the fast and robust optimization of systems when there are too many relevant parameters present for the traditional optimization processes. The optimization procedure follows the trend of natural evolution/selection by the use of multiple generations carrying partial information of their parent 'genes' by crossover and mutation. The group of Ismagilov used this evolution protocol to determine a new generation of active homogeneous catalyst systems for the aerobic oxidation of methane to methanol. ${ }^{162}$ Parameters chosen were the catalysts itself (gene A), co-catalysts (gene B) and ligands (gene C). Microfluidic devices were used in order to run numerous reactions in parallel while minimizing consumption of reagents, reducing waste and improving safety. A plug-based micro flow pattern was utilized to compartmentalize each different catalytic system (determined by GA) into an aqueous droplet. Each droplet was separated by the use of immiscible fluorocarbon carrier fluid between the aqueous droplets. This complex liquid-liquid slug flow array was pumped through a Teflon tubing by the use of a computer-controlled syringe pump. The Teflon tubing was placed into a stainless steel reactor. The reactor was pressurized with methane and molecular oxygen, which allowed the introduction of gasses into the aqueous droplets by diffusion through the Teflon tubing (similar to tube-in-tube reactor principle). Semi-quantitative data could be obtained directly by the use of indicator droplets. These droplets changed color (orange to purple) when methanol was present from the neighbouring active catalyst droplet. The success of this protocol proved that GA optimization could highly benefit from the use of microfluidic devices.

Favre-Réguillon et al. used high-throughput screening (HTS) to develop a more selective protocol for the room temperature, aerobic homogeneous oxidation of aldehydes. ${ }^{163}$ A microreactor was built from PFA tubing (1 mm ID, $4 \mathrm{~mL}$ ). Screening for active catalytic systems was done via sequential pulse experimentation, using a sample loop to introduce a different reaction mixture in each slug. The liquid slugs were separated by oxygen slugs (Taylor flow). Two parallel HTS experiments were conducted. First set of experiments was to find a proper metal catalyst in order to accelerate reaction kinetics, while retaining selectivity. $100 \mathrm{ppm}$ of $\mathrm{Mn}$ (II) was found to increase the conversion of the aerobic oxidation from $80 \%$ (uncatalyzed) to full conversion for a residence time of 6 minutes in continuous flow. For the second screening, the residence time was set to 15 minutes in order to ensure full conversion for the uncatalyzed reaction (selectivity $77 \%$ ). Different salts were evaluated for their ability to increase the selectivity. 2 wt\% of sodium 2-ethylhexanoate was found to increase selectivity up to $98 \%$. The last step was then to incorporate both the catalyst (Mn(II) $100 \mathrm{ppm}$ ) and the additive (sodium 2-ethylhexanoate $2 \mathrm{wt} \%$ ) into the same reaction for a 6 minutes flow run. As predicted, the combination of both resulted in a synergistic effect, achieving near quantitative conversion (98\%) of the aldehyde, while maintaining the selectivity of $98 \%$ towards its carboxylic acid (Scheme 8).

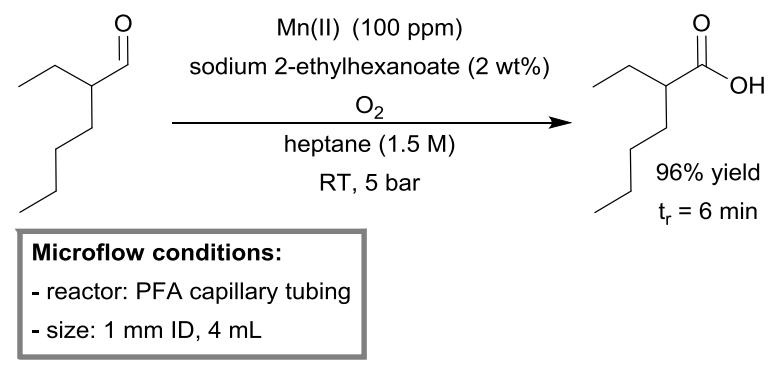

Scheme 8. Room temperature aerobic oxidation of 2-ethylhexanal catalyzed by $\mathrm{Mn}$ (II) in micro flow. ${ }^{163}$ 
Kappe et al. developed a continuous-flow system for the direct aerobic oxidation of 2-benzylpyridines, catalyzed by homogeneous $\mathrm{FeCl}_{3}{ }^{164}$ By the use of a high $\mathrm{T} / \mathrm{p}$ continuousflow process, the group was able to enhance the reaction kinetics significantly to a minute instead of hour scale. ${ }^{165}$ Molecular oxygen could be replaced by air and propylene carbonate (PC) was used as a green solvent. At high concentration (1.2 M) and low catalyst loading (5 mol\%), a yield of $81 \%$ phenyl(pyridin-2-yl)methanone was obtained within 13 minutes residence time (Scheme 9).

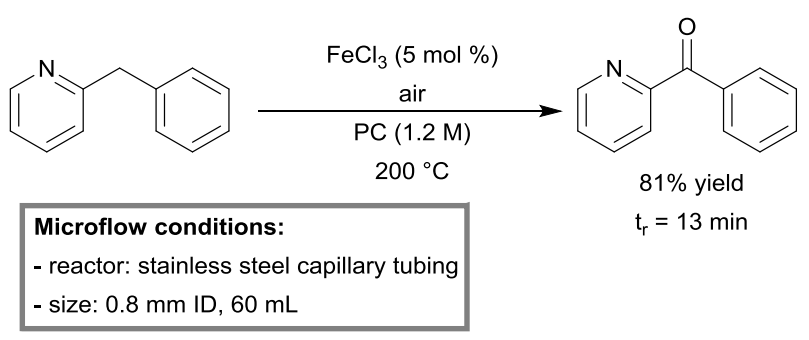

Scheme 9. Aerobic oxidation of 2-benzylpyridines in a gas-liquid continuous-flow reactor. ${ }^{164}$

Molecular oxygen is by far the choice of oxidant considering its low price and green character. However, in the case of partial oxidation, chemists tend to use alternative oxidants, since over-oxidation can play a significant problem. One such process, is the aerobic anti-Markovnikov Wacker oxidation of styrene compounds into phenylacetaldehydes. Ley et al. succeeded in making this aerobic oxidation possible by the use of microreactors. ${ }^{166}$ They developed an efficient anti-Markovnikov oxidation procedure of various styrenes utilizing a Teflon AF-2400 tube-in-tube microreactor $(0.7 \mathrm{~mL})$, coupled to a stainless steel coil $(30 \mathrm{~mL})$. With $(\mathrm{MeCN}){ }_{2} \mathrm{PdCl}_{2}(5$ mol \%) and $\mathrm{CuCl}_{2}(5 \mathrm{~mol} \%)$ as catalysts and molecular oxygen ( 8 bar) as oxidant, a scope of functionalized styrenes could successfully be oxidized to the corresponding aldehydes (56$80 \%$ ) with minimal over-oxidation and within 60 minutes residence time (Scheme 10). Due to the relative purity of the product stream, simple work up was possible via crystallization in the presence of sodium bisulfite.

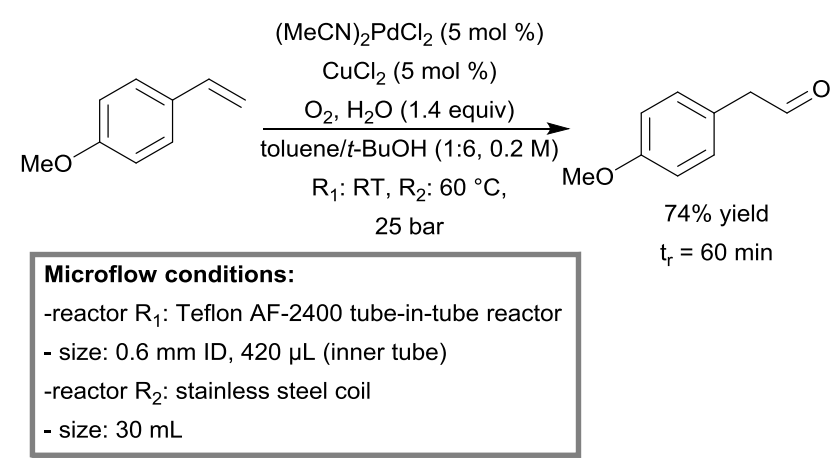

Scheme 10. A continuous-flow aerobic anti-Markovnikov Wacker oxidation of styrenes using molecular oxygen as oxidant. ${ }^{166}$

Kappe et al. constructed a continuous-flow reactor for the preparation of acetophenone and benzoic acid from ethyl benzene. ${ }^{167}$ The combination of $\mathrm{CoBr}_{2}$ (2.5 mol\%) in combination with $\mathrm{Mn}(\mathrm{OAc})_{2}(2.5 \mathrm{~mol} \%)$ in acetic acid was used as active catalytic system. The system is known in literature as the 'MC-system', and is one of the most active and selective catalytic systems available for aerobic, homogeneous liquid phase oxidations. ${ }^{168,169}$ In addition, synthetic air could be utilized as oxidant. The microreactor protocol showed to be superior compared to its batch counterpart. In the case of acetophenone, reaction time could be reduced significantly from $150 \mathrm{~min}$ in batch to 6 minutes residence time in flow, while maintaining selectivity (77\%). A microfluidic system was built from PFA capillary tubing $(0.8 \mathrm{~mm} \mathrm{ID,} 25 \mathrm{~mL})$. At $120^{\circ} \mathrm{C}$, essentially $66 \%$ of acetophenone was isolated without the need for chromatography (Scheme 11). For the full oxidation of ethyl benzene to benzoic acid, a second flow setup was built, consisting of a stainless steel capillary tubing $(0.8 \mathrm{~mm}$ ID, $60 \mathrm{~mL}$ ) in combination with a higher reaction temperature $\left(150{ }^{\circ} \mathrm{C}\right)$. An isolated yield of $71 \%$ was obtained within 16 minutes.

A continuous-flow homogeneous aerobic oxidation method for primary alcohols, with $\mathrm{Cu}(\mathrm{l}) /$ TEMPO catalyst and $\mathrm{N}$ methylimidazole (NMI) as base was reported by Stahl el al. ${ }^{170}$ This was an improvement to their previous pioneering report on palladium(II)-catalyzed aerobic oxidation of alcohols in flow. ${ }^{171}$ No catalyst poisoning from substrates containing sulfur or nitrogen heteroatoms was noticed. In addition, faster catalytic rates were observed, which allowed minimal exposure time of the substrate to oxygen, and therefore avoided over-oxidation. The system was a modification of the existing flow system. The microreactor was made from stainless steel (1/8" OD, $66 \mathrm{~mL}$ ) tubing. Temperature was set at $100{ }^{\circ} \mathrm{C}$ or $60{ }^{\circ} \mathrm{C}$ for benzylic alcohols or aliphatic alcohols respectively. Quantitative yield (99\%) for a variety of benzylic alcohols was obtained within 5 minutes residence time (Scheme 12). For aliphatic alcohols near quantitative yields (95-99\%) were obtained at longer residence times (30-45 minutes).

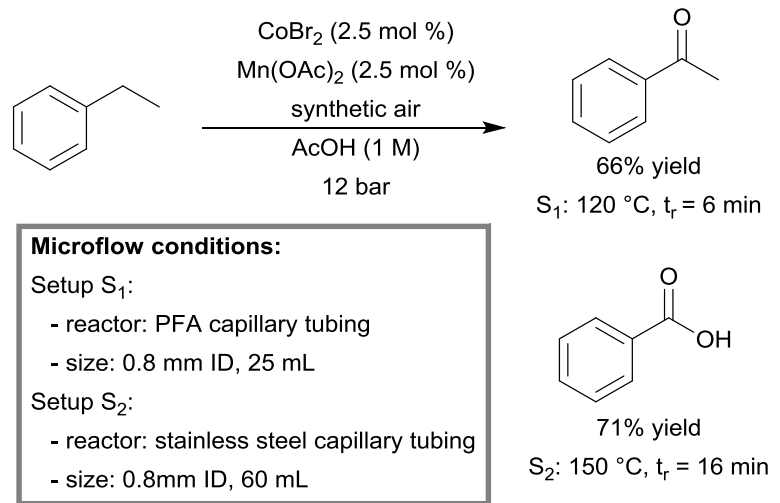

Scheme 11. Aerobic oxidation of ethyl benzene to acetophenone and benzoic acid in a continuous-flow microreactor. ${ }^{167}$ 


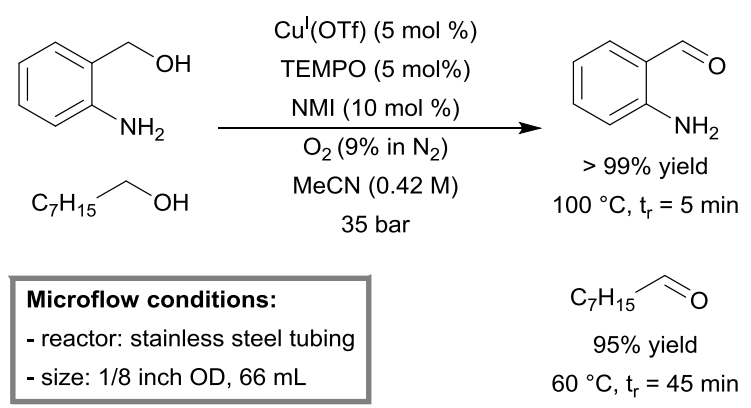

Scheme 12. Aerobic oxidation of primary alcohols by $\mathrm{Cu}(\mathrm{I})(\mathrm{OTf}) / \mathrm{TEMPO}$ catalyst in continuous flow. ${ }^{170}$

An improved protocol for the selective aerobic oxidation of primary alcohols by $\mathrm{Cu}(\mathrm{I}) / \mathrm{TEMPO}$ catalysis in micro flow was reported by Favre-Réguillon. ${ }^{172}$ Kinetic studies revealed that oxygen showed a first order relationship, which indicates that a higher oxygen concentration could be beneficial. Therefore, the mixture of $9 \% \mathrm{O}_{2}$ in $\mathrm{N}_{2}$ was exchanged for a pure oxygen feed. Furthermore, calculations of activation energy for dioxygen binding with copper revealed low activation values (4-12 $\left.\mathrm{kJ} \cdot \mathrm{mol}^{-1}\right)$, indicating that the use of high temperature will have limiting effect on the rate of oxidation. As a consequence, room temperature was utilized instead of the $60-100{ }^{\circ} \mathrm{C}$ as reported by Stahl previously. In addition, lower relative concentrations of TEMPO to copper (1:10) gave better results in screening experiments. $\mathrm{Cu}(\mathrm{I})$ species were found to be sensitive to aging, thus the $\mathrm{Cu}(\mathrm{I})$ species was replaced by a more active and stable $\mathrm{Cu}(\mathrm{II})$ source $\left([(\mathrm{bpy}) \mathrm{Cu}(\mathrm{II})-(\mathrm{OH})]_{2}(\mathrm{OTf})_{2}\right)$. For the reaction setup, a PFA microreactor $(1.6 \mathrm{~mm} \mathrm{ID,} 5 \mathrm{~mL}$ ) was constructed. Benzylic and allylic alcohols could be oxidized successfully to their corresponding aldehydes with excellent yield (90-99\%) (Scheme 13). Aliphatic alcohols proved to be less reactive (conversion $<50 \%$ ), but higher conversion could be acquired at longer residence times ( $>5 \mathrm{~min}$ ).

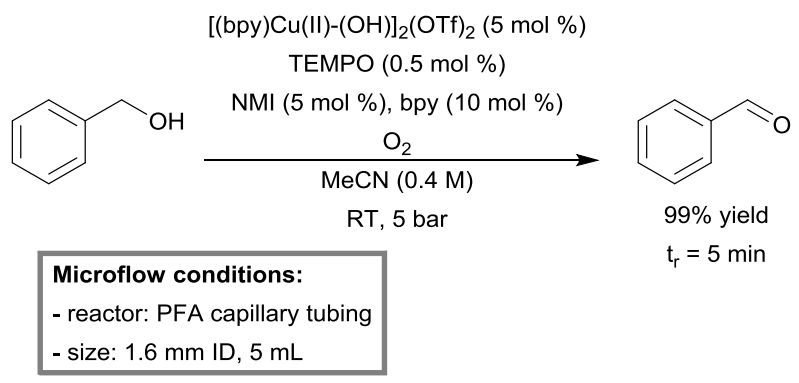

Scheme 13. Aerobic oxidation of primary alcohols by $[(\text { bpy }) \mathrm{Cu}(\mathrm{II})-(\mathrm{OH})]_{2}(\mathrm{OTf})_{2} / \mathrm{TEMPO}$ catalyst in continuous flow. ${ }^{172}$

\subsection{Photosensitized singlet oxygen oxidation processes in continuous flow}

Singlet oxygen is well known for its wide spread use in applications, such as synthetic chemistry, biology, medicine, and material science. ${ }^{173}$ Singlet oxygen can be produced in situ by the use of dye-based (e.g., rose Bengal) or metal-based photosensitizers (e.g., $\mathrm{Ru}(\mathrm{bpy})_{3} \mathrm{Cl}_{2}$ ) and light. These sensitizers absorb electromagnetic waves at certain wavelengths (e.g., visible light) depending on its specific structure. Due to its high electrophilicity, singlet oxygen is found to be much more active than its ground (triplet) state, and is capable of oxidizing substrates that would otherwise be unaffected by triplet oxygen. Therefore, photosensitized singlet oxygen oxidation processes are often associated with mild reaction conditions (e.g., room temperature, visible light). However, certain limitations are associate with the use of singlet oxygen. The lifetime of singlet oxygen is highly solvent dependant (e.g., 9.5 $\mu s$ in methanol) which results in very low effective concentrations of singlet oxygen. In addition, formation of byproducts is common at prolonged irradiation times due to the high activity of singlet oxygen and formation of peroxide intermediates. Furthermore, gas-liquid photoreactions are challenging on larger scale batch procedures, due to low interfacial area and limited irradiation of reaction mixture (Lambert-beer law).

Most of these limitations can be overcome by the implementation of micro flow technology. ${ }^{77,174-178}$ Due to their high surface-to-volume ratio, microreactors offer homogeneous irradiation of the reaction mixture, resulting in maximum photon absorption and faster reaction kinetics. In addition, high control of reaction time minimizes possible over-oxidation and by-product formation.

Homogeneous catalysis. A first example of the application of singlet oxygen in micro flow was performed by de Mello et al. ${ }^{179}$ The singlet oxygen mediated oxidation reaction of $\alpha$ terpinene $(0.15 \mathrm{M})$ to ascaridole was performed with rose bengal ( $3 \mathrm{~mol} \%$ ) as photosensitizer and methanol as solvent. The microreactor device consists of a glass microchip with a serpentine shaped single microchannel $(50 \mu \mathrm{m} \times 150 \mu \mathrm{m}, 50$ $\mathrm{mm}$ length) and was irradiated using a $20 \mathrm{~W}$ overhead tungsten lamp at a distance of $10 \mathrm{~cm}$ of the microchip. $85 \%$ conversion was obtained for a single pas run of 5 seconds residence time. The same group reported later an improved continuous-flow protocol for the production of ascaridole by the use of a semipermeable micro capillary film (MCF) containing 10 parallel channels (100 $\mu \mathrm{m}$ ID, $5 \mathrm{~m}$ length) in planar format. ${ }^{180}$ The MCF was built from fluorinated ethylene propylene (FEP) polymer material. Fluoropolymers are known to display an appreciable gas permeability, allowing to feed oxygen via through-wall mass-transport. At a residence time of 14 minutes, ascaridole could be obtained with yields over $90 \%$ (Scheme 14). In addition, this system may be advantageous for large-scale applications.

Another example is the photosensitized oxidation of citronellol to rose oxide in glass microreactors ( $1 \mathrm{~mm} \mathrm{ID,} 0.27$ $\mathrm{mL}$ ), performed by Meyer et al. ${ }^{181}$ A comparison was made between a batch reactor and microreactor in terms of spacetime yield and photonic efficiency. The photonic efficiency was approximately twice as high as that of the batch reaction. Further, the space-time yield (STY) was about one order of magnitude higher for the microreactor. 

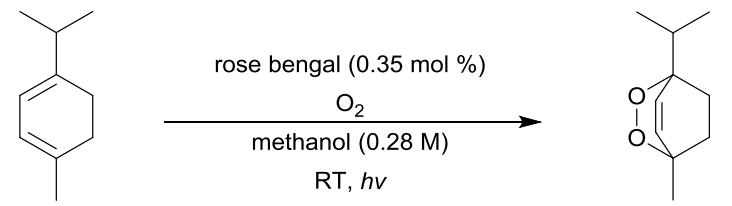

Microflow conditions:
- reactor: micro capillary film (MCF)
- size: $10 \times(150 \mu \mathrm{m} \times 5 \mathrm{~m}), 880 \mathrm{~mL}$
- light source: LED $(570 \pm 5 \mathrm{~nm})$

$>90 \%$ yield $\mathrm{t}_{\mathrm{r}}=14 \mathrm{~min}$

Scheme 14. Photosensitized singlet oxygen oxidation of $\alpha$-terpinene to ascardole in a micro capillary film (MCF) reactor. ${ }^{180}$

Kim et al. developed a dual channel PDMS microreactor for the (-)-citronellol oxidation (Figure 6). ${ }^{182,183}$ The upper channel was coated with polyvinylsilazane (PVSZ) in order to protect the reactor from solvent swelling. The bottom channel was used for gaseous oxygen feed. The two channels were separated by a PDMS gas permeable membrane. The photosensitized oxidation of (-)-citronellol was chosen as model reaction. The dual-channel microreactor performance was compared with a conventional batch setup and a single channel microreactor. Both microreactors provided a higher yield $(95-97 \%)$ of rose oxide as compared to the batch setup (89\%). With a residence time of only 3 minutes and an internal volume of $285 \mu \mathrm{L}$, the dual-channel provided a daily output of $45.49 \mathrm{mmol}$, outperforming the single channel (same reaction volume) and batch reactor $(50 \mathrm{~mL})$ by more than 10 and 2.6 times respectively.
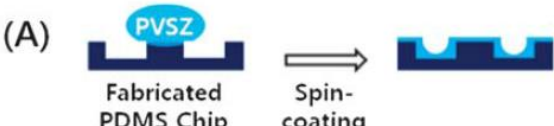

Cleaning PVSZ in Convex Surface
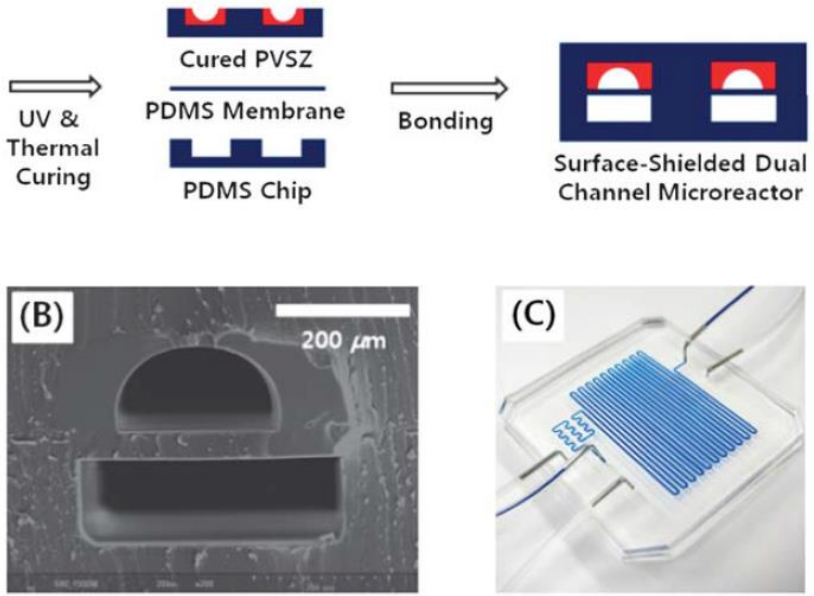

Figure 6. A) Schematic illustration for the fabrication of the dual-channel microreactor with PVSZ coated upper channel. B) Cross-sectional view of dual-channel microreactor. C) Dual-channel microreactor under operating conditions. Reproduced from Ref. 182 with permission from The Royal Society of Chemistry.

The importance of light source and microreactor geometry optimization was shown by Lapkin et al. ${ }^{184}$ The oxidation of $\alpha$ pinene to pinocarvone under photochemical conditions was used as model reaction. Various flow reactors, a recirculating annular reactor and a microreactor chip $(500 \mu \mathrm{m} \times 240 \mu \mathrm{m}, \mathrm{V}=$ $240 \mu \mathrm{L})$ were investigated. Combined with each flow setup, different light sources (75 W Xe arc lamp, $48 \mathrm{~W}$ LED array and $250 \mathrm{~W}$ metal halide lamp) were utilized. A conventional immersed-well batch photoreactor, equipped with a $125 \mathrm{~W}$ mercury lamp, was used as reference. In case of the annular recirculating flow reactor, a much better efficiency was obtained (23 times increase) due to higher photon flux and more efficient mixing. In case of the microreactors, actinometric measurements revealed that the $416 \mathrm{~nm}$ LED array was most efficient, both in lower energy consumption and largest amount of absorbed photon flux. This can be attributed to the match between microscale LEDs and the dimensions of the microreactor. Space time yield (STY) calculations favored microreactors (3-7 times higher STY), mostly because of better light utilization. In order to find the window of maximum performance/productivity, a costanalysis model was derived for the homogeneous singlet oxygen oxygenation of $\alpha$-pinene in microreactors. The model described the optimal operating costs $(\$ / \mathrm{mol}$ pinocarvone produced) as function of the microchannel depth; $240 \mu \mathrm{m}$ was considered as ideal.

Park et al. developed a general continuous-flow design for the photooxidation of monoterpenes (e.g., $\alpha$-pinene, $\beta$-pinene, $\delta$-limonene, $\alpha$-terpinene and (-)-citronellol). ${ }^{185,186}$ They evaluated two photochemical reactors, i.e., a monochannel reactor and a tube-in-tube reactor. The monochannel microreactor (PEEK tubing, $500 \mu \mathrm{m} I D, 26 \mu \mathrm{L}$ ) was used for small scale optimizations and rapid screening of the reaction scope. The tube-in-tube reactor (AF-2400 tubing, $600 \mu \mathrm{m}$ ID, $7.92 \mathrm{~mL}$ ) was tested for possible scale up. Photooxidation of representative terpenes were carried out and daily output $(\mathrm{DOP}=$ reagent concentration $(\mathrm{M}) \times$ reactor volume $(\mathrm{mL}) \times$ yield (\%) $\times 1440 \mathrm{~min} /$ reaction time $(\mathrm{min})$ ) was used as benchmark parameter. DOP results concluded that the tubein-tube microreactor clearly outperforms the conventional batch procedures (e.g., DOP 67.9 fold greater in case of (-)citronellol). To further increase the eco-friendly character of microreactors, an experiment with natural sunlight was conducted. During midday, $\beta$-pinene in methanol $(0.5 \mathrm{M})$, together with methylene blue (5 wt\%), was merged with oxygen and injected into the monochannel microreactor under a segmented flow regime. Natural sunlight was concentrated by a convex lens $(d=270 \mathrm{~mm})$. At 3 bar backpressure, a yield up to $62 \%$ was obtained within 30 minutes residence time (Scheme 15).

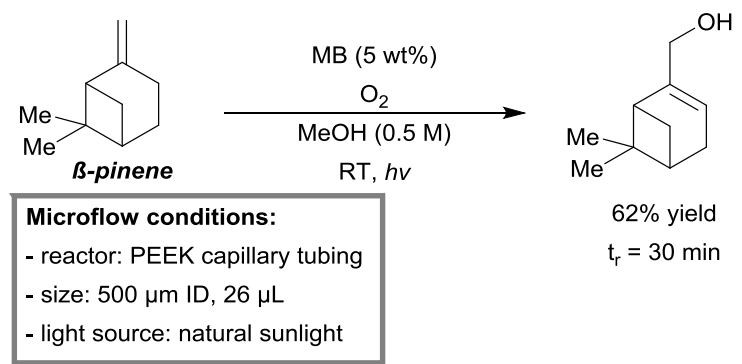


Scheme 15. Continuous-flow photooxygenation of ß-pinene under sunlight. ${ }^{185}$

Seeberger et al. used a capillary FEP reactor $(750 \mu \mathrm{m}$ ID, 14 $\mathrm{mL}$ ) for photosensitized singlet oxygen oxidation chemistry in flow. ${ }^{187}$ The tubing was wrapped tightly around a quartz immersion well (cooled by a thermostat), containing a $450 \mathrm{~W}$ medium pressure mercury lamp and a Pyrex filter. Tetraphenylporphyrin (TPP) was used as a stable photosensitizer. Under steady state conditions, $27 \mathrm{~mL}$ of citronellol could be oxidized within one hour, resulting in a productivity of $2.5 \mathrm{mmol} / \mathrm{min}$. To further demonstrate the utility of the photoreactor, substrates with various functionalities, including alkenes, 1,3-dienes, furan and thioethers, were oxidized to their key intermediates. As example, 2-methylfuran could be oxidized successfully to 3acetylacrylic acid, a key substrate to produce drug substances ${ }^{188,189}$, with a yield of $68 \%$ within 0.8 minutes residence time (Scheme 16).

A multi-step flow reactor was designed for the synthesis of artemisinin from dihydroartemisinic acid (DHAA) was developed by Seeberger et al. ${ }^{190}$ Artemisinin is known as the most effective antimalarial drug today, but due to its complex structure (Scheme 17), total synthesis of artemisinin is considered inapplicable for large scale production. $(<5 \%$ yield over 15 steps). The alternative is to start form the precursor DHAA, which is found in the same plant (Artemisia annua) as where artemisinin is isolated from. However, DHAA can be isolated in much higher yields. The following steps to yield artemisinin from DHAA are: singlet oxygen photooxidation, Hock cleavage, triplet oxygen oxidation and multiple ring closure condensations. Especially, the first step, the singlet oxygen photooxygenation, was considered to be highly beneficial in micro flow. The multi-step micro flow system was capable of producing $200 \mathrm{~g}$ (39\% yield) artemisinin per day. Recent modifications resulted in an improved artemisinin production in terms of efficiency. ${ }^{191}$ For the first step, the former $450 \mathrm{~W}$ medium pressure mercury lamp was replaced by high-power LEDS of $72 \mathrm{~W}$ in total and temperature was set to $-20{ }^{\circ} \mathrm{C}$. Tetraphenylporphyrin (TPP) was replaced by 9,10 dicyanoanthracene (DCA), a much more stable and efficient photocatalyst. Finally, the chlorinated solvent (DCM) was exchanged for toluene, as being more environmental benign. With a total residence time of 11.5 minutes, a production of $165 \mathrm{~g}(65 \%$ yield) artemisinin per day could be obtained (Scheme 17).

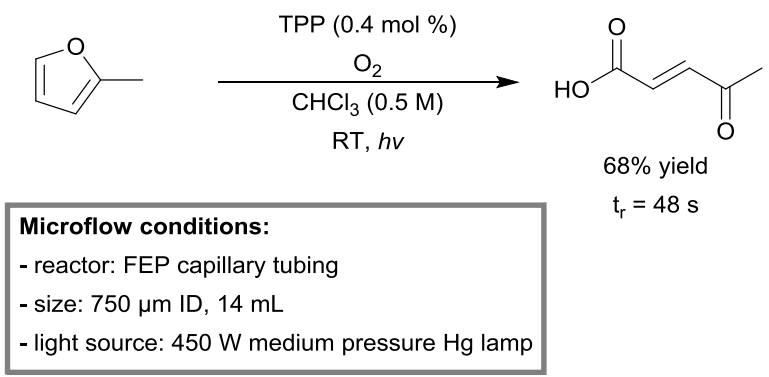

Scheme 16. Singlet oxygen oxidation of 2-methylfuran to 3-acetylacryl acid in continuous flow. ${ }^{187}$

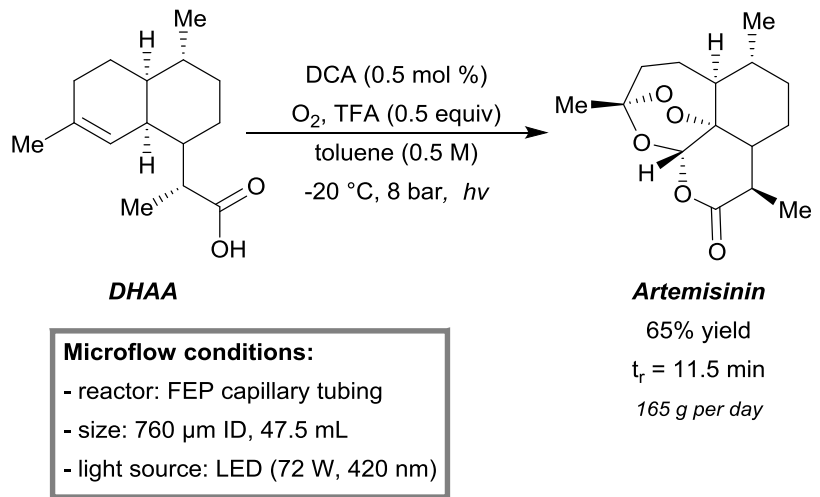

Scheme 17. Multi-step continuous-flow setup for the artemisinin synthesis from dihydroartemisinic acid (DHAA). ${ }^{191}$

A similar photo microreactor was used for the direct oxidative cyanation of primary and secondary amines. ${ }^{192}$ Amines could be successfully oxidized to their corresponding imines by the presence of singlet oxygen. Consequently, the in situ generated imines were trapped by trimethylsilyl cyanide (TMSCN) to yield the corresponding $\alpha$-aminonitriles in good to excellent yields. In the case of dibenzylamine, quantitative yield (99\%) was obtained within 90 seconds residence time (Scheme 18). The reactor could be operated at room temperature with low loading of TPP (0.1 - $0.3 \mathrm{~mol} \%)$ as photosensitizer. By lowering the temperature to $-50{ }^{\circ} \mathrm{C}$ and adding sub stoichiometric amounts of tetra- $n$ butylammoniumfluoride (TBAF), they were able produce, for the first time, $\alpha$-aminonitriles directly from primary amines. Recently, the method was extended to allow for the preparation unnatural amino acids ${ }^{193}$ and selective crosscondensation of amines. ${ }^{194}$

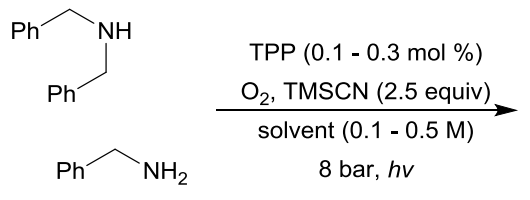

Microflow conditions:

- reactor: FEP capillary tubing

- size: $760 \mu \mathrm{m} I D, 7.5 \mathrm{~mL}$

- light source: LED (12 W, $420 \mathrm{~nm})$

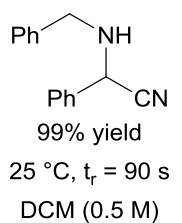

$0.5 \mathrm{M}$

$$
\begin{gathered}
90 \% \text { yield } \\
-50{ }^{\circ} \mathrm{C}, \mathrm{t}_{\mathrm{r}}=3 \mathrm{~min} \\
\operatorname{THF}(0.1 \mathrm{M})
\end{gathered}
$$

Scheme 18. Continuous-flow aerobic oxidative cyanation of primary and secondary amines using singlet oxygen. ${ }^{192}$

Itoh and et al. demonstrated the use of photo microreactors for the improvement of the aerobic oxidation of toluene derivatives. ${ }^{195}$ A microreactor setup was built, consisting out of a glass microreactor chip $(500 \mu \mathrm{m} \times 300 \mu \mathrm{m}$, $360 \mu \mathrm{L})$ and $375 \mathrm{~nm}$ LED light (11.4 W). The chip was fed with a liquid phase and molecular oxygen, generating a segmented flow regime. The liquid phase contained substrate $(0.5 \mathrm{M})$ and photosensitizer 2-tert-butylanthraquinone (10 mol \%) in toluene. A yield of $48 \%$ was obtained for the photooxidation of 
toluene into benzoic acid, within 2 hours residence time. As compared to batch, 24 hours were necessary in order to complete the reaction.

Recently, Noël et al. reported a metal-free batch and continuous-flow protocol to access disulfide linkages through photooxidation of thiols. ${ }^{196}$ With Eosin Y $(1 \mathrm{~mol} \%)$ as metalfree photosensitizer and a $24 \mathrm{~W}$ compact fluorescent light bulb they were able to obtain quantitative yield of disulfides for a variety of (hetero)aromatic and aliphatic thiols in an open flask procedure. It was observed that the mixing rate greatly influenced the rate of oxidation. Therefore, a biphasic microreactor setup was developed in order to overcome mass transfer limitations. A PFA capillary microreactor $(750 \mu \mathrm{m}, 950$ $\mu L)$ was constructed and exposed to LED light (3.12 W). Segmented gas-liquid flow was used to further increase mass transfer efficiency. A variety of thiophenol substrates was evaluated and resulted in near quantitative yields (93-99\%) within 20 minutes residence time. Notably, the substrate furfuryl mercaptan could be exclusively dimerized under micro flow conditions with a yield of $87 \%$. To demonstrate the mild character of this procedure, an intramolecular disulfide bond formation was conducted in flow to prepare oxytocin, a peptide hormone. Full conversion was obtained within 200 seconds residence time (Scheme 19). The same reactor was used for kinetic studies. ${ }^{100} \mathrm{~A} 1^{\text {st }}$ for thiophenol and $2^{\text {nd }}$ order for molecular oxygen was observed. Furthermore, the calculated Hatta number $(\mathrm{Ha}=0.06)$ suggested that gas-liquid mass transfer limitations were completely eliminated by the use of microreactors.

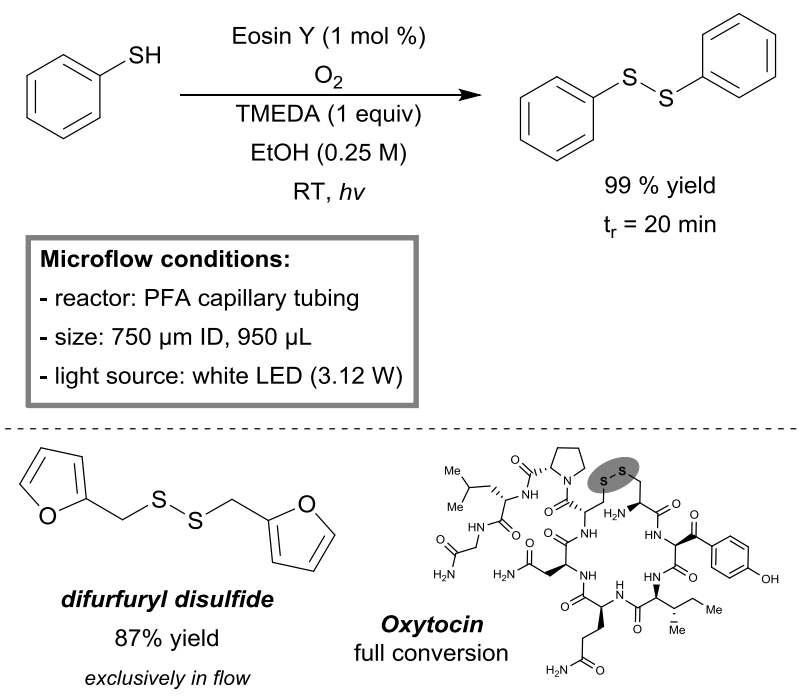

Scheme 19. Metal-free oxidative S-S coupling of thiols in continuous flow. ${ }^{196}$

5-hydroxymethylfurfural (5-HMF) is recognized as a new platform molecule from the biobased industry. ${ }^{197,198} \mathrm{~A}$ potential compound of interest derived from the HMFplatform, is 5-hydroxy-5-(hydroxymethyl)-furan-2(5H)-one $\left(\mathrm{H}^{2} \mathrm{MF}\right)$. This scaffold is directly available from $5-\mathrm{HMF}$ by means of singlet oxygen oxidation, but was only accessible in low to moderate yields and selectivities. ${ }^{199}$ However, Kappe et al. recently developed a continuous-flow procedure for the $\mathrm{H}^{2} \mathrm{MF}$ production to form 5-HMF. ${ }^{200}$ The microreactor was built from commercially available PFA tubing ( $1 \mathrm{~mm} \mathrm{ID,} 10 \mathrm{~mL}$ ) and wrapped around a glass cylinder. As a light source, a $60 \mathrm{~W}$ compact fluorescent light bulb was employed. After optimization (0.2 M 5-HMF, 0.5 mol\% rose bengal, 17 bar BPR and $\mathrm{PrOH}: \mathrm{H}_{2} \mathrm{O}$ (1:1) solvent), $\mathrm{H}^{2} \mathrm{MF}$ could be isolated in excellent yield (93\%) within 40 minutes residence time (Scheme 20). The micro flow setup was applicable for a variety of bio-based furfural substrates. The synthetic method was considered sustainable, since only visible light, oxygen, catalytic amounts of photosensitizer and an environmental friendly solvent mixture was used.

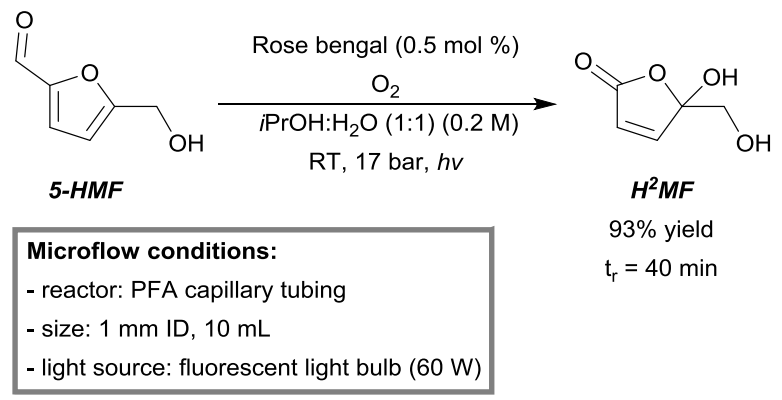

Scheme 20. Singlet oxygen oxidation of 5-HMF in continuous flow. ${ }^{200}$

Heterogeneous catalysis. Immobilization of photosensitizers for the production of singlet oxygen in microreactors can beneficial for several reasons (e.g., catalyst recuperation, high TON, easy work-up procedures). However, only few reports have demonstrated this concept.

Lammertink et al. developed a new concept of microreactors, based on membrane technology. ${ }^{201} \mathrm{~A}$ porous photocatalytic membrane microreactor was built and applied for various photooxidation reactions. The reactor was microfabricated (CNC milling) from porous aluminium oxide ( $\alpha$ $\mathrm{Al}_{2} \mathrm{O}_{3}$ ). A layer of $\mathrm{TiO}_{2}$ was immobilized onto the channel walls and via UV treatment, selective hydrophilization of the photocatalyst. The hydrophilic character of the $\mathrm{TiO}_{2}$ layer allowed efficient contact of the aqueous reaction mixture inside the microchannels, while molecular oxygen was fed through hydrophobic membrane (Figure 7). The photocatalytic oxidative degradation of methylene blue and phenol was used as a benchmark.

A thiolene-based microreactor was loaded with an immobilized fullerene catalyst. ${ }^{202}$ Fullerenes were used as photosensitizer for the singlet oxygen oxidation of $\alpha$-terpinene and methionine. In both cases, quantitative conversions could be obtained within 40-50 seconds of residence time.

Boyle et al. functionalized a commercially available, 16 channel, glass microreactor with photo-active porphyrins. ${ }^{203}$ The oxidation of three model substrates (i.e., cholesterol, $\alpha$ terpinene and citronellol), with molecular oxygen, were performed and compared to their batch equivalent. Although overall yields were low in the microreactor, space time yields were higher because of increased efficiency in singlet oxygen production. 
Several other papers describe the application of microreactors for the photocatalytic degradation of organic compounds, employing immobilized $\mathrm{TiO}_{2},{ }^{204,205}$ silicon nanoporous silicon, ${ }^{206}$ cyanoaromatics encapsulated on porous silica ${ }^{207}$ and sulfonated zinc phtalocyanine $\left(\mathrm{ZnPcS}_{\text {mix }}\right)^{208}$

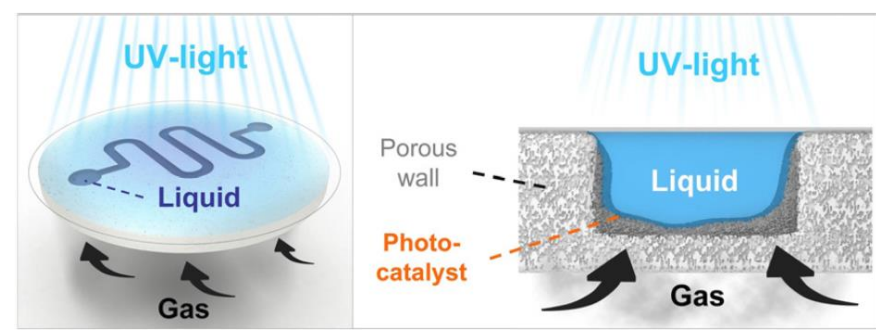

Figure 7. The use of a porous photocatalytic membrane microreactor for the oxygenation of methylene blue and phenol. Reproduced from Ref. 150 with permission from Elsevier.

\subsection{Biocatalytic aerobic oxidation processes in continuous flow}

Oxidation reactions can also be carried out by enzymes. These biocatalysts often outperform conventional catalysts (e.g., transition metal catalysts) in terms of selectivity. Enzymes used for oxidation chemistry (e.g., glucose oxidase (GOx)), often use air as the oxidant and are therefore mostly limited by gasliquid mass transport of oxygen. Consequently, enzymatic oxidative reactions could highly benefit from microreactor technology.

The first miniaturized enzymatic reaction systems have already been developed decades ago for high-throughput screening analysis, and could be regarded as predecessors of the current continuous-flow microreactors. ${ }^{209}$ Recently, research on the combination of biocatalysis and microscale technology is increasing. ${ }^{210-213}$ In addition, efforts have been made to develop enzyme microreactors as biosensors for biomedical applications (e.g., glucose detection). ${ }^{214-216}$

Homogeneous catalysis. Several groups reported meso-scale batch reactors for the Baeyer-Villiger oxidation of ketones to chiral lactones. ${ }^{217,218}$ In order to avoid enzyme deactivation from gas-liquid interfaces, a meso-scale thin-walled silicon tube reactor ( $5 \mathrm{~mm} \mathrm{ID}, 7.9 \mathrm{~mL}$ ) was used to aerate the reaction mixture in a bubble-free manner.

Plazl et al. developed a two-phase liquid-liquid microreactor for the selective aerobic oxidation of cholesterol to 4-cholesten-3-one, catalyzed by cholesterol oxidase. ${ }^{219,220 ~ I n ~}$ a Y-shaped mixer the aqueous phase (containing the enzyme) and the organic phase (containing the substrate) were merged, forming a parallel aqueous-organic two-phase flow pattern. At optimal conditions, $67 \%$ yield was obtained with a residence time of 62 seconds.

The same group reported a laccase-catalyzed 3,4dihydroxy-L-phenylalanine (L-DOPA) oxidation, performed in an identical microreactor $(220 \mu \mathrm{m} \times 50 \mu \mathrm{m}, 3.6 \mu \mathrm{L})$. A twodimensional mathematical model was developed and was found to be in good agreement with experimental data $(87 \%$ conversion of L-DOPA at a residence time of 100 seconds).
Zelic et al. demonstrated the laccase-catalyzed oxidation of catechol and L-DOPA in microreactors. ${ }^{221}$ In the case of catechol, oxidation rates were up to 167 -fold higher than for the macroreactor.

A falling film microreactor (FFMR) was used for the GOxcatalyzed oxidation of $\beta$-D-glucose (Scheme 21). ${ }^{222}$ FFMR utilizes gravity to establish a thin liquid film which is brough inot contact with the gas phase. The FFMR ensures permanent oxygen saturation, even at high reaction rates. A 12 -fold and 588-fold faster reaction kinetics as compared to the bubble column or batch reaction respectively were obtained for the microreactor. The STY increased by a factor of 300 compared to the batch reactor (at 30\% conversion), demonstrating the more efficient use of the enzyme activity. Scalability was demonstrated by the use of a larger FFMR model (50 channels, $1200 \mu \mathrm{m} \times 400 \mu \mathrm{m}$ ).

Schmid et al. used a Teflon AF-2400 tube-in-tube microreactor $(0.8 \mathrm{~mm} \mathrm{ID}, 0.5 \mathrm{~mL}$ ) to administer oxygen through the reactor wall continuously to the enzyme-catalyzed oxidation of 2-hydroxybiphenyl.223 2-hydroxybiphenyl 3monooxygenase ( $\mathrm{HbpA}$ ) was used to enable the oxidation of the substrate. Formate dehydrogenase (FDH) was added to ensure constant recycling of the cofactor NADH. The productivity achieved in the tube-in-tube microreactor was 4 times higher than in a three-phase aqueous-organic-air segmented flow microreactor.

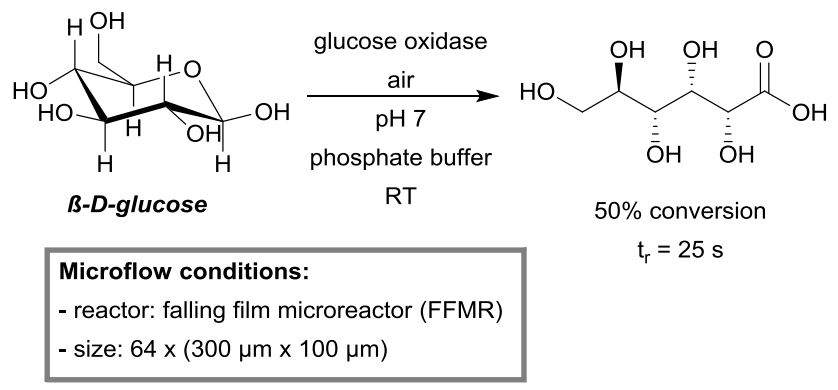

Scheme 21. Aerobic oxidation of ß-D-glucose catalyzed by glucose oxidase in a FFMR. ${ }^{222}$

With the use of a sequential tube-in-tube reactor setup, Buehler et al. were able to produce 3-phenylcatechol on a preparative scale (1 gram) with a STY of $14.5 \mathrm{~g} . \mathrm{L}^{-1} \cdot \mathrm{h}^{-1}$ (Scheme 22). ${ }^{224}$

Heterogeneous catalysis. Immobilized enzymes demonstrate improved stability and can efficiently be reused and separated from reaction mixtures.

Several immobilization techniques have been developed in flow. ${ }^{225-228}$ However, loss of activity due to blockage of the active sites, denaturation of enzymes, fouling and leaching still limits its application. ${ }^{229,230}$

Ho et al. developed a stable capillary enzyme bioreactor for the determination of blood glucose. ${ }^{231}$ Glucose levels could be monitored in a wide range of concentrations with high sensitivity (detection limit $10 \mu \mathrm{M}$ ) and demonstrated high reproducibility. Enzymatic activity could be retained for over 120 days. 
<smiles>Oc1ccccc1-c1ccccc1</smiles>

$$
\begin{gathered}
\mathrm{HbpA}, \mathrm{FDH} \\
\underset{\mathrm{O}_{2}}{\longrightarrow \mathrm{NAD}^{+}, \mathrm{KCOOH}} \\
\text { phosphate buffer:decanol }(1: 1) \\
\mathrm{pH} 7.5 \\
35^{\circ} \mathrm{C}, 6.9 \text { bar }
\end{gathered}
$$

Microflow conditions:
- reactor: Teflon AF-2400 tube-in-tube microreactor
- size: $800 \mu \mathrm{m} \mathrm{ID}, 0.5 \mathrm{~mL}$

Scheme 22. Enzyme mediated aerobic oxidation of 2-hydroxybiphenyl to 3 phenylcatechol in a tube-in-tube microreactor. ${ }^{224}$

Yang et al. demonstrated the successful immobilization of GOx on polyamidoamine dendrimer (PAMAM). ${ }^{228}$ Because of its unique dendritic structure, PAMAM could be used as a flexible spacer between the solid support (capillary wall) and active enzyme. The dendritic structure allowed higher amounts of enzyme to be immobilized onto the reactor wall without constraining the availability of the active sites. The microreactor proved to be stable, whereas activity decreased by less than $10 \%$ over 5 days of operation.

\subsection{Uncatalyzed aerobic oxidation processes in continuous flow}

The increasing environmental awareness demands for more atom efficient, mild and sustainable chemical processes. Conventional oxidation processes however, are often undesired because of their excessive need of heavy metals and hazardous oxidants, which lead to laborious waste treatment and inevitable pollution. Last decade chemists are striving to develop oxidation processes which guarantee high selectivity in metal-free and uncatalyzed reaction conditions. One such example is the uncatalyzed, aerobic oxidation of cyclohexane to cyclohexanol and cyclohexanone. This mixture of products, also called KA oil, is produced on a large scale for Nylon production. ${ }^{232}$ However, the process suffers from selectivity problems and therefore conversion is kept low. ${ }^{101}$ In order to enhance the process selectivity, several research groups have employed continuous-flow microreactors. Bellefon et al. developed a chip microreactor setup to selectively oxidize cyclohexane under explosive conditions. ${ }^{82}$ Jevtic $^{134}$ and Fischer ${ }^{99}$ both utilized capillary microreactors. Fraulin used microreactors and studied the progress of the reaction by in situ Raman spectroscopy studies. ${ }^{233}$

Jensen et al. developed a continuous-flow metal-free oxidation of picolines by using air as oxidant. ${ }^{234}$ In a $240 \mu \mathrm{L}$ chip microreactor, 2-, 3- and 4-picoline could be selectively oxidized within 5 minutes reaction time. In the case of 4picoline, $100 \%$ HPLC yield was obtained after 1 minute residence time at room temperature (Scheme 23). Jia et al. reported another aerobic benzylic $\mathrm{C}-\mathrm{H}$ oxidation procedure. ${ }^{235}$ Microreactor technology was used to safely produce molecular oxygen in situ, by merging tert-butyl hydroperoxide $(t-\mathrm{BuOOH})$ and sodium hypochlorite $(\mathrm{NaOCl})$. Due to high heat dissipation, the reactor could be operated at room temperature.

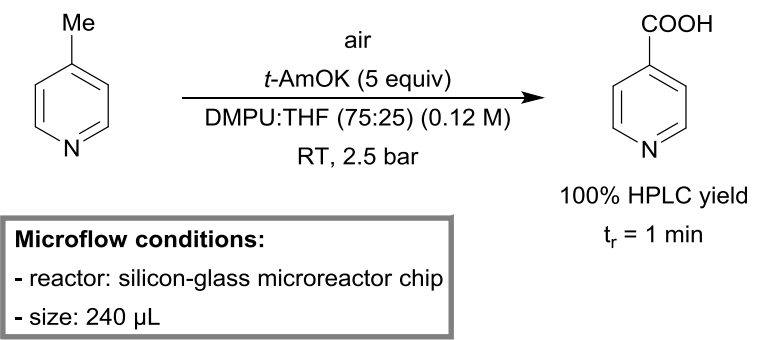

Scheme 23. Continuous-flow metal-free oxidation of picolines by using air as oxidant. ${ }^{234}$

A mild and straightforward aerobic flow oxidation procedure for aliphatic aldehydes to their corresponding carboxylic acids was developed by de Bellefon et al. ${ }^{236}$ The reactor operated at room temperature and was built from PFA capillary tubing ( $1 \mathrm{~mm} \mathrm{ID,} 11.7 \mathrm{~mL}$ ). On-line GC-analysis was conducted using a sample valve. Mass transfer efficiency between the gaseous (oxygen) and liquid phase was assessed by changing the superficial velocity of the segmented flow while maintaining a constant residence time. An optimum was reached for superficial velocities $>0.5 \mathrm{~m} . \mathrm{min}^{-1}$, indicating the the chemical limited regime was reached. 2-ethylhexanal was converted quantitatively to its corresponding carboxylic acid at high concentration $(3.2 \mathrm{M})$ and with a selectivity of $75 \%$ (Scheme 24). The residence time was approximately 15 minutes.

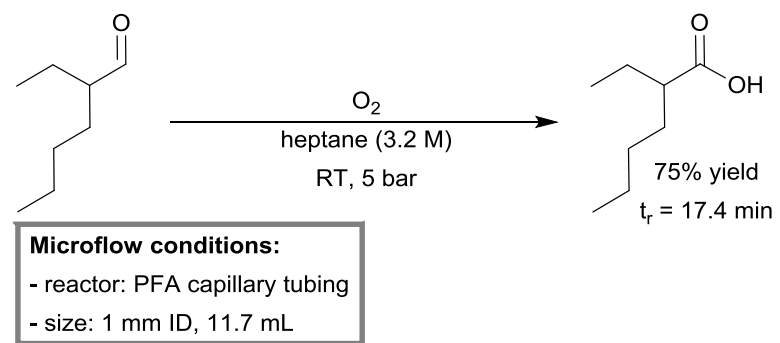

Scheme 24. Uncatalyzed aerobic oxidation of 2-ethylhexanal in a PFA capillary microreactor. ${ }^{236}$

The continuous-flow synthesis of ortho-functionalized phenols by aerobic oxidation of aryl Grignard reagents has been demonstrated by Jamison et al. ${ }^{237}$ The integrated micro flow system consisted of a three-step setup. In the first capillary reactor, a sulfur or nitrogen containing nucleophile was exposed to isopropylmagnesium chloride lithium chloride (i-PrMgCl.LiCl) at room temperature, in order to deprotonate the substrate. The resulting mixture was then mixed with 1,2dihalobenzenes, at elevated temperatures $\left(80-120^{\circ} \mathrm{C}\right)$, for the in situ formation of the reactive benzyne intermediate, followed by a nucleophilic addition, obtaining the orthofunctionalized organomagnesium intermediate. Finally the reaction stream was cooled to $-25{ }^{\circ} \mathrm{C}$ and mixed with compressed air in order to produce the desired orthofunctionalized phenol compound. The overall residence time was 14 minutes with yields varying between $33-55 \%$ for nucleophiles, including thiophenols, $\mathrm{N}$-containing heterocycles and secondary anilines (Scheme 25). 


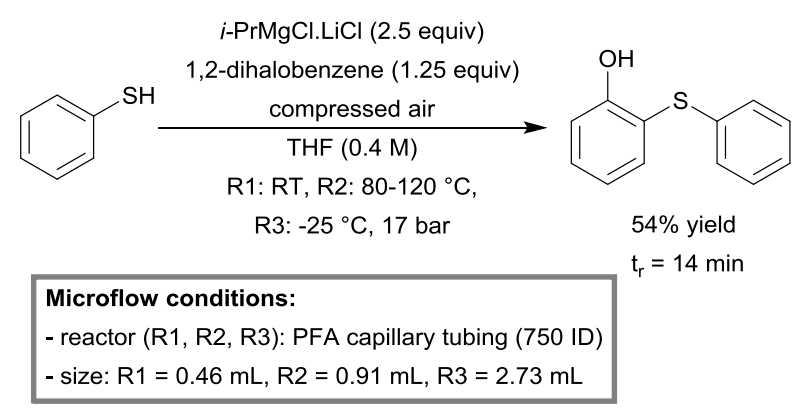

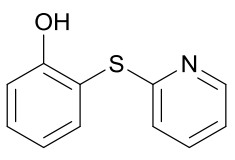

$46 \%$ yield

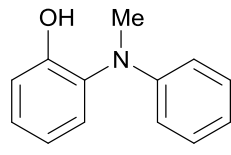

$55 \%$ yield
Scheme 25. Integrated three-step preparation of ortho-functionalized phenols in continous-flow. ${ }^{237}$

\subsection{Aerobic coupling chemistry processes in continuous flow}

Since its introduction in the 1970s, cross-coupling chemistry has played an important role in organic chemistry. ${ }^{238-241}$ Crosscoupling allows for the efficient formation of carbon-carbon and carbon-heteroatom bonds in the presence of a transition metal catalyst, and has found substantial application in pharmaceutical industry and material science. ${ }^{242}$ Recently, with the introduction of microreactor technology, several research groups reported the use of micro-scale devices to conduct two-phase aerobic cross-coupling reactions. ${ }^{243-247}$

An example of a continuous-flow oxidative Heck reaction, performed in a dual-channel microreactor, was reported by Kim et al. ${ }^{243} \mathrm{~A}$ three-layered PDMS microreactor was built with a dual-channel structure (Figure 8). The upper channel was fed with a solution containing substrate and catalyst. The bottom channel, was fed with gaseous molecular oxygen. Between the two channels, a thin gas permeable PDMS layer $(45 \mu \mathrm{m})$ ensured oxygen dosing to the reaction mixture. Due to intimate contact between the gas and solution phase, a significant enhancement was obtained for both yield (72-82\%) and selectivity (87-93\%). Because of the high availability of oxygen, the palladium catalyst could easily be reoxidized to its activate $\mathrm{Pd}(\mathrm{II})$ format, thus accelerating reaction kinetics. As result the reaction time was reduced from 12 hours in batch to 30 minutes in flow.

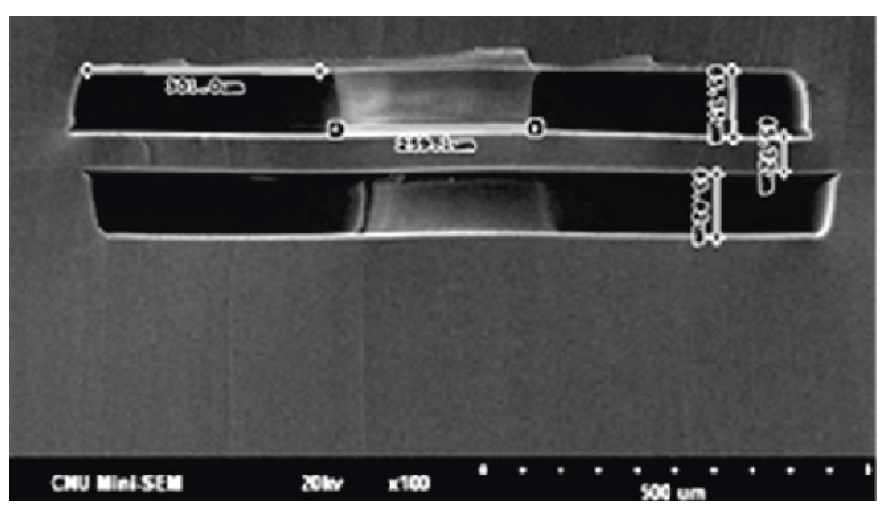

Figure 8. Dual-channel microreactor cross section. Microchannel dimensions: $85 \mu \mathrm{mx}$ $300 \mu \mathrm{m} \times 120 \mathrm{~cm}$. Membrane: $45 \mu \mathrm{M}$ thickness. Reprinted with permission from Ref. 243. Copyright (2010) American Chemical Society.

Noël et al. realized the aerobic cross-dehydrogenative Heck coupling of indoles in micro flow. ${ }^{245}$ The reactor was built from commercially available FEP capillary tubing (750 $\mu \mathrm{m}$ ID, 3.8 $\mathrm{mL}$ ). During optimization studies, it was found that a segmented flow regime (Taylor flow) with molecular oxygen, was crucial for the successful reoxidation of the palladium catalyst. Moreover, catalyst degradation was completely prevented due to high surface-to-volume ratios between the two phases. The high degree of control over both mass- and heat-transfer, enabled the acceleration of reaction kinetics from hour to minute scale. As an example, the coupling between indole and 2,2,2-trifluoroethyl acrylate, could be completed within a residence time of 10 minutes, yielding $82 \%$ of coupled product (Scheme 26). This was a significant improvement in yield and time as compared to its batch counterpart ( $58 \%$ yield after 4 hours batch reaction). The setup was effective to prepare a wide range of 3-vinylindoles (27$92 \%$ yield), including the preparation of methyl $(E)$-3-(6-fluoro$1 \mathrm{H}$-indol-3-yl)acrylate (67\% yield), a potential anticancer agent. $^{248}$

Ley et al. demonstrated the implementation of a tube-intube microreactor for the synthesis of 1,3-butadiynes, via an aerobic Glaser-Hay acetylene coupling. ${ }^{246}$ The tube-in-tube reactor was used to saturate an acetonitrile solvent stream with oxygen before merging with the catalyst and substrate stream. The resulting mixture entered a $20 \mathrm{~mL}$ heating coil $\left(100{ }^{\circ} \mathrm{C}\right)$. After the reaction coil, in line purification methods (packed-bed cartridges) were utilized to scavenge the copper catalyst and TMEDA base. This allowed product isolation of various 1,3-butadiynes in high purity (49-99\% yield), without the need of additional chromatographic purification. As an example, the coupling reaction of 3-ethynylanisole could be carried out on a gram scale ( 2.3 grams), yielding $84 \%$ of pure product without further need of additional chromatography.

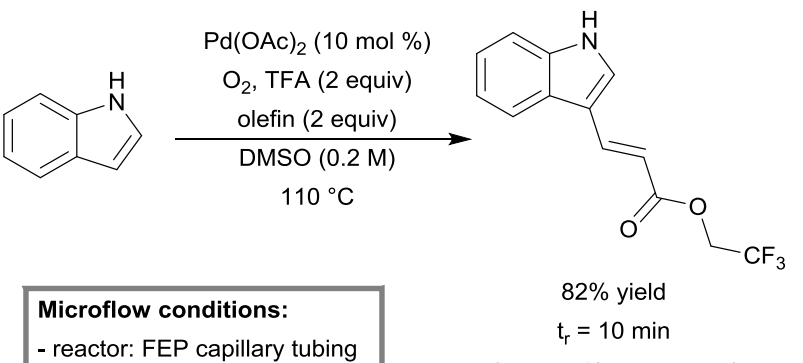

reactor: FEP capillary tubing size: $750 \mathrm{ID}, 3.8 \mathrm{~mL}$

(batch: $58 \%$ yield, 4 hours)

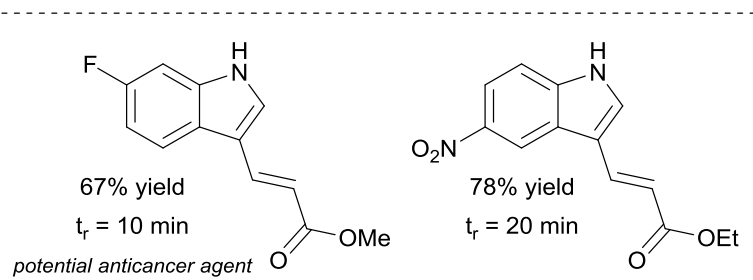


Scheme 26. Aerobic cross-dehydrogenative Heck reaction of indoles in continuous flow. ${ }^{245}$

\section{Oxidation processes in flow by means of hydrogen peroxide}

Besides oxygen, hydrogen peroxide constitutes another important oxidant in organic synthetic chemistry. However, the utilization of $\mathrm{H}_{2} \mathrm{O}_{2}$ in batch is normally only possible in low concentration and under mild reaction conditions due to its intrinsic hazardous properties. Due to the advantages of microreactor technology, i.e., high mass and heat transfer efficiency and easy scale-up, the application of $\mathrm{H}_{2} \mathrm{O}_{2}$ in a microreactor has received more and more attention.

Gavriilidis et al. used hydrogen peroxide as an oxidant to facilitate epoxidation of 1-pentene in a microchannel coated with titanium silicalite-1 zeolite (TS-1, Scheme 27). ${ }^{249,250}$ Reaction rates increased with increasing amounts of $\mathrm{Ti}$ in the zeolite framework. It was also observed that the crystal size largely affected the reaction rate. A smaller crystal size resulted in a higher surface area and an improved mass transfer efficiency, providing higher reaction rates. The catalyst deactivated under the reaction conditions via a shortterm reversible deactivation mechanism and a long-term irreversible deactivation. It was hypothesized that the shortterm deactivation was caused by the deposition of by-product and $\mathrm{H}_{2} \mathrm{O}$, while the long-term deactivation was the result of leaching.
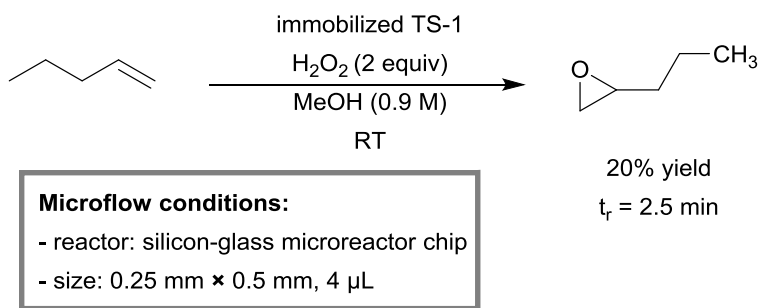

Scheme 27. Epoxidation of 1-pentene with $\mathrm{H}_{2} \mathrm{O}_{2}$ in a TS-1 immobilized microreactor. ${ }^{249}$

Epoxidized soybean oil (ESO) is an important chemical intermediate, which can be used as plasticizer in polyvinyl chloride plastics and stabilizer for plastics. ${ }^{251}$ Kinetic modelling of soybean oil epoxidation at elevated temperatures in a microreactor demonstrated that this would lead to much shorter reaction times. ${ }^{252}$ Increasing the temperature also led to an increased decomposition of $\mathrm{H}_{2} \mathrm{O}_{2}$, which eventually became the dominant reaction. Santacesaria et al. employed a glass tubular reactor $(1 \mathrm{~cm} \mathrm{ID,} 22$ or $38 \mathrm{~mL}$ ) packed with stainless steel spheres $(2.2 \mathrm{~mm} \varnothing)$ to carry out the soybean oil epoxidation under biphasic reaction conditions. ${ }^{253}$ They found that it was difficult to reach the industrial target (oxirane number $\approx 6.5$, residual iodine number $\leq 2$ ) with only a single packed-bed reactor. A two reactor system allowed to overcome these limitations. The first reactor provided a high surface area and short residence time, which facilitated the initial conversion of soybean oil and reduced the ring-opening side reaction. The second reactor had a lower surface area and extended the residence time. According to simulation results, the two reactor strategy met the industrial requirement within 45 min residence time while the industrial process needed 6-8 h. Guo et al. investigated the epoxidation of soybean oil in a Bayer sandwich microreactor and found that the reaction could be improved by making in situ peracids. ${ }^{254}$

Dordick et al. have reported the first continuous-flow polyphenol synthesis by means of biocatalysis. ${ }^{255}$ Soybean peroxidase (SBP) was used as biocatalyst in the presence of $\mathrm{H}_{2} \mathrm{O}_{2}$ and substrate. Various phenolic substrates (e.g., $p$-cresol, p-methoxyphenol, $p$-hydroxyphenetyl alcohol) where introduced intro the biochip (15 $\mu \mathrm{m} \times 200 \mu \mathrm{m}, 90 \mathrm{~nL})$ and could be polymerized successfully.

The poly-L-leucine (PLL)-catalyzed oxidation of chalcone by hydrogen peroxide was carried out in a specially designed plate reactor, which consisted of two staggered herringbone micromixer-microchannel sections in series. ${ }^{256} \mathrm{~A}$ conversion of $87 \%$ and $88 \%$ ee could be obtained for the target compound (Scheme 28). A mathematical model was used to aid the reactor design and the results from the model were closely resembling the experimental ones.

The oxidation of 1-methylcyclohexene catalyzed by Candida antarctica lipase $B\left(N^{2}\right.$ ovozym $\left.{ }^{\circledR} 435\right)$ with $\mathrm{H}_{2} \mathrm{O}_{2}$ in a continuous-flow packed-bed reactor was investigated by Wiles and Watts et al. ${ }^{257}$ They employed a borosilicate glass tube ( 3 $\mathrm{mm}$ ID, $2.5 \mathrm{~mL}$ ) loaded with Novozym ${ }^{\circledR} 435$. Ethyl acetate was used as solvent and could be enzymatically hydrolyzed to form acetic acid and subsequently oxidized to peracetic acid, which was the final oxidant for 1-methylcyclohexene oxidation. ${ }^{258,259}$ Full conversion for this substrate was observed at $70{ }^{\circ} \mathrm{C}$ with a residence time of $2.6 \mathrm{~min}$ (99\% yield, Scheme 29). The use of flow allowed to use larger amounts of $\mathrm{H}_{2} \mathrm{O}_{2}$ (4x higher) before deactivation of the enzyme was noticed. The catalytic performance of the enzyme was consistent even after $24 \mathrm{~h}$ of use.

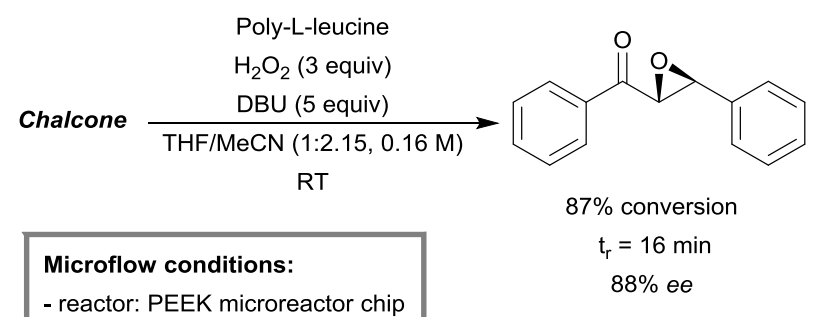

- reactor: PEEK microreactor chip
- size: $320 \mu \mathrm{L}$

Scheme 28. Continuous-flow asymmetric epoxidation of chalcone with $\mathrm{H}_{2} \mathrm{O}_{2}$, catalyzed by poly-L-leucine. ${ }^{256}$ 

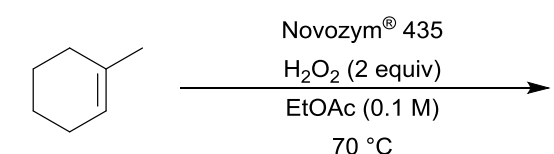

$70{ }^{\circ} \mathrm{C}$

Microflow conditions:
- reactor: packed-bed microreactor
- size: $3 \mathrm{~mm}$ ID, $2.5 \mathrm{~mL}$

Scheme 29. Lipase-mediated epoxidation of 1-methylcyclohexene with $\mathrm{H}_{2} \mathrm{O}_{2}$ in a packed-bed microreactor. ${ }^{257}$

Organic peroxides are strong oxidizers, which are widely used in chemical industry. However, they are difficult to handle due to easy decomposition and risk for explosion hazards. Ebrahimi et al. studied the sulfuric acid catalyzed synthesis of performic and peracetic acids from $\mathrm{H}_{2} \mathrm{O}_{2}$ in a PTFE capillary (1.0 or $1.6 \mathrm{~mm}$ ID, $0.59-10 \mathrm{~mL}$ ). ${ }^{260}$ The formation of perfomic acid could reach equilibrium within $4 \mathrm{~min}$ at $40{ }^{\circ} \mathrm{C}$, while the synthesis of peracetic acid needed $10 \mathrm{~min}$ at $70^{\circ} \mathrm{C}$. Furthermore, they designed a plate reactor, which allowed them to work on an industrial production scale. The reactor was composed of alternating heat transfer and reaction channels. This unit has potential to be applicable for on-site or on-demand production of performic and peracetic acids due to the high production capacity up to $100 \mathrm{t} / \mathrm{a}$ performic acid and up to $170 \mathrm{t} / \mathrm{a}$ peracetic acid. Based on the results from flow experiments, they developed several kinetic models. ${ }^{261} \mathrm{~A}$ laminar flow model with velocity distribution in the radial direction had the best accuracy according to the Markov chain Monte Carlo analysis.

Although sulfuric acid is an efficient catalyst for the synthesis of percarboxylic acids, the homogeneous catalyst causes corrosion of the reaction equipment and needs to be removed after reaction. ${ }^{262}$ Ebrahimi et al. further investigated the formation of performic acid in the presence of a cation exchange resin loaded in a packed-bed micro-structured reactor. ${ }^{263}$ Dowex $50 \mathrm{~W} \times 8$ was selected as the optimal catalyst due to excellent reusability. The results showed that the reaction could reach equilibrium in $2 \mathrm{~min}$ at $40{ }^{\circ} \mathrm{C}$, while it needs at least $30 \mathrm{~min}$ for the corresponding batch reaction. However, Dowex $50 \mathrm{~W} \times 8$ had lower activity than $\mathrm{H}_{2} \mathrm{SO}_{4}$, indicating that the active sites of Dowex $50 \mathrm{~W} \times 8$ were partially deactivated.

Sulfoxides and sulfones are important moieties to taylor the properties of pharmaceuticals, pesticides and polymer stabilizers. Noguchi et al. synthesized sulfoxides from sulfides by using $30 \%$ hydrogen peroxide and no catalyst in a stainless steel capillary microreactor ( $1 \mathrm{~mm} \mathrm{ID,} 730 \mu \mathrm{L}$, Scheme 30). ${ }^{264}$ The oxidation of thioanisole showed that $97 \%$ yield of sulfoxide could be reached within a residence time of $2.12 \mathrm{~s}$ in microreactor. In a conventional batch reactor, it required $3 \mathrm{~h}$ in batch to reach full conversion with only $82 \%$ yield and $15 \%$ of the over-oxidized sulfone.

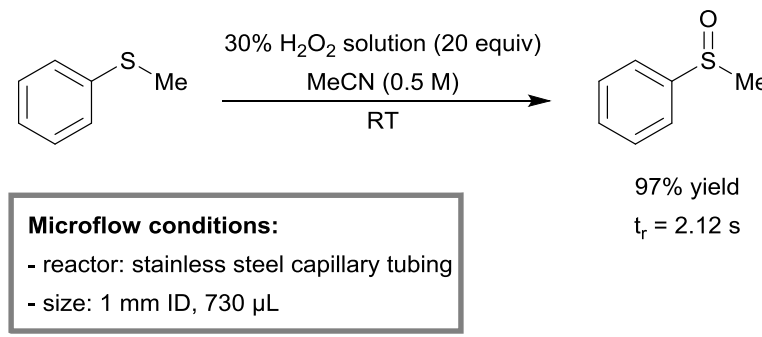

Scheme 30 . Synthesis of sulfoxides from thioanisol with a $30 \%$ solution of $\mathrm{H}_{2} \mathrm{O}_{2}$ in a stainless steel capillary microreactor. ${ }^{264}$

Doherty, Hardacre et al. have developed a new catalyst $\left[\mathrm{PO}_{4}\left\{\mathrm{WO}\left(\mathrm{O}_{2}\right)_{2}\right\}_{4}\right] @ \mathrm{PIILP}$ based on the polymer immobilized ionic liquid phase (PIILP) concept, which facilitates catalyst recovery and allows to minimize the amount of ionic liquid. ${ }^{265}$ The catalyst can be loaded in a packed-bed microreactor and the catalyst bed is further diluted with silica. A high yield of sulfoxide (92\%) was obtained in methanol with $4 \mathrm{~min}$ residence time, while the corresponding sulfone could be obtained with $96 \%$ yield in acetonitrile in a $15 \mathrm{~min}$ residence time (Scheme 31). The catalyst remained active for 8 hours under continuous-flow conditions (TON $=46428$ ). Amberlite IR-120H as a solid supported catalyst for the sulfide oxidation in flow has been reported as well. ${ }^{266}$

Adipic acid is a basic building block in the chemical industry, which is mainly used as the starting material for the synthesis of nylon 6,6. ${ }^{267}$ Hessel et al. reported the continuousflow synthesis of adipic acid via the oxidation of cyclohexene with $50 \%$ aqueous $\mathrm{H}_{2} \mathrm{O}_{2}{ }^{268}$ The biphasic mixture was introduced in a packed-bed microreactor with glass spheres, which allowed to intensify the mixing efficiency. $\left[\mathrm{CH}_{3}(n-\right.$ $\left.\left.\mathrm{C}_{8} \mathrm{H}_{17}\right)_{3} \mathrm{~N}\right] \mathrm{HSO}_{4}$ and $\mathrm{Na}_{2} \mathrm{WO}_{4} \cdot 2 \mathrm{H}_{2} \mathrm{O}$ were used as a phase transfer catalyst and oxidation catalyst, respectively. At $110^{\circ} \mathrm{C}$, a $50 \%$ isolated yield for adipic acid was obtained within $20 \mathrm{~min}$ residence time (Scheme 32). The yield could be further increased by using a multi-stage temperature ramping approach. ${ }^{269}$ This strategy allowed to avoid hot spot formation throughout the reactor and extensive degradation of $\mathrm{H}_{2} \mathrm{O}_{2}$. With a three reactor system and a temperature profile of 70 $100-110{ }^{\circ} \mathrm{C}$ respectively, a total isolated yield of $66 \%$ for adipic acid could be obtained within 20 min residence time. Kappe et al. developed another protocol which did not require a phase transfer catalyst and employed $25 \%$ aqueous $\mathrm{H}_{2} \mathrm{O}_{2}$ in the presence of tungstic acid as a catalyst. ${ }^{270}$ The isolated yield of adipic acid reached $63 \%$ at $140^{\circ} \mathrm{C}$ with just 20 min residence time. 


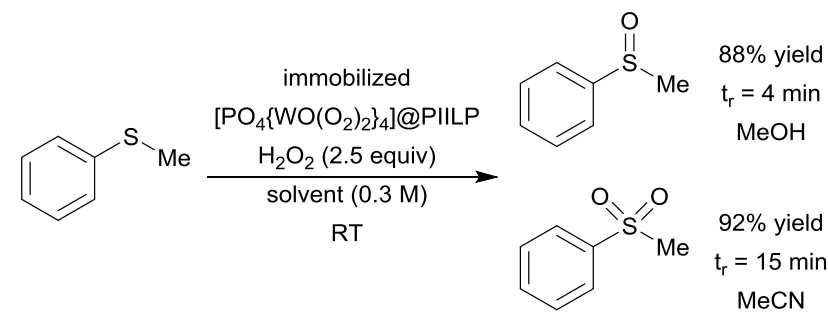

Microflow conditions:

- reactor: glass column reactor cartridge

- size: $10 \mathrm{~mm} I D, 7.9 \mathrm{~mL}$

Scheme 31. The synthesis of sulfoxide and sulfones from thioanisole and $\mathrm{H}_{2} \mathrm{O}_{2}$ in a microreactor using a peroxometalate-based polymer immobilized ionic liquid phase catalyst. 265

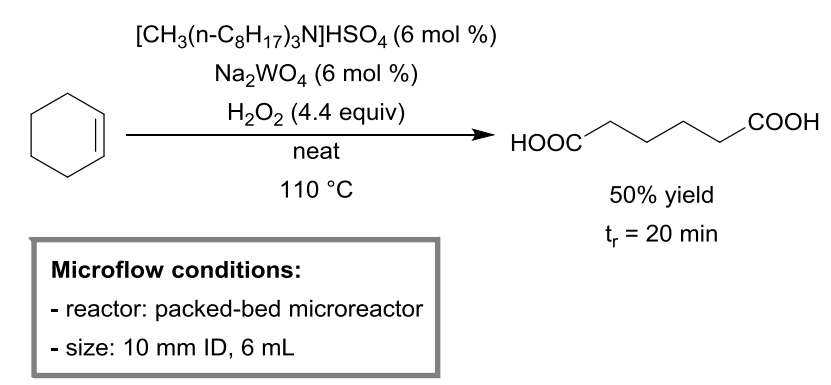

Scheme 32. Continuous synthesis of adipic acid from cyclohexene with $\mathrm{H}_{2} \mathrm{O}_{2}$ in a packed-bed microreactor. ${ }^{268}$

The preparation of vitamin K3 (2-methyl-1,4-naphthoquinone) was carried out in a stainless steel capillary microreactor (1.0 $\mathrm{mm} \mathrm{ID}, 8 \mathrm{~mL}$ ). ${ }^{271} \mathrm{~A}$ high concentrated $\mathrm{H}_{2} \mathrm{O}_{2}$ solution (60\%) was safely used for the oxidation process of 2-methylnaphthalene at $70{ }^{\circ} \mathrm{C}$, but led to low selectivities. Alternatively, by using $26 \%$ aqueous peracetic acid, the selectivity could be improved at $80{ }^{\circ} \mathrm{C}(50 \%$ yield vitamin $\mathrm{K} 3)$.

Jensen et al. have developed a continuous-flow protocol for the direct oxidative amidation of aromatic aldehydes using $\mathrm{H}_{2} \mathrm{O}_{2}$ as the oxidant. ${ }^{272}$ In a silicon-Pyrex spiral microreactor $(230 \mu \mathrm{L})$, a wide variety of aldehydes and amines were explored and the optimal reaction conditions for each aldehyde were rapidly selected due to the flexibility of microreactor assembly. Moreover, the use of elevated pressures allowed to safely heat solvents above their boiling point, broadening the operational window significantly. The yield of the corresponding amides varied from $79-92 \%$ with 20 40 min residence time at $80-110{ }^{\circ} \mathrm{C}$ (Scheme 33). Notably, the authors found that racemization was effectively suppressed when chiral amino acid derivatives were converted to their corresponding amides.

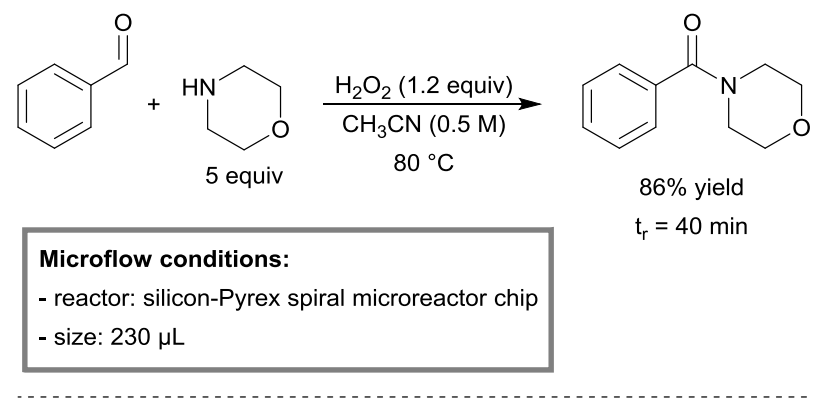<smiles>COc1cccc(C(=O)N2CCOCC2)c1</smiles>

$88 \%$ yield

$90^{\circ} \mathrm{C}, \mathrm{t}_{\mathrm{r}}=40 \mathrm{~min}$<smiles>O=C(c1ccc(Br)cc1)N1CCOCC1</smiles>

$88 \%$ yield

$110^{\circ} \mathrm{C}, \mathrm{t}_{\mathrm{r}}=20 \mathrm{~min}$
Scheme 33. The direct oxidative amidation of aromatic aldehydes with $\mathrm{H}_{2} \mathrm{O}_{2}$ as oxidant in a silicon-Pyrex microreactor. ${ }^{272}$

Park et al. have investigated the continuous-flow diacetoxylation of alkenes using peracetic acid $\left(\mathrm{AcO}_{2} \mathrm{H}\right)$ as the oxidant and triflic acid (TfOH) as the catalyst. ${ }^{273} \mathrm{AcO}_{2} \mathrm{H}$ was prepared in situ by combining acetic anhydride $\left(\mathrm{Ac}_{2} \mathrm{O}\right)$ and $\mathrm{H}_{2} \mathrm{O}_{2}$ prior to combining it with the alkene substrate. A variety of alkenes were subsequently converted in flow within $10 \mathrm{~min}$ residence time (Scheme 34).

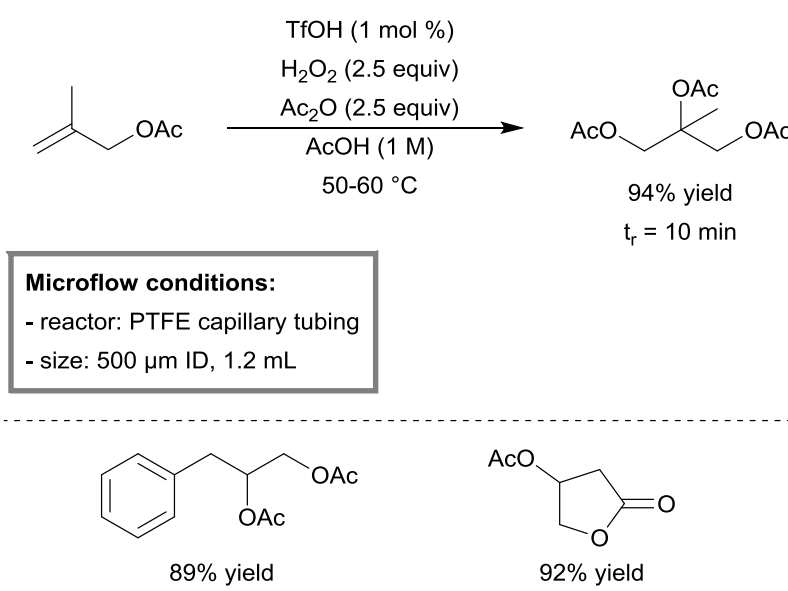

Scheme 34. Trifluoromethanesulfonic acid-catalyzed diacetoxylation of alkenes with peracetic acid generated in situ from acetic anhydride and $\mathrm{H}_{2} \mathrm{O}_{2}$ in a microreactor. ${ }^{273}$

A continuous-flow protocol for the two-step hydroboration/oxidation of olefins was developed by Souto et al. ${ }^{274}$ In the first step, the olefin was hydroborated by $\mathrm{BH}_{3}$.THF in a PFA capillary microreactor $(1 \mathrm{~mm} I D, 2 \mathrm{~mL})$. Next, the reaction stream was merged with a basic $\mathrm{H}_{2} \mathrm{O}_{2}$ solution to oxidize the boron intermediate to the corresponding alcohol. The authors also used an inline extraction device to facilitate the work up and to minimize manual labor. The maximum productivity reached $120 \mathrm{mmol} / \mathrm{h}$ at a residence time of $70 \mathrm{~s}$.

Other examples using $\mathrm{H}_{2} \mathrm{O}_{2}$ in flow involve the oxidation of methyl ethyl ketone, ${ }^{275}$ phenol ${ }^{276}$ and cyclohexene to the corresponding trans-1,2-cyclohexanediol. ${ }^{277}$ 


\section{Ozonolysis in flow}

The use of ozone $\left(\mathrm{O}_{3}\right)$ in organic synthetic chemistry has been recognized for decades as it enables the oxidative cleavage of unsaturated molecules. ${ }^{278,279}$ In general, oxidation processes with $\mathrm{O}_{3}$ are considered environmentally friendly due to its atom efficiency. However, the exothermic nature of the reaction and production of the explosion hazardous ozonides requires to take special safety considerations when using this reagent on a large scale. These concerns provide opportunities for microreactors to use ozone in a safe and reliable fashion.

Kappe et al. used a commercially available reactor system (O-Cube ${ }^{\mathrm{TM}}$ ) to perform ozonolysis at atmospheric pressure and at temperatures between $-25^{\circ} \mathrm{C}$ and room temperature. ${ }^{280}$ The setup consists of a precooling section, which allows to cool the substrate solution. Subsequently, the liquid stream is merged with the ozone gas flow, which is generated in situ. The segmented gas-liquid flow is then entering a thermostatic reactor coil (PTFE, $1 \mathrm{~mm} \mathrm{ID,} 4 \mathrm{~mL}$ ) and is quenched (oxidative or reductive cleavage) upon exiting the reactor coil. The in situ quench allows to minimize the amount of explosive ozonides, making this process environmentally benign. A wide variety of substrates was processed in the reactor system, thus preparing aldehydes, ketones (Scheme 35), nitro compounds, sulfones and sulfoxides.
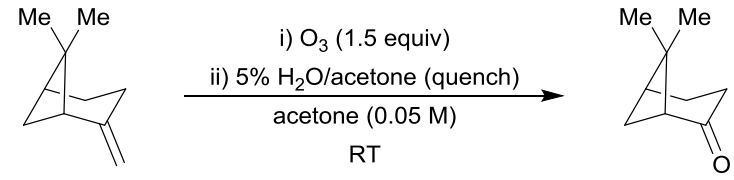

B-pinene

$70 \%$ yield $\mathrm{t}_{\mathrm{r}}=40 \mathrm{~min}$

Microflow conditions:

- reactor: O-Cube ${ }^{\mathrm{TM}}$

size: $1 \mathrm{~mm}$ ID, $4 \mathrm{~mL}$

Scheme 35. Ozonolysis of $B$-pinene in a O-Cube ${ }^{\mathrm{TM}}$ microreactor. ${ }^{280}$

Ley et al. used a semipermeable capillary microreactor (Teflon AF-2400, $0.6 \mathrm{~mm}$ ID, $250 \mu \mathrm{L}$ ) which enables ozone transport through the reactor walls to the liquid reaction stream. ${ }^{281}$ Next, a variety of substrates was subjected to the ozonolysis conditions using methanol as the solvent. All reached full conversion within $1 \mathrm{~h}$ residence time (Scheme 36 ).

Another practical ozonolysis procedure in flow was developed by Roydhouse and Gavriilidis et al.282,283 The authors used a commercially available Vapourtec flow system which was equipped with a cooled flow cell (1 mm ID, $2 \mathrm{~mL}$ ). The use of the cooled flow cell was required to accommodate the highly exothermic reaction in a safe and reliable fashion. A wide variety of different substrates were oxidized by ozone, including heterocycles such as furan and quinolones. As example, 2-(3-methoxyoxetan-3-yl)furan could by successfully converted into the corresponding oxetane acid $(79 \%$, Scheme 37), which represents a relevant pharmaceutical compound.

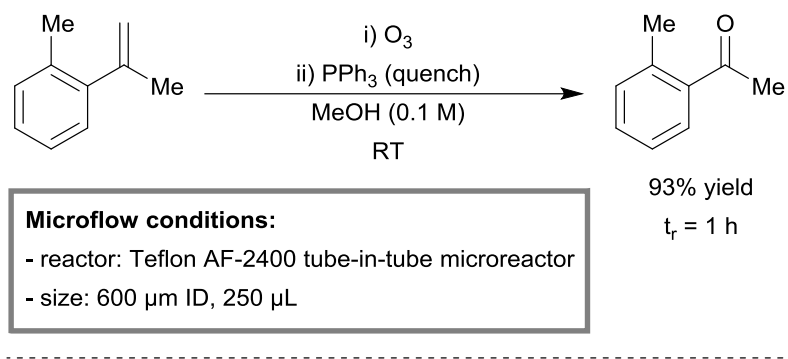

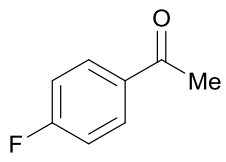

$95 \%$ yield
TBS

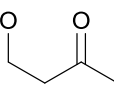

$93 \%$ yield
Scheme 36. The ozonolysis of alkenes in a Teflon AF-2400 semipermeable capillary microreactor. ${ }^{281}$

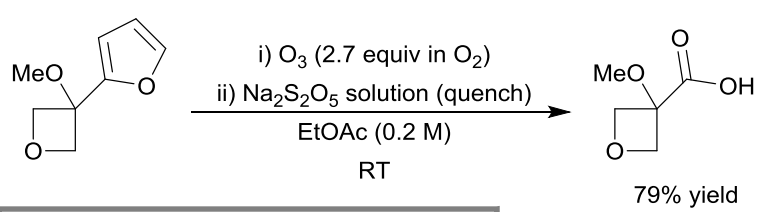

Microflow conditions:

$\mathrm{t}_{\mathrm{r}}=10 \mathrm{~min}$

- reactor: Vapourtec cooled reaction module

- size: $1 \mathrm{~mm} I \mathrm{D}, 2 \mathrm{~mL}$

Scheme 37. Ozonolysis of 2-(3-methoxyoxetan-3-yl)furan to its oxetane acid in a Vapourtec cooled reaction module. ${ }^{283}$

Sun et al. have reported on the ozone degradation of pentachlorophenol in a T-junction microchannel reactor (400 $\mu \mathrm{m} \times 500 \mu \mathrm{m}, 14 \mu \mathrm{L}){ }^{284}$ The authors have performed a systematic study to the ozone mass transfer characteristics in different gas-liquid flow regimes. An increase of the liquid side volumetric mass transfer coefficient $\left(k_{L} a\right)$ was observed with increasing superficial gas and liquid velocities. This increase was mainly caused by the increasing gas-liquid interfacial area. Also, it was found that an increase in pentachlorophenol and ozone concentration resulted in a higher ozone mass flux. The reaction between ozone and the substrate was instantaneous, which was confirmed by the absence of ozone in the bulk solution.

\section{Miscellaneous oxidation processes in flow}

Herein, other than aerobic, hydrogen peroxide or ozone mediated oxidation processes in continuous-flow microreactors are discussed. This chapter includes, metal oxide and anaerobic enzymatic oxidation reactions. Swern oxidations and electrochemical oxidations reactions. Furthermore, oxidations enabled by TEMPO, HOX, hypervalent iodine, and oxone will be discussed.

\section{1 metal oxide oxidation processes in continuous flow}

Kobayashi et al. developed a highly active, immobilized ruthenium catalyst for the non-aerobic flow oxidation of 
alcohols. $^{285}$ Using a self-designed novel immobilization method, Kobayashi et al. could successfully immobilize $\mathrm{RuCl}_{2}\left(\mathrm{PPh}_{3}\right)_{3}$ to an epoxide-containing copolymer. The solid catalyst (PI-Ru) was pre-oxidized and placed into a micro column ( $2 \mathrm{~mm} \mathrm{ID}, 214 \mu \mathrm{L}$ ). A reaction stream, containing substrate and NMO as co-oxidant, was send over the catalytic bed. Notably, the immobilized PI-Ru catalyst showed higher activity as compared to its original non-immobilized counterpart. In the case of benzyl alcohol, 92\% yield of the corresponding aldehyde was obtained during an 8 hour continuous operation (Scheme 38). No leaching of catalyst was detected

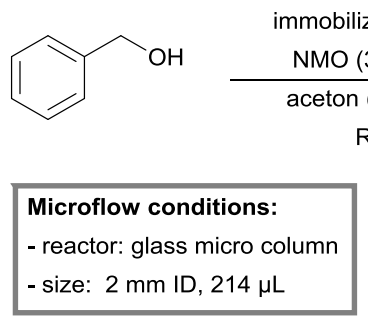

Scheme 38. Ruthenium catalyzed oxidation of benzyl alcohol to benzaldehyde in flow system. ${ }^{285}$

In terms of sustainable chemistry, Kirschning et al. demonstrated the application of inductive heating for the continuous-flow oxidation of several functional organic compounds (i.e., alcohols, amines and alkenes). ${ }^{286} \mathrm{~A}$ packedbed microreactor $(4 \mathrm{~mL})$ was filled with a mixture of superparamagnetic nanoparticles and solid oxides $\left(\mathrm{CrO}_{2}\right.$ and $\mathrm{NiO}_{2}$ ). Operating under continuous flow, efficient heating was achieved inside the packed bed by exposing the highly conducting nanoparticles to a rapidly changing magnetic field $(25 \mathrm{kHz})$. Full conversion was achieved for a single pass run.

Ley et al. demonstrated the use of microreactors for the efficient transformation of alcohols and aldehydes to carboxylic acids and nitro alkanes to its corresponding carbonyl compounds. ${ }^{287}$ Homogeneous permanganate $\left(\mathrm{KMnO}_{4}\right)$ was used as cheap oxidant. In order to avoid possible blockage of the capillary reactor (due to $\mathrm{MnO}_{2}$ solids formation), ultrasound was applied. Oxidized products could be isolated easily without the need of chromatography, providing high yields (58-98\%) with excellent purity (>95\%).

The same group reported the use of a pre-packed column of polymer supported perruthenate (PSP) for the oxidation reaction of commercially available 3,4-dimethoxybenzyl alcohol to its corresponding aldehyde. ${ }^{288}$ This transformation was then implemented in an integrated flow process for the multi-step synthesis of oxomaritidine, a bioactive molecule.

Recently, Ley reported a practical flow procedure for the in situ generation of unstable diazo compounds. ${ }^{289}$ A hydrazone solution was passed through a pre-oxidized manganese oxide $\left(\mathrm{MnO}_{2}\right)$ supported micro packed bed, generating diazo compounds as oxidized intermediates. Consecutively, these reactive species where quenched by aryl boronic acids, yielding the cross-coupling product in moderate to excellent yields (48-96\%). The same procedure has been utilized for the cyclopropanation of flow-generated diazo compounds. ${ }^{290}$

$\mathrm{OsO}_{4}$ was immobilized in a PDMS microreactor by Kim et al. ${ }^{291}$ The microchannel was coated with a layer of polyvinylsilazane (PVSZ) polymer to increase its chemical resistance. Furthermore, poly(4-vinylpyridine) (P4VP) polymer was attached to the PVSZ layer in a nanobrush-like manner. Finally, the repeating pyridine units on the P4VP polymer could be used for the immobilization of the $\mathrm{OsO}_{4}$ catalyst (Figure 9). The microreactor was used for the room-temperature dihydroxylation and oxidative cleavage reaction of alkenes in the presence of $\mathrm{NMI}$ or $\mathrm{NaIO}_{4}$, respectively. All substrates could be converted quantitatively within 10 minutes contact time, obtaining the respective products in good to excellent yields (67-95\%).

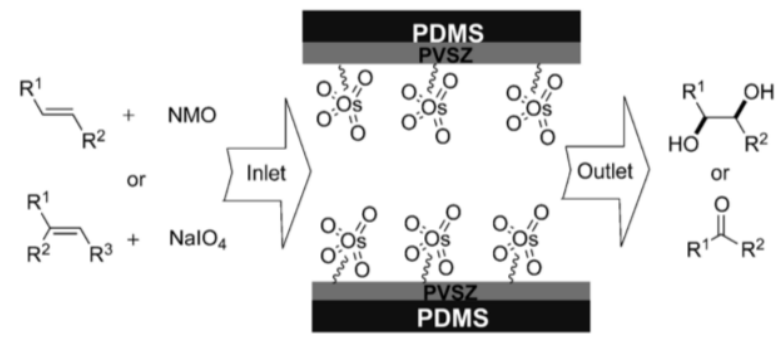

Figure 9. Continuous-flow dihydroxylation and oxidative cleavage of alkenes in a $\mathrm{OsO} 4$ immobilized nanobrush microreactor. Reproduced from Ref. 291 with permission from John Wiley and Sons.

Silica-supported Jones' reagents $\left(\mathrm{CrO}_{3} / \mathrm{H}_{2} \mathrm{SO}_{4}\right)$ has been used in continuous-flow by Watts et al. for the oxidation of primary alcohols to their aldehydes or carboxylic acids, depending on the flow rates employed. ${ }^{292}$

\subsection{Anaerobic enzymatic oxidation processes in continuous} flow.

Zelic et al. reported multiple papers on the enzymatic oxidation of $n$-hexanol to the green noted food additive, $n$ hexanal, in microreactors. ${ }^{293-295}$ Recently, they reported an alcohol dehydrogenase (ADH) catalyzed $n$-hexanol oxidation reaction in flow with an integrated NADH coenzyme regeneration system. ${ }^{296}$ The regeneration of $\mathrm{NADH}$ was conducted in a second microchip by the addition of acetaldehyde to the existing reaction stream. Finally, the enzyme and coenzyme were reused immediately by the use of a recirculation loop to the first microreactor. The microfluidic setup could run up to three days without the addition of fresh $\mathrm{NADH}$.

The oxidation of phenols by the use of an immobilized biocatalyst in a microfluidic reactor was investigated by Parvulesco et al.297 Horseradish peroxidase (HRP) was deposited on a gold layered silicon wafer microreactor. Different layer thicknesses form nano- to micro-scale were developed and the catalytic performance was measured. A maximum conversion of phenol (35\%) was acquired. The immobilized enzyme remained active for multiple reaction 
cycles, proving that enzyme immobilized microchip devices can be utilized for potential biosensor applications.

In the field of biotechnology, a lot of effort has been made to develop biochips capable of detecting low quantities of important chemical compounds (e.g., ethanol, glucose) with the emphasis on applications to pharmaceutical, food, clinical and environmental analysis. ${ }^{298}$ Much research have been reported on the use of immobilized oxidase enzymes, such as horseradish peroxidase ${ }^{299}$, alcohol oxidase ${ }^{300}$, soybean peroxidase $\mathrm{e}^{301}$ and glucose oxidase ${ }^{302}$ in microfluidic devices for flow injection analysis (FIA) purposes.

\subsection{Swern-type oxidation processes in continuous flow.}

The Swern-Moffatt oxidation is known as an mild and selective method for the oxidation of primary and secondary alcohols to their corresponding aldehydes and ketones. The oxidation procedure is remarkable in terms of selectivity. ${ }^{303}$ However, in conventional setups, Swern-Moffatt oxidation reactions are conducted at low temperatures $\left(<-50^{\circ} \mathrm{C}\right)$ in order to suppress possible side reactions (e.g., Pummerer rearrangement).

To make this transformation more appealing for industrial application, Yoshida et al. reported the development of a room-temperature Swern-oxidation, enabled by the use of a micro-scale flow system. ${ }^{304}$ Three stainless steel tube microreactors were built in series $(1 \mathrm{~mm} \mathrm{ID,} 1 \mathrm{~mL}$ ), each having a multilamination-type micromixer ( $40 \mu \mathrm{m}$ channel width) at the inlet. In the first reactor, activation of DMSO was achieved by the addition of trifluoroacetic anhydride (TFAA) at roomtemperature. It was found that by shortening the residence time up to 10 milliseconds in the first reactor, Pummerer rearrangement could be avoided. In the second reactor, the alcohol was added, forming the reactive intermediate with the activated DMSO. Finally, the reaction mixture was treated with triethylamine $\left(\mathrm{Et}_{3} \mathrm{~N}\right)$ in a third microreactor, obtaining the corresponding carbonyl compound within 8.31 seconds overall residence time. In the case of cyclohexanol, a 3 hour during run resulted in a consistent yield of $91 \%$ cyclohexanone (Scheme 39).

Other high-temperature continuous-flow Swern oxidations have been reported. McConnell et al. developed a semicontinuous process, with oxalyl chloride as DMSO activator. ${ }^{305}$ The reaction took place in an in-line mixer $(3.5 \mathrm{~mL})$ with residence times of $0.1-1.4$ seconds, before discharging the reaction mixture in a $\mathrm{Et}_{3} \mathrm{~N}$ containing reactor vessel.

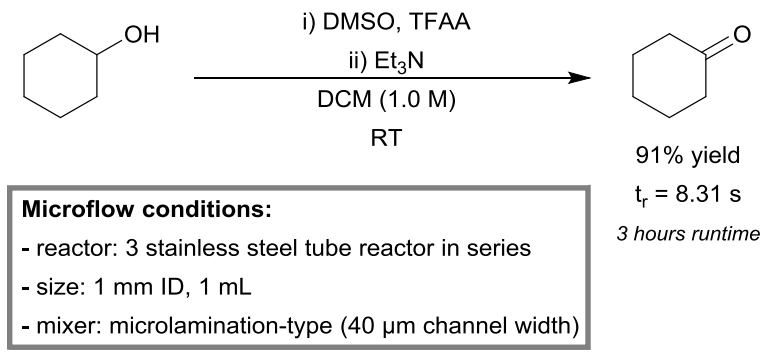

Scheme 39. Room-temperature Swern oxidation of cyclohexanol in continous flow. ${ }^{304}$
With the help of a continuous-flow microreactor setup, Kemperman et al. were capable to transform testosterone to 4 -androstene-3,17-dione ( $95 \%$ yield) in milliseconds. ${ }^{306}$ With the reactor running at $0{ }^{\circ} \mathrm{C}$, the system was reliable for at least 1.5 hour runtime, resulting in a production rate of $64 \mathrm{~g} . \mathrm{h}^{-1}$.

Rutjes et al. developed an automated microreactor platform for the optimization of the Swern oxidation procedure. ${ }^{103}$ Five parameters (temperature, stoichiometrics of both TFAA and DMSO, substrate concentration and residence time) were screened systematically with the use of a $140 \mathrm{~nL}$ microreactor, generating large amounts of chemical information. Multidimensional contour plots were developed by the aid of the program MATLAB in order to find optimal reaction conditions. For the model reaction of benzyl alcohol to benzaldehyde, $70{ }^{\circ} \mathrm{C}$ (approximately $150{ }^{\circ} \mathrm{C}$ higher than conventional batch Swern oxidation reactions) was found as the optimal temperature, yielding $96 \%$ of benzaldehyde within 32 milliseconds of residence time.

\subsection{Electrochemical oxidation processes in continuous flow.}

Electrochemical microreactors have the advantage of providing a homogeneous electrical field, which avoids the formation of hot spots and, in some cases, the necessity to use electrolytes. ${ }^{307,308}$ Typically, more efficient reactions can be carried out in micro flow due to the small diffusion distance to the electrodes.

An interesting example of an electrochemical oxidation was given by Roth et al. ${ }^{309}$ They used a commercially available electrochemical flow reactor (Asia Flux) to facilitate electrochemical oxidations to prepare metabolites from commercial drug structures, thus mimicking the single electron transfer mechanism of cytochrome P450. Diclofenac, tolbutamide, primidone, albendazole and chlorpromazine were selected to demonstrate the potential of this device to enable different oxidation chemistries (i.e., aliphatic oxidation, aromatic hydroxylation, $\mathrm{S}$ oxidation, $\mathrm{N}$ oxidation and dehydrogenation). By using a continuous-flow protocol, the authors were able to prepare large quantities $(10-100 \mathrm{mg})$ of the metabolites, which is required for full characterization and toxicity studies (Scheme 40).

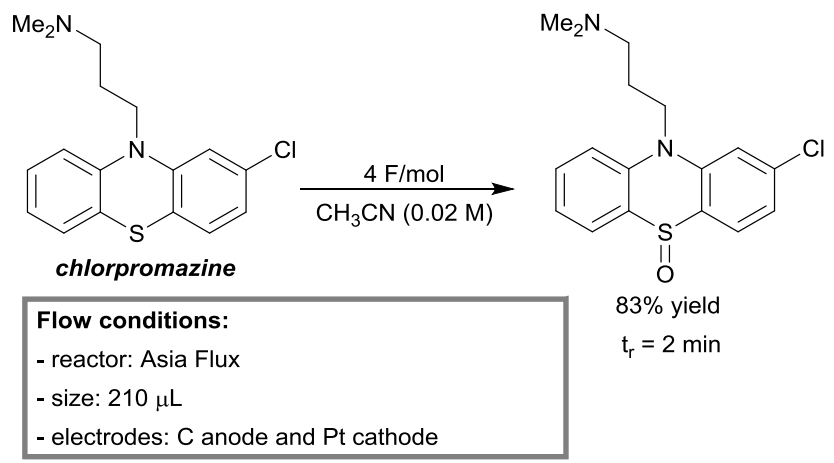

Scheme 40. Oxidation of chlorpromazine in a electrochemical reactor. ${ }^{309}$

Due to the fast mass transfer characteristics, microreactors are ideal to prepare unstable reactive intermediates and use 
them in a subsequent trapping reaction. Atobe et al. have demonstrated this principle by preparing reactive ortho benzoquinones and subsequently consume them in a Michael addition with thiophenols. ${ }^{310,311}$ In a batch electrolytic cell, a maximum yield of $32 \%$ could be obtained. Black precipitation due to decomposition of ortho quinone was observed prior to addition of the thiol. However, in flow, the unstable ortho benzoquinone could be prepared rapidly and immediately quenched by 4-isopropyl-thiophenol providing the target compound in excellent yield ( $88 \%$ yield, Scheme 41 ).

Similar setups, both commercially available and custom made ones, have been used by others to enable oxidations of furan, $^{312}$ chlorophenols, ${ }^{313}$ and cyclic amines (Shono oxidation). ${ }^{314-316}$

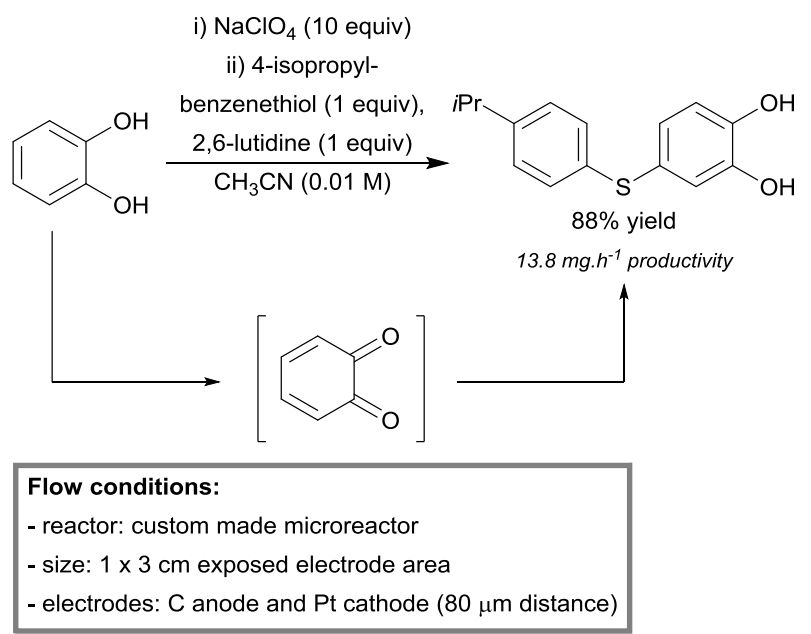

Scheme 41. Oxidation of catechol in a electrochemical reactor to ortho benzoquinone and subsequent Michael addition. ${ }^{310,311}$

\subsection{TEMPO, HOX, hypervalent iodine and oxone mediated oxidation processes in continuous flow.}

Oxidation reactions which do not require transition metal catalysts are appealing since there is no need for removal and regeneration of precious metals. ${ }^{317}$

2,2,6,6-tetramethylpiperidine-1-oxyl (TEMPO), and other stable nitroxyl radicals, are considered as well suited substitutes for metal oxide in oxidation reactions of primary and secondary alcohols. When used in catalytic amounts, the nitroxide radical (TEMPO) is readily oxidized into the highly electrophile oxoammonium species with the aid of a terminal oxidant (e.g., $\mathrm{HOCl}, \mathrm{BAIB}, \mathrm{O}_{2}$ ). It is this oxoammonium intermediate which then serves as the active oxidizing agent in the alcohol oxidation reaction.

In order to overcome possible hot spot generation in the reaction mixture, Hampton et al. demonstrated the use of a spinning tube-in-tube microreactor (STT, $1.43 \mathrm{~mL}$ ). ${ }^{318}$ The organic (TEMPO/tetrabutylammonium bromide/primary alchohol) and aqueous (sodium hypochlorite/sodium bicarbonate) solutions were merged and rapidly mixed inside the STT at rotor speeds of 4000-6000 RPM, preventing heat build-up. The demonstrate its heat transfer capacity, the oxidation of benzyl alcohol was examined under neat conditions, with a high concentration of bleach ( $13 \%$ solution). Benzaldehyde could be isolated in excellent yields (91-95\%) at a short residence time of 27 seconds, while no temperature increase was observed at the reactor output.

Another way to promote excellent mixing between biphasic systems, was demonstrated by McQuade et al. ${ }^{319}$ The TEMPO catalyst was immobilized on a commercially available resin (AMBERZINE ${ }^{\circledR}$ Oxirane) and was packed in polymer tubing $(1.2 \mathrm{~mL})$. A liquid-liquid slug flow was formed between the aqueous bleach phase and organic alcohol phase before entering the packed bed. When passed through the catalytic bed, complete emulsification occurred, demonstrating the excellent mixing behaviour of the microreactor (Figure 10). Within 5 minutes, a variety of substrates could be converted quantitatively, resulting in good to excellent yields (71-95\%). Moreover, the TEMPO resins were completely recyclable (used for over 100 trials), showing no loss in activity.
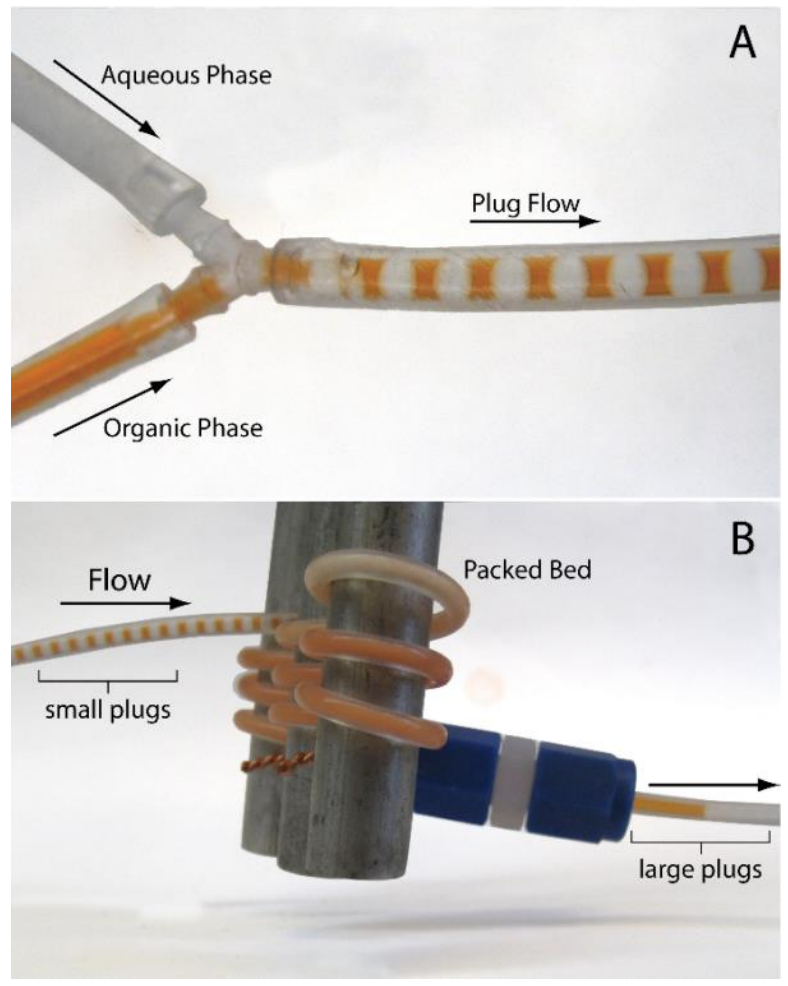

Figure 10. A) The organic (colored solution) and aqueous phase (colorless solution) forming plugs at the $\mathrm{Y}$-junction. B) The phases mix upon reaching the packed bed, leading to a coalescence of drops at the outlet of the microchannel. Reproduced from Ref. 319 with permission from Creative Commons.

Further intensification was demonstrated by Hermans et al. 320 A packed-bed microreactor was operated under threephase conditions. The reactor was filled with silica immobilized TEMPO. Before entering the reactor, a liquid solution, containing the appropriate alcohol and catalytic amounts of $\mathrm{HNO}_{3}$, was merged with gaseous molecular oxygen. In this example molecular oxygen was used as terminal oxidant in order to reactivate the TEMPO catalyst. This system proved to be much milder as compared to their previous reported research. ${ }^{321}$ The procedure was applicable for a broad substrate scope. Acid sensitive alcohols (e.g., prenol, 
isoprenol) could be smoothly oxidized to their corresponding carbonyls within two minutes residence time. Furthermore, 5hydroxymethylfurfural (HMF) could be selectively oxidized to its aldehyde or carboxylic acid depending on the residence time applied ( $2-6$ minutes). To further extent the scope, the pharmaceutical intermediate pyruvic acid, was synthesized successfully in high yield (96\%, 15 seconds) from lactic acid, without decarboxylation (Scheme 42).

Flow conditions:
- reactor: packed-bed microreactor
- size: $640 \mu \mathrm{L}$

Scheme 42. TEMPO mediated synthesis of pyruvic acid from lactic acid in a packed-bed microreactor. ${ }^{320}$

The use of hypervalent iodine(III), as terminal oxidant in TEMPO catalyzed oxidations of alcohols in micro flow, has been reported by Wirth et al. ${ }^{322}$

Kirschning et al. reported the use of a functionalized polymer with oxidizing bromate(I) anions in a packed-bed microreactor. ${ }^{323}$ The immobilized anions ensured the reactivation of the TEMPO catalyst during the oxidation of a steroid compound to its ketone.

In search of new catalytic systems for the oxidation of alcohols, Jamison et al. discovered that secondary alcohols could be readily oxidized in micro flow, in the presence of only a stoichiometric amount of sodium hypochloride $(12.6 \%$ solution) and catalytic amounts of tetrabutylammonium bromide salt (TBAB), without the need of any additional supported catalyst. ${ }^{324}$ A liquid-liquid two-phase continuousflow microfluidic setup (PFA tubing, $500 \mu \mathrm{m} \mathrm{ID,} 750 \mu \mathrm{L}$ ) was developed and optimized, and was capable of oxidizing secondary alcohols to ketones, aldehydes directly to their methyl ester and benzylic alcohols to aldehydes or methyl esters for over 60 substrates in total. Ethyl acetate could be used as green organic solvent and 10 equivalents of methanol were used in the case of ester formation.

In the context of multi-step continuous-flow synthesis, Seeberger et al. developed the first non-iterative chemical assembly system. ${ }^{325}$ The system existed out of five different flow modules, each representing an essential transformation (e.g., oxidation, olefination, hydrogenation), which could be used interchangeably to give access to a variety of APIs. One module allowed the oxidation of primary and secondary alcohols in a biphasic manner, catalyst by TEMPO and bleach. With this proof-of-principle, the group was able to synthesize five APIs (i.e., Rolipram, Lyrica, Phenibut, Baclofen, and Gabapentin) in good overall yields (49-75\%).

The HOF.MeCN system can be formed readily by introducing fluorine gas into a solution of wet acetonitrile, and the complex is known to be a uniquely effective electrophilic oxidizing agent. ${ }^{326}$ However, having a half-life of approximately four hours at room temperature, the use HOF.MeCN in batch reactions is still underdeveloped. Since the complex should be produced 'on demand', Sandford et al. considered that the implementation of microreactors could offer an effective way of generating and consuming HOF.MeCN in situ. ${ }^{327} \mathrm{~A}$ microreactor setup was built for the epoxidation of alkenes and proved to be highly efficient. In a first microreactor, diluted fluorine gas $\left(10 \%\right.$ in $\left.N_{2}\right)$ was introduced into a wet acetonitrile stream. At the outlet of the reactor, freshly generated HOF.MeCN was merged immediately with the alkene solution, producing the corresponding epoxide in moderate to excellent yield (38-99\%). Cooling of the microreactor was unnecessary. The same microreactor setup was used for the oxidation of aliphatic amines into their corresponding nitro derivatives. ${ }^{328}$

Due to its stability, cost-effectiveness and non-toxic nature, the oxidizing agent, Oxone ${ }^{\circledR}\left(2 \mathrm{KHSO}_{5} \cdot \mathrm{KHSO}_{4} \cdot \mathrm{K}_{2} \mathrm{SO}_{4}\right)$, shows potential as an effective substitute for conventional oxidants. ${ }^{329}$ However, known for its fire and explosion hazards, large-scale use of Oxone ${ }^{\circledR}$ is considered impractical. Uozumi et al. demonstrated that these potentially hazardous conditions could be overcome by the use of a microfluidic system. ${ }^{330}$ The microreactor was composed of PTFE tubing ( $1 \mathrm{~mm} \mathrm{ID,} 40 \mu \mathrm{L}$ ) and was used for the oxidative cyclization of alkenols. With a residence time of 5 minutes and temperature set at $80{ }^{\circ} \mathrm{C}$, the reaction proceeded smoothly to afford the corresponding cyclic ethers in high conversion (70-99\%).

\section{Scale up potential}

Increasing the production scale of liquid phase oxidation processes is an important, though challenging and timeconsuming task for the process engineer. Crucial in the design process is that the hydrodynamics and transport properties are maintained on each scale (from lab to pilot to production). ${ }^{331}$ Furthermore, the safety risks, associated with oxidation chemistry, further aggravates the complexity of the scale-up problem. ${ }^{121}$

As discussed in detail in this review, microreactor technology can overcome many challenges associated with oxidation chemistry. However, scale-up of such devices is rather challenging as the throughput is mostly limited to small quantities. Several strategies to obtain larger quantities with continuous-flow reactors can be distinguished: 1 ) longer operation times + increasing the throughput by using higher flow rates; 2) numbering-up by placing several devices in parallel; 3 ) smart scale out by a dimension enlarging strategy.

The use of longer operation times is probably the most used strategy on a laboratory scale as it is effective and simple to carry out. This strategy allows one to optimize the reaction parameters on small amounts of material and then directly scale up without re-optimization of the reaction protocol and the device itself. Typically, up to few hundreds of grams can be prepared in this fashion, which is more than sufficient for the different stages in a drug discovery process. ${ }^{332}$ Increasing the flow rate in microreactors is also an easy way to increase the throughput. Hereto, the length of the microreactor can be 
extended while the residence time is kept constant. Special care should be dedicated towards the variation of hydrodynamics and transport properties. Higher flow rates typically result in improved mixing efficiency and higher heat transfer rates, which can boost the reaction rate. It is important to note that many reactions can already be substantially accelerated in a microreactor due to the excellent transport properties, which allows to increase the throughput in a "natural" way.

Numbering-up of individual microreactors has been communicated in the past as a straightforward way of scaling a microreactor process. However, this statement has been overruled recently as it became obvious that even flow distribution over the different channels is difficult. ${ }^{333}$ Especially, the distribution of multiphase flows, which are common in oxidation chemistry, are very hard to achieve. Schouten et al. have developed an efficient barrier-based distributor which allows to achieve a homogeneous distribution within $\pm 10 \%$ in eight different channels for gasliquid flows (Figure 11a). ${ }^{334,335}$ This is an example of internal numbering up which is achieved by using a single microstructured device, with different microchannels in parallel, in combination with a process control system. Flow distributors are required to regulate and equalize the flow distribution over the different channels. Small differences in pressure drop can lead to large variations and thus to a different performance in each reaction channel. Examples of this principle in oxidation chemistry have been developed, such as the multichannel microreactors, ${ }^{336}$ the falling film microreactor, ${ }^{337}$ and the multichannel microcapillary films ${ }^{180}$ (Figure 11, b, c, d).

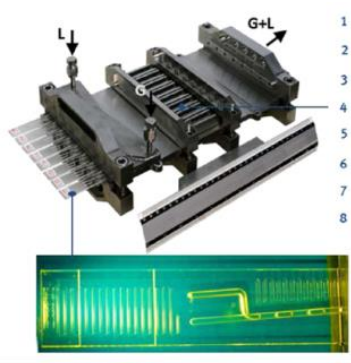

(a)

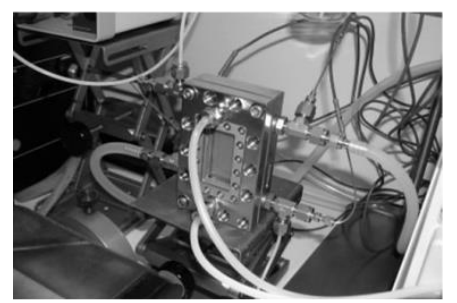

(c)
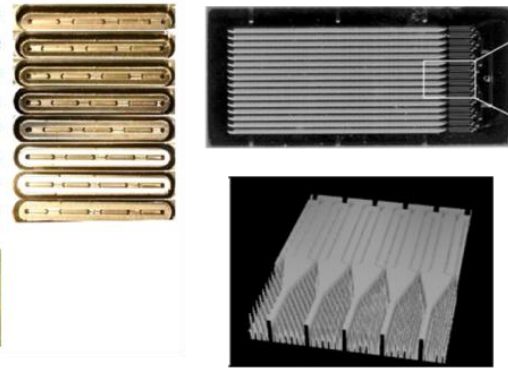

(b)

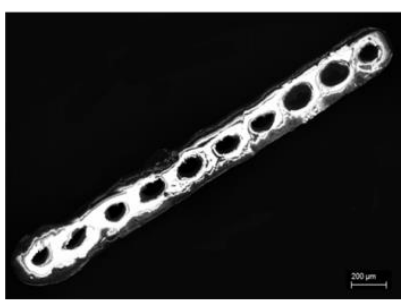

(d)
Figure 11. Examples of internal numbering-up: a) barrier-based microchannel reactor with a gas-liquid distributor unit. ${ }^{335} \mathrm{~b}$ ) gas-liquid multichannel microreactor for ozonolysis, top: picture of the reactor; bottom: details of the reaction channels and the pressure drop channels. ${ }^{336}$ c) falling-film microreactor for ozonolysis. ${ }^{337}$ d) FEP multichannel microcapillary for singlet oxygen chemistry. ${ }^{180}$ Reprinted with permission from Ref. 335, 336, 337 and 180. Copyright of American Chemical Society.
External numbering-up is achieved by placing different microreactors and their individual process control units in parallel. ${ }^{338}$ This is a reliable strategy which ensures equal process conditions in each microreactor. In case of failure of an individual device, the other devices can operate autonomously. However, external numbering-up is very expensive as each microreactor requires its own process control (e.g., pumps, mass flow controllers).

Another strategy for the scale-up of oxidation chemistry involves increasing the characteristic dimensions. Such milliscale reactors can be designed to have similar heat and mass transfer characteristics to microreactors by incorporating active mixers (smart scale out). Lonza has developed the FlowPlate TM concept, which allows to scale flow chemistry from lab scale to pilot plant production (Figure 12). ${ }^{339-343}$ The reactor consists of stainless steel plates containing tangential mixing elements. The plates are stacked between thermal conductive aluminium plates to ensure high heat transfer. Higher throughput is obtained by increasing the hydraulic diameter whilst keeping the heat and mass transfer characteristics constant. The lab plate is used as a development tool and produces a few grams, while A6, A5 to A4 plates are used to subsequently increase the reaction scale to up to $2500 \mathrm{~kg}$ for the A4 plate.

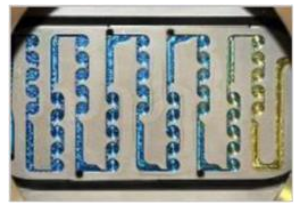

(a)

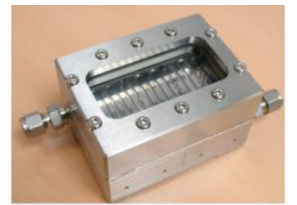

(b)

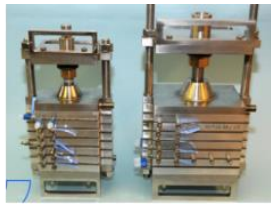

(c)
Figure 12. The Lonza FlowPlate TM concept for a step-wise scale-up of continuous-flow reactions: a) a single reactor plate with tangential mixing elements. b) Laboratory scale reactor with a transparent view glass for optical inspection. c) Lonza's plate stack reactors for step-wise scale-up. Reproduced from Ref. 339 with permission from Elsevier.

A similar concept has been developed by Corning and uses glass flow reactors with heart-shaped split-and-recombine mixers. ${ }^{88,343,344}$ Jensen et al. have used the Corning Low Flow $(0.45 \mathrm{~mL})$ and the Advanced Flow Reactor ( $8.9 \mathrm{~mL}$ volume) to enable scalability of the oxidation of alcohols and aldehydes using bleach (Figure 13). ${ }^{345}$ Compared to a silicon microreactor chip $(0.25 \mathrm{~mL}$ volume, $0.0064 \mathrm{~g} / \mathrm{min})$, the productivity of the preparation acetophenone could be gradually increased in the Low Flow Reactor $(0.37 \mathrm{~g} / \mathrm{min})$ and Advanced Flow Reactor $(4.08 \mathrm{~g} / \mathrm{min})$ by a factor of 58 and 640 , respectively. 
(a)
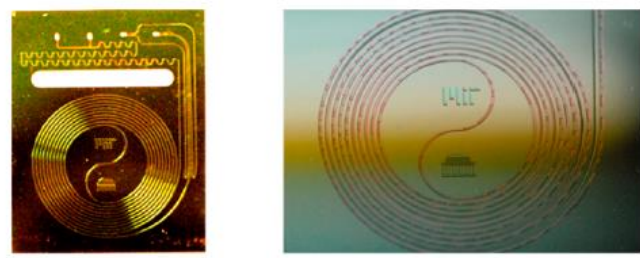

(b)

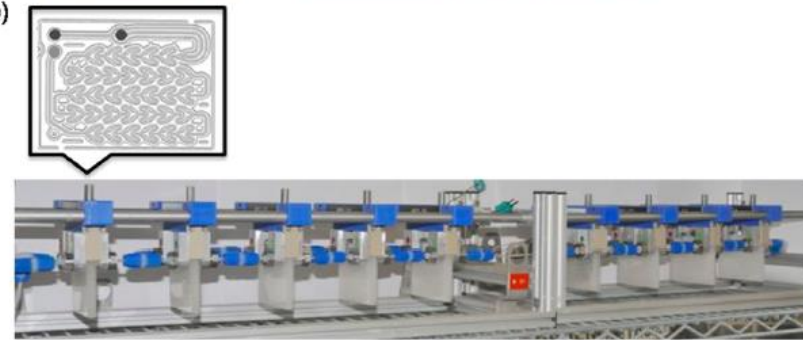

(c)

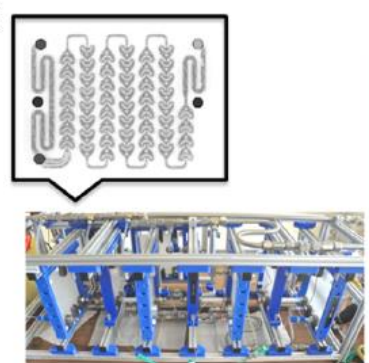

Figure 13. Scalability of the oxidation of alcohols using bleach: a) silicon microreactor chip. b) Corning Low Flow Reactor plates. c) Corning Advanced Flow Reactor plates. Reprinted with permission from Ref. 345. Copyright (2014) American Chemical Society.

\section{Conclusions and outlook}

The use of continuous-flow microreactor technology, as outlined in this review, has many benefits for liquid phase oxidation chemistry, including high heat and mass transfer rates, safe handling of explosive reaction mixtures, and potential to scale up efficiently. In the last decade, we have witnessed a remarkable expansion in the use of this technology for liquid phase oxidation chemistry. Commercial available flow devices exist for both lab and production scale making the technology broadly available. In addition, more and more chemists get acquainted with the use of flow chemistry in their own laboratories. Given these trends, we anticipate that more researchers will continue to be attracted by these advantages.

However, progress in this field is still highly desired and will require a combined effort of chemists, engineers and material scientists. Only now, due to the improved safety characteristics, researchers dare to use pure oxygen gas or other hazardous reagents in organic synthetic chemistry. In other words, we have only seen the tip of the iceberg and still many different opportunities lay ahead of us. An example of this is the preparation of short living species (e.g., peroxides), which can be subsequently used in a follow-up reaction. To exploit the full potential of these reagents, fundamentals of multiphase transport phenomena are required and need to be further developed in combination with the chemistry.
To make progress in continuous-flow oxidation chemistry, full support from the industry is crucial. Interest from the industry is fuelled by the increased safety, the higher reaction selectivity and the overall efficiency of the oxidation protocol. Such collaborative efforts are not only important from a funding perspective but industrial applications will facilitate the widespread use of this technology, reduce the overall cost, and stimulate innovations in real life examples. ${ }^{346,347}$ Examples which still require substantial collaborative research efforts are, e.g., (i) controlled scalability from lab to full production scale; (ii) efficient recycling of metal catalysts; (iii) safe use of non-diluted oxygen sources and their impact on the reaction kinetics. ${ }^{317}$

\section{Acknowledgements}

Financial support is provided by the Dutch Science Foundation (NWO) via an ECHO grant (Grant No. 713.013.001) and a VENI grant for T.N. (Grant No. 12464). We also acknowledge the European Union for a Marie Curie CIG grant for T.N. (Grant No. 333659), for a Marie Curie Intra-European Fellowship for Y.S. (Grant No. 622415), and an ERC Advanced Grant for V.H. (Grant No. 267443). T.N. and R.L. would like to thank generous funding from the European Union within the Photo4Future Innovative Training Network (Grant No. 641861). M.S. thanks Chinese Scholarship Council for financial support.

\section{Notes and references}

M. G. Clerici and O. A. Kholdeeva, Liquid Phase Oxidation via Heterogeneous Catalysis: Organic Synthesis and Industrial Applications., John Wiley \& Sons, Hoboken, 2013.

J. C. J. Bart and S. Cavallaro, Ind. Eng. Chem. Res., 2015, 54, $1-46$.

J. C. J. Bart and S. Cavallaro, Ind. Eng. Chem. Res., 2015, 54, 567-576.

F. Cavani and J. H. Teles, ChemSusChem, 2009, 2, 508-534.

Q. Cao, L. M. Dornan, L. Rogan, N. L. Hughes and M. J. Muldoon, Chem. Commun., 2014, 50, 4524-4543.

Z. Shi, C. Zhang, C. Tang and N. Jiao, Chem. Soc. Rev., 2012, 41, 3381-3430.

B. L. Ryland and S. S. Stahl, Angew. Chem. Int. Ed., 2014, 53, 8824-8838.

S. D. McCann and S. S. Stahl, Acc. Chem. Res., 2015, 48, 1756-1766.

A. N. Campbell and S. S. Stahl, Acc. Chem. Res., 2012, 45, 851-863. 

Int. Ed., 2011, 50, 11062-11087.

S. E. Allen, R. R. Walvoord, R. Padilla-Salinas and M. C. Kozlowski, Chem. Rev., 2013, 113, 6234-6458.

L. Boisvert and K. I. Goldberg, Acc. Chem. Res., 2012, 45, 899-910.

A. M. Suess, M. Z. Ertem, C. J. Cramer and S. S. Stahl, J. Am. Chem. Soc., 2013, 135, 9797-9804.

B. L. Ryland, S. D. McCann, T. C. Brunold and S. S. Stahl, J. Am. Chem. Soc., 2014, 136, 12166-12173.

M. L. Scheuermann and K. I. Goldberg, Chem. Eur. J., 2014, 20, 14556-14568.

M. N. Kashid and L. Kiwi-Minsker, Ind. Eng. Chem. Res., 2009, 48, 6465-6485.

M. P. Duduković, F. Larachi and P. L. Mills, Catal. Rev., 2002, 44, 123-246.

M. N. Kashid, A. Renken and L. Kiwi-Minsker, Chem. Eng. Sci., 2011, 66, 3876-3897.

V. Hessel, D. Kralisch, N. Kockmann, T. Noël and Q. Wang, ChemSusChem, 2013, 6, 746-789.

I. R. Baxendale, R. D. Braatz, A. J. Florence, B. K. Hodnett, K. F. Jensen, M. D. Johnson, P. Sharratt and J. Sherlock, J. Pharm. Sci., 2015, 104, 781-791.

B. Gutmann, D. Cantillo and C. O. Kappe, Angew. Chem. Int. Ed., 2015, 54, 6688-6728.

F. G. Finelli, L. S. M. Miranda and R. O. M. A. de Souza, Chem. Commun., 2015, 51, 3708-3722.

I. M. Mándity, S. B. Ötvös and F. Fülöp, ChemistryOpen, 2015, 4, 212-223.

R. Munirathinam, J. Huskens and W. Verboom, Adv. Synth. Catal., 2015, 357, 1093-1123.

C. Wiles and P. Watts, Green Chem., 2014, 16, 55-62.

L. Vaccaro, D. Lanari, A. Marrocchi and G. Strappaveccia, Green Chem., 2014, 16, 3680-3704.

K. F. Jensen, B. J. Reizman and S. G. Newman, Lab Chip, 2014, 14, 3206-3212.

S. V. Ley, D. E. Fitzpatrick, R. J. Ingham and R. M. Myers, Angew. Chem. Int. Ed., 2015, 54, 3449-3464.
T. Rodrigues, P. Schneider and G. Schneider, Angew. Chem. Int. Ed., 2014, 53, 5750-5758.

V. Hessel, H. Lowe, A. Muller and G. Kolb, Chemical Micro Process Engineering: Processing and Plants, Wiley-VCH, Weinheim, 2005.

V. Hessel, A. Renken, J. C. Schouten and J. Yoshida, Micro Process Engineering: A Comprehensive Handbook, WileyVCH, Weinheim, 2009.

C. Wiles and P. Watts, Micro Reaction Technology in Organic Synthesis, CRC Press, Boca Raton, FL, 2011.

T. Wirth, Microreactors in Organic Chemistry and Catalysis, Wiley-VCH, Weinheim, 2013.

J.-I. Yoshida, Basics of Flow Microreactors Synthesis, Springer Japan, Kyoto, 2015.

A. Pohar and I. Plazl, Chem. Biochem. Eng. Q., 2009, 23, 537-544.

K. Boodhoo and A. Harvey, Process Intensification Technologies for Green Chemistry: Engineering Solutions for Sustainable Chemical Processing, John Wiley \& Sons, Chichester, 2013.

A. Gorak and A. I. Stankiewicz, Annu. Rev. Chem. Biomol. Eng., 2011, 2, 431-451.

V. Kumar and K. D. P. Nigam, Green Process. Synth., 2012, 1, 79-107.

G. Kolb, Chem. Eng. Process. Process Intensif., 2013, 65, 144.

G. Kolb, J. Schürer, D. Tiemann, M. Wichert, R. Zapf, V. Hessel and H. Löwe, J. Power Sources, 2007, 171, 198-204.

G. Kolb, V. Cominos, C. Hofmann, H. Pennemann, J. Schürer, D. Tiemann, M. Wichert, R. Zapf, V. Hessel and H. Löwe, Chem. Eng. Res. Des., 2005, 83, 626-633.

T. Noël and V. Hessel, in Ullmann's Encyclopedia of Industrial Chemistry, Wiley-VCH, 2014, pp. 1-35.

Z. Hou, N. Theyssen, A. Brinkmann and W. Leitner, Angew. Chem. Int. Ed., 2005, 44, 1346-1349.

E. Garcia-Verdugo, J. Fraga-Dubreuil, P. A. Hamley, W. B. Thomas, K. Whiston and M. Poliakoff, Green Chem., 2005, 7, 294-300.

E. Garcia-Verdugo, E. Venardou, W. B. Thomas, K. Whiston, W. Partenheimer, P. A. Hamley and M. Poliakoff, $A d v$. Synth. Catal., 2004, 346, 307-316. 

Vaquero, L. M. Dudd, I. Pearson, D. Housley, W. Partenheimer, W. B. Thomas, K. Whiston and M. Poliakoff, Green Chem., 2007, 9, 1238-1245.

R. A. Bourne, X. Han, M. Poliakoff and M. W. George, Angew. Chem. Int. Ed., 2009, 48, 5322-5325.

A. O. Chapman, G. R. Akien, N. J. Arrowsmith, P. Licence and M. Poliakoff, Green Chem., 2010, 12, 310-315.

X. Han, R. A. Bourne, M. Poliakoff and M. W. George, Chem. Sci., 2011, 2, 1059-1067.

J. F. B. Hall, R. A. Bourne, X. Han, J. H. Earley, M. Poliakoff and M. W. George, Green Chem., 2013, 15, 177-180.

U. Schuchardt, D. Cardoso, R. Sercheli, R. Pereira, R. S. Da Cruz, M. C. Guerreiro, D. Mandelli, E. V. Spinacé and E. L. Pires, Appl. Catal. A Gen., 2001, 211, 1-17.

J. H. J. Kluytmans, A. P. Markusse, B. F. M. Kuster, G. B. Marin and J. C. Schouten, Catal. Today, 2000, 57, 143-155.

P. L. Mills and R. V. Chaudhari, Catal. Today, 1999, 48, 1729.

G. Langhendries, D. E. De Vos, B. F. Sels, I. Vankelecom, P. A. Jacobs and G. V. Baron, Clean Technol. Environ. Policy, 1998, 1, 21-29.

P. L. Mills and R. V. Chaudhari, Catal. Today, 1997, 37, 367404.

H. Yin, C. Sheng, Z. Chen, S. Yuan, H. Li and J. Mei, Chem. Eng. Technol., 2014, 37, 1797-1804.

F. Wang, J. Xu, X. Li, J. Gao, L. Zhou and R. Ohnishi, Adv. Synth. Catal., 2005, 347, 1987-1992.

H. Ge, G. W. Chen, Q. Yuan and H. Q. Li, Catal. Today, 2005, 110, 171-178.

V. Tukač, J. Vokál and J. Hanika, J. Chem. Technol. Biotechnol., 2001, 76, 506-510.

R. Pohorecki, J. Bałdyga, W. Moniuk, A. Krzysztoforski and Z. Wójcik, Chem. Eng. Sci., 1992, 47, 2559-2564.

T. Chou and F. Lin, Can. J. Chem., 1983, 61, 1295-1300.

H. Nakajima, Mass Transfer - advanced aspects, InTech, 2011.

G. R. Astbury, Org. Process Res. Dev., 2002, 6, 893-895.

J.-R. Chen, Process Saf. Prog., 2004, 23, 72-81.
T. A. Kletz, J. Hazard. Mater., 1975, 1, 165-170.

V. Tukač, J. Hanika and V. A. Chyba, Catal. Today, 2003, 7980, 427-431.

A. Pintar, G. Berčič and J. Levec, Chem. Eng. Sci., 1997, 52, 4143-4153.

V. Hessel, P. Angeli, A. Gavriilidis and H. Löwe, Ind. Eng. Chem. Res., 2005, 44, 9750-9769.

Y. Su, Y. Zhao, G. Chen and Q. Yuan, Chem. Eng. Sci., 2010, 65, 3947-3956.

Y. Zhao, G. Chen and Q. Yuan, AIChE J., 2007, 53, 30423053.

A. L. Dessimoz, L. Cavin, A. Renken and L. Kiwi-Minsker, Chem. Eng. Sci., 2008, 63, 4035-4044.

J. H. Xu, J. Tan, S. W. Li and G. S. Luo, Chem. Eng. J., 2008, 141, 242-249.

C. Yao, Z. Dong, Y. Zhao and G. Chen, Chem. Eng. Sci., 2014, $112,15-24$.

K. S. Elvira, X. Casadevall i Solvas, R. C. R. Wootton and A. J. de Mello, Nat. Chem., 2013, 5, 905-15.

R. L. Hartman, J. P. McMullen and K. F. Jensen, Angew. Chem. Int. Ed., 2011, 50, 7502-7519.

F. E. Valera, M. Quaranta, A. Moran, J. Blacker, A. Armstrong, J. T. Cabral and D. G. Blackmond, Angew. Chem. Int. Ed., 2010, 49, 2478-2485.

Y. Su, N. J. W. Straathof, V. Hessel and T. Noël, Chem. Eur. J., 2014, 20, 10562-10589.

C. Wiles and P. Watts, Green Chem., 2012, 14, 38-54.

Y. Su, G. Chen, Y. Zhao and Q. Yuan, AIChE J., 2009, 55, 1948-1958.

J. Yue, L. Luo, Y. Gonthier, G. Chen and Q. Yuan, Chem. Eng. Sci., 2009, 64, 3697-3708.

T. Cubaud, M. Sauzade and R. Sun, Biomicrofluidics, 2012, 6, DOI: 10.1063/1.3693591.

A. Leclerc, M. Alamé, D. Schweich, P. Pouteau, C. Delattre and C. de Bellefon, Lab Chip, 2008, 8, 814-817.

S. Waelchli and P. Rudolf von Rohr, Int. J. Multiph. Flow, 2006, 32, 791-806. 
K. A. Triplett, S. M. Ghiaasiaan, S. I. Abdel-Khalik and D. L. Sadowski, Int. J. Multiph. Flow, 1999, 25, 377-394.

Y. Zhao, G. Chen, C. Ye and Q. Yuan, Chem. Eng. Sci., 2013, 87, 122-132.

J. Yue, L. Luo, Y. Gonthier, G. Chen and Q. Yuan, Chem. Eng Sci., 2008, 63, 4189-4202.

C. X. Zhao and A. P. J. Middelberg, Chem. Eng. Sci., 2011, 66, 1394-1411.

A. Woitalka, S. Kuhn and K. F. Jensen, Chem. Eng. Sci., 2014, 116, 1-8.

G. Berčič and A. Pintar, Chem. Eng. Sci., 1997, 52, 37093719.

J. M. van Baten and R. Krishna, Chem. Eng. Sci., 2004, 59, 2535-2545.

P. Sobieszuk, R. Pohorecki, P. Cygański and J. Grzelka, Chem. Eng. Sci., 2011, 66, 6048-6056.

C. Yao, Z. Dong, Y. Zhao and G. Chen, Chem. Eng. Sci., 2015, 123, 137-145.

W. E. Carroll, J. Organomet. Chem., 1981, 205, 14-15.

A. K. Suresh, M. M. Sharma and T. Sridhar, Ind. Eng. Chem. Res., 2000, 39, 3958-3997. 14, 7450-7459.
P. J. Nieuwland, K. Koch, N. Van Harskamp, R. Wehrens, J. C. M. Van Hest and F. P. J. T. Rutjes, Chem. Asian J., 2010, 5, 799-805.

T. Schwalbe, V. Autze, M. Hohmann and W. Stirner, Org. Process Res. Dev., 2004, 8, 440-454.

V. Hessel and T. Noel, in Ullmanns Encycl. Ind. Chem., Wiley-VCH, 2012, pp. 2-54.

R. Dey, T. Das and S. Chakraborty, Heat Transf. Eng., 2012, 33, 425-446.

P. Rosa, T. G. Karayiannis and M. W. Collins, Appl. Therm. Eng., 2009, 29, 3447-3468.

N. Kockmann, M. Gottsponer, B. Zimmermann and D. M. Roberge, Chem. Eur. J., 2008, 14, 7470-7477.

T. Illg, V. Hessel, P. Löb and J. C. Schouten, Green Chem., 2012, 14, 1420-1433.

J. Haber, M. N. Kashid, A. Renken and L. Kiwi-Minsker, Ind. Eng. Chem. Res., 2012, 51, 1474-1489.

F. Incropera, A. Lavine and D. DeWitt, Fundamentals of heat and mass transfer, John Wiley \& Sons, Hoboken, 2011.

W. M. Deen, Analysis of Transport Phenomena, Oxford University Press, Oxford, 1998.

A. Odedra and P. H. Seeberger, Angew. Chem. Int. Ed., 2009, 48, 2699-2702.

A. C. Hordijk and J. J. De Groot, Thermochim. Acta, 1986, 101, 45-63.

C. W. Jones, Applications of Hydrogen Peroxide and Derrivatives, Royal Society of Chemistry, Cambridge, 1999.

T. Illg, V. Hessel, P. Lçb and J. C. Schouten, ChemSusChem, 2011, 4, 392-398.

M. T. Musser, in Ullmann's Encyclopedia of Industrial Chemistry, Wiley-VCH, 2012, pp. 49-58.

M. L. Campbell, in Ullmann's Encyclopedia of Industrial Chemistry, Wiley-VCH, 2012, pp. 134-182.

J. R. Chen, H. H. Yang and C. H. Wu, Org. Process Res. Dev., 2004, 8, 252-255. J. R. Martinelli, T. E. Johnson, T. W. Root and S. S. Stahl, Org. Process Res. Dev., 2015, DOI: 10.1021/op500328f. 
121 R. A. Baker, W.E., Cox, P.A., Westine, P.S., Kulesz, J.J., Strehlow, Explosion Hazards and Evaluation, Elsevier Scientific Publishing Company, Amsterdam, Oxford, New York, 1983.

R. A. Strehlow, AIAA J., 1985, 23, 1139-1139.

M. Gödde, C. Liebner and H. Hieronymus, ChemieIngenieur-Technik, 2009, 81, 73-78.

C. Liebner, J. Fischer, S. Heinrich, T. Lange, H. Hieronymus and E. Klemm, Process Saf. Environ. Prot., 2012, 90, 77-82.

S. Heinrich, F. Edeling, C. Liebner, H. Hieronymus, T. Lange and E. Klemm, Chem. Eng. Sci., 2012, 84, 540-543.

N. B. Siccamat and K. R. Westerterp, Ind. Eng. Chem. Res., 1993, 32, 1304-1314.

N. B. Siccamat and K. R. Westerterp, Ind. Eng. Chem. Res., 1995, 34, 1755-1768. 144.

J. P. McMullen and K. F. Jensen, Annu. Rev. Anal. Chem., 2010, 3, 19-42.

130 J. Alagy, P. Trambouze and H. Van Landeghem, Ind. Eng. Chem. Process Des. Dev., 1974, 13, 317-323.

131 J. Hao, H. Cheng, H. Wang, S. Cai and F. Zhao, J. Mol. Catal. A: Chem., 2007, 271, 42-45.

132 N. Theyssen, Z. Hou and W. Leitner, Chem. Eur. J., 2006, 12, 3401-3409.

R. Jevtic, P. A. Ramachandran and M. P. Dudukovic, Chem. Eng. Res. Des., 2010, 88, 255-262.

X. Liu and K. F. Jensen, Green Chem., 2013, 15, 1538-1541.

U. Neuenschwander and K. F. Jensen, Ind. Eng. Chem. Res., 2014, 53, 601-608.

137 S. Kuhn, R. L. Hartman, M. Sultana, K. D. Nagy, S. Marre and K. F. Jensen, Langmuir, 2011, 27, 6519-6527.

138 D. V. Bavykin, A. A. Lapkin, S. T. Kolaczkowski and P. K. Plucinski, Appl. Catal. A Gen., 2005, 288, 175-184.

139 P. K. Plucinski, D. V. Bavykin, S. T. Kolaczkowski and A. A. Lapkin, Ind. Eng. Chem. Res., 2005, 44, 9683-9690.
P. K. Plucinski, D. V. Bavykin, S. T. Kolaczkowski and A. A. Lapkin, Catal. Today, 2005, 105, 479-483.

E. Cao, W. B. Motherwell and A. Gavriilidis, Chem. Eng. Technol., 2006, 29, 1372-1375.

E. Cao, M. Sankar, S. Firth, K. F. Lam, D. Bethell, D. K. Knight, G. J. Hutchings, P. F. McMillan and A. Gavriilidis, Chem. Eng. J., 2011, 167, 734-743.

D. Obermayer, A. M. Balu, A. A. Romero, W. Goessler, R. Luque and C. O. Kappe, Green Chem., 2013, 15, 1530-1537.

G. Wu, A. Constantinou, E. Cao, S. Kuhn, M. Morad, M. Sankar, D. Bethell, G. J. Hutchings and A. Gavriilidis, Ind. Eng. Chem. Res., 2015, 54, 4183-4189.

E. Cao, M. Sankar, E. Nowicka, Q. He, M. Morad, P. J. Miedziak, S. H. Taylor, D. W. Knight, D. Bethell, C. J. Kiely, A. Gavriilidis and G. J. Hutchings, Catal. Today, 2013, 203, 146-152.

T. Noël and V. Hessel, ChemSusChem, 2013, 6, 405-407.

S. R. Chaudhuri, J. Hartwig, L. Kupracz, T. Kodanek, J. Wegner and A. Kirschning, Adv. Synth. Catal., 2014, 356, 3530-3538. 
T. Osako, K. Torii and Y. Uozumi, RSC Adv., 2015, 5, 26472654.

158 J. H. Holland, Adaptation on Natural and Artificial Systems, MIT Press, Cambridge, MA, 1992.

Y. Chu, W. Heyndrickx, G. Occhipinti, V. R. Jensen and B. K. Alsberg, J. Am. Chem. Soc., 2012, 134, 8885-8895.

J. E. Kreutz, A. Shukhaev, W. Du, S. Druskin, O. Daugulis and R. F. Ismagilov, J. Am. Chem. Soc., 2010, 132, 31283132.

L. Vanoye, M. Pablos, N. Smith, C. de Bellefon and A. FavreRéguillon, RSC Adv., 2014, 4, 57159-57163.

B. Pieber and C. O. Kappe, Green Chem., 2013, 15, 320324.

J. De Houwer, K. Abbaspour Tehrani and B. U. W. Maes, Angew. Chem. Int. Ed., 2012, 51, 2745-2748.

166 S. L. Bourne and S. V. Ley, Adv. Synth. Catal., 2013, 355, 1905-1910.

B. Gutmann, P. Elsner, D. Roberge and C. O. Kappe, ACS Catal., 2013, 3, 2669-2676.

168 B. Saha and J. H. Espenson, J. Mol. Catal. A: Chem., 2007, 271, 1-5.

W. Partenheimer, Adv. Synth. Catal., 2004, 346, 297-306

170 J. F. Greene, J. M. Hoover, D. S. Mannel, T. W. Root and S. S. Stahl, Org. Process Res. Dev., 2013, 17, 1247-1251.

171 X. Ye, M. D. Johnson, T. Diao, M. H. Yates and S. S. Stahl, Green Chem., 2010, 12, 1180-1186.

172 L. Vanoye, M. Pablos, C. de Bellefon and A. Favre-Réguillon Adv. Synth. Catal., 2015, 357, 739-746.

173 P. R. Ogilby, Chem. Soc. Rev., 2010, 39, 3181-3209.

174 T. Noël, X. Wang and V. Hessel, Chim. Oggi, 2013, 31, 1014.

175 Z. J. Garlets, J. D. Nguyen and C. R. J. Stephenson, Isr. J. Chem., 2014, 54, 351-360.

176 M. Oelgemoeller, Chem. Eng. Technol., 2012, 35, 11441152.
J. P. Knowles, L. D. Elliott and K. I. Booker-Milburn, Beilstein J. Org. Chem., 2012, 8, 2025-2052.

M. Oelgemöller and O. Shvydkiv, Molecules, 2011, 16, 7522-7550.

R. C. R. Wootton, R. Fortt and A. J. De Mello, Org. Process Res. Dev., 2002, 6, 187-189.

K. S. Elvira, R. C. R. Wootton, N. M. Reis, M. R. Mackley and A. J. deMello, ACS Sustain. Chem. Eng., 2013, 1, 209-213.

S. Meyer, D. Tietze, S. Rau, B. Schäfer and G. Kreisel, J. Photochem. Photobiol. A Chem., 2007, 186, 248-253.

C. P. Park, R. A. Maurya, J. H. Lee and D.-P. Kim, Lab Chip, 2011, 11, 1941-1945.

R. A. Maurya, C. P. Park and D. P. Kim, Beilstein J. Org. Chem., 2011, 7, 1158-1163.

K. Loponov, J. Lopes, M. Barłóg, E. V Astrova, A. V. Malkov and A. Lapkin, Org. Process Res. Dev., 2014, 18, 1443-1454.

C. Y. Park, Y. J. Kim, H. J. Lim, J. H. Park, M. J. Kim, S. W. Seo and C. P. Park, RSC Adv., 2015, 5, 4233-4237.

C. Y. Park, J. H. Park, H. J. Lim, G.-S. Hwang and C. P. Park, Bull. Korean Chem. Soc., 2014, 35, 983-984.

F. Lévesque and P. H. Seeberger, Org. Lett., 2011, 13, 5008-5011.

T. Etrych, M. Šírovaé, L. Starovoytova, B. Řiéhovaé and K. Ulbrich, Mol. Pharm., 2010, 7, 1015-1026.

M. D. Altman, A. Ali, G. S. K. K. Reddy, M. N. L. Nalam, S. G. Anjum, H. Cao, S. Chellappan, V. Kairys, M. X. Fernandes, M. K. Gilson, C. A. Schiffer, T. M. Rana and B. Tidor, J. Am. Chem. Soc., 2008, 130, 6099-6113.

F. Lévesque and P. H. Seeberger, Angew. Chem. Int. Ed., 2012, 51, 1706-1709.

D. Kopetzki, F. Lévesque and P. H. Seeberger, Chem. Eur. J., 2013, 19, 5450-5456.

D. B. Ushakov, K. Gilmore, D. Kopetzki, D. T. McQuade and P. H. Seeberger, Angew. Chem. Int. Ed., 2014, 53, 557-561.

S. Vukelić, D. B. Ushakov, K. Gilmore, B. Koksch and P. H. Seeberger, Eur. J. Org. Chem., 2015, 3036-3039.

D. B. Ushakov, M. B. Plutschack, K. Gilmore and P. H. Seeberger, Chem. Eur. J., 2015, 21, 6528-6534. 
195 Y. Nagasawa, K. Tanba, N. Tada, E. Yamaguchi and A. Itoh, Synlett, 2015, 26, 412-415.

196 A. Talla, B. Driessen, N. J. W. Straathof, L.-G. Milroy, L. Brunsveld, V. Hessel and T. Noël, Adv. Synth. Catal., 2015, DOI: 10.1002/adsc.201401010.

197 R. J. Van Putten, J. C. Van Der Waal, E. De Jong, C. B. Rasrendra, H. J. Heeres and J. G. De Vries, Chem. Rev., 2013, 113, 1499-1597.

A. A. Rosatella, S. P. Simeonov, R. F. M. Frade and C. A. M Afonso, Green Chem., 2011, 13, 754-793.

C. Richard, A. M. Martre and P. Boule, J. Photochem. Photobiol. A Chem., 1992, 66, 225-234.

200 T. S. A. Heugebaert, C. V. Stevens and C. O. Kappe, ChemSusChem, 2015, 8, 1648-1651.

201 H. C. Aran, D. Salamon, T. Rijnaarts, G. Mul, M. Wessling and R. G. H. Lammertink, J. Photochem. Photobiol. A Chem., 2011, 225, 36-41.

202 T. Carofiglio, P. Donnola, M. Maggini, M. Rossetto and E. Rossi, Adv. Synth. Catal., 2008, 350, 2815-2822.

203 E. K. Lumley, C. E. Dyer, N. Pamme and R. W. Boyle, Org. Lett., 2012, 14, 5724-5727.

204 R. Gorges, S. Meyer and G. Kreisel, J. Photochem. Photobiol. A Chem., 2004, 167, 95-99.

205 H. Lindstrom, R. Wootton and A. Iles, AlChE J., 2007, 53, 695-702.

206 A. A. Lapkin, V. M. Boddu, G. N. Aliev, B. Goller, S. Polissk and D. Kovalev, Chem. Eng. J., 2008, 136, 331-336.

207 S. Lacombe, J. P. Soumillion, A. El Kadib, T. Pigot, S. Blanc, R. Brown, E. Oliveros, C. Cantau and P. Saint-Cricq, Langmuir, 2009, 25, 11168-11179.

208 S. Hejda, M. Drhova, J. Kristal, D. Buzek, P. Krystynik and P. Kluson, Chem. Eng. J., 2014, 255, 178-184.

209 J. Růžička and E. H. Hansen, Anal. Chim. Acta, 1986, 179, 158.

210 I. Dencic, J. Meuldijk, M. Croon and V. Hessel, J. Flow Chem., 2011, 1, 13-23.

211 I. Denčić, T. Noël, J. Meuldijk, M. De Croon and V. Hessel, Eng. Life Sci., 2013, 13, 326-343.

212 V. Hessel, J. Tibhe, T. Noël and Q. Wang, Chem. Biochem. Eng. Q. J., 2014, 28, 167-188.

213
R. Wohlgemuth, I. Plazl, P. Žnidaršič-Plazl, K. V. Gernaey and J. M. Woodley, Trends Biotechnol., 2015, 33, 302-314.

T. B. Goriushkina, A. P. Soldatkin and S. V. Dzyadevych, J. Agric. Food Chem., 2009, 57, 6528-6535.

G. A. M. Mersal and U. Bilitewski, Electrophoresis, 2005, 26, 2303-2312.

J. Wang, M. P. Chatrathi and G. E. Collins, Anal. Chim. Acta, 2007, 585, 11-16.

S. Rissom, U. Schwarz-Linek, M. Vogel, V. I. Tishkov and U. Kragl, Tetrahedron: Asymmetry, 1997, 8, 2523-2526.

U. Schwarz-Linek, A. Krödel, F.-A. Ludwig, A. Schulze, S. Rissom, U. Kragl, V. I. Tishkov and M. Vogel, Synthesis, 2001, 6, 947-951.

M. P. C. Marques, P. Fernandes, J. M. S. Cabral, P. Žnidaršič-Plazl and I. Plazl, Chem. Eng. J., 2010, 160, 708714.

M. P. C. Marques, P. Fernandes, J. M. S. Cabral, P. Žnidaršič-Plazl and I. Plazl, N. Biotechnol., 2012, 29, 227234.

A. J. Tušek, M. Tišma, V. Bregović, A. Ptičar, Ž. Kurtanjek and B. Zelić, Biotechnol. Bioprocess Eng., 2013, 18, 686696.

S. Illner, C. Hofmann, P. Löb and U. Kragl, ChemCatChem, 2014, 6, 1748-1754.

B. Tomaszewski, R. C. Lloyd, A. J. Warr, K. Buehler and A. Schmid, ChemCatChem, 2014, 6, 2567-2576.

B. Tomaszewski, A. Schmid and K. Buehler, Org. Process Res. Dev., 2014, 18, 1516-1526.

E. M. Forsberg, J. R. A. Green and J. D. Brennan, Anal. Chem., 2011, 83, 5230-5236.

R. Chirillo, G. Caenaro, B. Pavan and A. Pin, Clin. Chem., $1979,25,1744-1748$.

L. Babich, A. F. Hartog, M. A. Van Der Horst and R. Wever, Chem. Eur. J., 2012, 18, 6604-6609.

S. Wang, P. Su and Y. Yang, Anal. Biochem., 2012, 427, 139-143.

U. Hanefeld, L. Gardossi and E. Magner, Chem. Soc. Rev., 2009, 38, 453-468. 
230 C. Mateo, J. M. Palomo, G. Fernandez-Lorente, J. M. Guisan and R. Fernandez-Lafuente, Enzyme Microb. Technol., 2007, 40, 1451-1463.

231 J. A. A. Ho, L. C. Wu, N. C. Fan, M. S. Lee, H. Y. Kuo and C. S. Yang, Talanta, 2007, 71, 391-396.

232 U. Schuchardt, W. A. Carvalho and E. V. Spinace, Synlett, 1993, 10, 713-718.

233 C. Fräulin, G. Rinke and R. Dittmeyer, J. Flow Chem., 2013, 3, 87-91.

234 M. Hamano, K. D. Nagy and K. F. Jensen, Chem. Commun., 2012, 48, 2086-2088.

235 X.-M. Lv, L.-J. Kong, Q. Lin, X.-F. Liu, Y.-M. Zhou and Y. Jia, Synth. Commun., 2011, 41, 3215-3222.

236 L. Vanoye, A. Aloui, M. Pablos, R. Philippe, A. Percheron, A. Favre-Réguillon and C. de Bellefon, Org. Lett., 2013, 15, 5978-5981.

237 Z. He and T. F. Jamison, Angew. Chem. Int. Ed., 2014, 53, 3353-3357.

238 F. Diederich and A. de Meijere, Metal-Catalyzed Crosscoupling Reactions, Wiley-VCH, New York, 2004.

239 N. Miyaura, Cross-Coupling Reactions: A Practical Guide, Springer, 2002, vol. 219.

240 T. Noël and S. L. Buchwald, Chem. Soc. Rev., 2011, 40, 5010-5029.

241 D. Cantillo and C. O. Kappe, ChemCatChem, 2014, 6, 32863305.

242 Y. Nishihara, Applied Cross-Coupling Reactions, Springer, 2013, vol. 80.

243 C. P. Park and D. P. Kim, J. Am. Chem. Soc., 2010, 132, 10102-10106.

244 D. M. Rudzinski and N. E. Leadbeater, Green Process. Synth., 2013, 2, 323-328.

245 H. P. L. Gemoets, V. Hessel and T. Noël, Org. Lett., 2014, 16, 5800-5803.

T. P. Petersen, A. Polyzos, M. O'Brien, T. Ulven, I. R. Baxendale and S. V Ley, ChemSusChem, 2012, 5, 274-277.

247 M. Brzozowski, J. A. Forni, G. Paul Savage and A. Polyzos, Chem. Commun., 2015, 51, 334-337.
E. Dolusic, P. Larrieu, L. Moineaux, V. Stroobant, L. Pillote, D. Colau, L. Pochet, B. Van den Eynde, B. Masereel, J. Wouters and R. Frédérick, J. Med. Chem., 2011, 54, 53205334

Y. S. S. Wan, J. L. H. Chau, A. Gavriilidis and K. L. Yeung, Chem. Commun., 2002, 2, 878-879.

Y. S. S. Wan, J. L. H. Chau, K. L. Yeung and A. Gavriilidis, J. Catal., 2004, 223, 241-249.

O. Fenollar, D. García, L. Sánchez, J. López and R. Balart, Eur. Polym. J., 2009, 45, 2674-2684.

B. Cortese, M. De Croon and V. Hessel, Ind. Eng. Chem. Res., 2012, 51, 1680-1689.

E. Santacesaria, A. Renken, V. Russo, R. Turco, R. Tesser and M. Di Serio, in Industrial and Engineering Chemistry Research, 2012, vol. 51, pp. 8760-8767.

W. He, Z. Fang, D. Ji, K. Chen, Z. Wan, X. Li, H. Gan, S. Tang, K. Zhang and K. Guo, Org. Process Res. Dev., 2013, 17, 1137-1141.

A. Srinivasan, X. Wu, M. Y. Lee and J. S. Dordick, Biotechnol. Bioeng., 2003, 81, 563-569.

S. P. Kee and A. Gavriilidis, Org. Process Res. Dev., 2009, 13, 941-951.

C. Wiles, M. J. Hammond and P. Watts, Beilstein J. Org. Chem., 2009, 5, DOI:10.3762/bjoc.5.27.

F. Björkling, S. E. Godtfredsen, O. Kirk, F. Björkling, S. E. Godtfredsen and O. Kirk, J. Chem. Soc. Chem. Commun., 1990, 1301-1303.

F. Bjorkling, H. Frykman, S. E. Godtfredsen and O. Kirk, Tetrahedron, 1992, 48, 4587-4592.

F. Ebrahimi, E. Kolehmainen, P. Oinas, V. Hietapelto and I. Turunen, Chem. Eng. J., 2011, 167, 713-717.

F. Ebrahimi, E. Kolehmainen, A. Laari, H. Haario, D. Semenov and I. Turunen, Chem. Eng. Sci., 2012, 71, 531538.

S. Leveneur, J. Wärnå, K. Eränen and T. Salmi, Chem. Eng. Sci., 2011, 66, 1038-1050.

F. Ebrahimi, E. Kolehmainen and I. Turunen, Chem. Eng. J., 2012, 179, 312-317. 3040-3042. 
S. Doherty, J. G. Knight, M. A. Carroll, J. R. Ellison, S. J. Hobson, S. Stevens, C. Hardacre and P. Goodrich, Green Chem., 2015, 17, 1559-1571.

R. Maggi, S. Chitsaz, S. Loebbecke, C. G. Piscopo, G. Sartori and M. Schwarzer, Green Chem., 2011, 13, 1121-1123.

267 A. Castellan, S. Cavallaro and J. C. J. Bart, Catal. Today, 1991, 9, 237-254.

M. Shang, T. Noël, Q. Wang and V. Hessel, Chem. Eng. Technol., 2013, 36, 1001-1009.

269 M. Shang, T. Noël, Q. Wang, Y. Su, K. Miyabayashi, V. Hessel and S. Hasebe, Chem. Eng. J., 2015, 260, 454-462.

270 M. Damm, B. Gutmann and C. O. Kappe, ChemSusChem, 2013, 6, 978-982.

271 K. Yube and K. Mae, Chem. Eng. Technol., 2005, 28, 331336.

272 X. Liu and K. F. Jensen, Green Chem., 2012, 14, 1471.

273 J. H. Park, C. Y. Park, H. S. Song, Y. S. Huh, G. H. Kim and C. P. Park, Org. Lett., 2013, 15, 752-755.

274 J. Souto, R. Stockman and S. V Ley, Org. Biomol. Chem., 2015, 13, 3871-3877.

275 W. Wu, G. Qian, X. G. Zhou and W. K. Yuan, Chem. Eng. Sci., 2007, 62, 5127-5132.

276 K. Yube, M. Furuta and K. Mae, Catal. Today, 2007, 125, 56-63.

277 A. Hartung, M. A. Keane and A. Kraft, J. Org. Chem., 2007, 72, 10235-10238.

P. Bailey, Chem. Rev., 1958, 58, 925-1010.

279 S. G. Van Ornum, R. M. Champeau and R. Pariza, Chem. Rev., 2006, 106, 2990-3001.

280 M. Irfan, T. N. Glasnov and C. O. Kappe, Org. Lett., 2011, 13, 984-987.

281 M. O’Brien, I. R. Baxendale and S. V. Ley, Org. Lett., 2010, 12, 1596-1598.

282 M. D. Roydhouse, A. Ghaini, A. Constantinou, A. CantuPerez, W. B. Motherwell and A. Gavriilidis, Org. Process Res. Dev., 2011, 15, 989-996.

283 M. D. Roydhouse, W. B. Motherwell, A. Constantinou, A. Gavriilidis, R. Wheeler, K. Down and I. Campbell, RSC Adv., 2013, 3, 5076.
J. Ren, S. He, C. Ye, G. Chen and C. Sun, Chem. Eng. J., 2012, 210, 374-384.

285

S. Kobayashi, H. Miyamura, R. Akiyama and T. Ishida, J. Am. Chem. Soc., 2005, 127, 9251-9254.

J. Wegner, S. Ceylan, C. Friese and A. Kirschning, Eur. J. Org. Chem., 2010, 4372-4375.

J. Sedelmeier, S. V. Ley, I. R. Baxendale and M. Baumann, Org. Lett., 2010, 12, 3618-3621.

I. R. Baxendale, J. Deeley, C. M. Griffiths-Jones, S. V Ley, S. Saaby and G. K. Tranmer, Chem. Commun., 2006, 25662568.

D. N. Tran, C. Battilocchio, S.-B. Lou, J. M. Hawkins and S. V. Ley, Chem. Sci., 2015, 6, 1120-1125.

N. M. Roda, D. N. Tran, C. Battilocchio, R. Labes, R. J. Ingham, J. M. Hawkins and S. V. Ley, Org. Biomol. Chem., 2015, 13, 2550-2554.

K. C. Basavaraju, S. Sharma, R. A. Maurya and D. P. Kim, Angew. Chem. Int. Ed., 2013, 52, 6735-6738.

C. Wiles, P. Watts and S. J. Haswell, Tetrahedron Lett., 2006, 47, 5261-5264.

A. Šali, A. Tušek, Ž. Kurtanjek and B. Zelić, Biotechnol. Bioprocess Eng., 2011, 16, 495-504.

A. Tušek, A. Šalić, Ž. Kurtanjek and B. Zelić, Eng. Life Sci., 2012, 12, 49-56.

A. Šalić, K. Pindrić and B. Zelić, Appl. Biochem. Biotechnol., 2013, 171, 2273-2284.

A. Šalić and B. Zelić, RSC Adv., 2014, 4, 41714-41721.

M. Tudorache, D. Mahalu, C. Teodorescu, R. Stan, C. Bala and V. I. Parvulescu, J. Mol. Catal. B Enzym., 2011, 69, 133139.

P. J. Keay and Y. Wang, Trends Biotechnol., 1997, 15, 7681.

A. M. Azevedo, V. Vojinović, J. M. S. Cabral, T. D. Gibson and L. P. Fonseca, J. Mol. Catal. B Enzym., 2004, 28, 121128.

A. M. Azevedo, J. M. S. Cabral, T. D. Gibson and L. P. Fonseca, J. Mol. Catal. B Enzym., 2004, 28, 45-53.

M. Y. Lee, A. Srinivasan, B. Ku and J. S. Dordick, Biotechnol. Bioeng., 2003, 83, 20-28. 
302 J. Drott, K. Lindström, L. Rosengren and T. Laurell, J. Micromech. Microeng., 1999, 7, 14-23.

303

T. T. Tidwell, Org. React., 2004, 39, 297-555.

304 T. Kawaguchi, H. Miyata, K. Ataka, K. Mae and J. I. Yoshida, Angew. Chem. Int. Ed., 2005, 44, 2413-2416.

305 J. R. Mcconnell, J. E. Hitt, E. D. Daugs and T. A. Rey, Org. Process Res. Dev., 2008, 12, 940-945.

J. J. M. van der Linden, P. W. Hilberink, C. M. P. Kronenburg and G. J. Kemperman, Org. Process Res. Dev., 2008, 12, 911-920.

307 K. Watts, A. Baker and T. Wirth, J. Flow Chem., 2014, 4, 211.

308 F. J. Del Campo, Electrochem. commun., 2014, 45, 91-94.

309 R. Stalder and G. P. Roth, ACS Med. Chem. Lett., 2013, 4, 1119-1123.

310 T. Kashiwagi, F. Amemiya, T. Fuchigami and M. Atobe, Chem. Commun., 2012, 48, 2806-2808.

311 F. Amemiya, T. Fuchigami and M. Atobe, J. Flow Chem., 2012, 3, 17-22.

312 K. Watts, W. Gattrell and T. Wirth, Beilstein J. Org. Chem. $2011,7,1108-1114$.

313 O. Radovici, A. Banu and C. Pirvu, ECS Trans., 2009, 16, 1-9.

314 R. A. Green, R. C. D. Brown and D. Pletcher, J. Flow.Chem., 2015, 5, 31-36.

315 M. A. Kabeshov, B. Musio, P. R. D. Murray, D. L. Browne and S. V Ley, Org. Lett., 2014, 16, 4618-4621.

316 J. Kuleshova, J. T. Hill-Cousins, P. R. Birkin, R. C. D. Brown D. Pletcher and T. J. Underwood, Electrochim. Acta, 2011, 56, 4322-4326.

317 For continuous-flow precious metal recycling see: I. Vural Gürsel, T. Noel, Q. Wang and V. Hessel, Green Chem., 2015, 17, 2012-2026.

318 P. D. Hampton, M. D. Whealon, L. M. Roberts, A. A. Yaeger and R. Boydson, Org. Process Res. Dev., 2008, 12, 946-949.

319 A. Bogdan and D. T. McQuade, Beilstein J. Org. Chem., 2009, 5, DOI:10.3762/bjoc.5.17.

320 C. Aellig, D. Scholz, S. Conrad and I. Hermans, Green Chem., 2013, 15, 1975-1980.
C. Aellig, D. Scholz and I. Hermans, ChemSusChem, 2012, 5, 1732-1736.

N. Ambreen, R. Kumar and T. Wirth, Beilstein J. Org. Chem. 2013, 9, 1437-1442.

A. Kirschning, C. Altwicker, G. Dräger, J. Harders, N. Hoffmann, U. Hoffmann, H. Schönfeld, W. Solodenko and U. Kunz, Angew. Chem. Int. Ed., 2001, 40, 3995-3998.

A. B. Leduc and T. F. Jamison, Org. Process Res. Dev., 2012, 16, 1082-1089.

D. Ghislieri, K. Gilmore and P. H. Seeberger, Angew. Chem. Int. Ed., 2014, 54, 678-682.

S. Rozen, Eur. J. Org. Chem., 2005, 2433-2447.

C. B. McPake, C. B. Murray and G. Sandford, Tetrahedron Lett., 2009, 50, 1674-1676.

C. B. Mcpake, C. B. Murray and G. Sandford, Chim. Oggi, 2010, 28, 28-29.

B. R. Travis, M. Sivakumar, G. O. Hollist and B. Borhan, Org. Lett., 2003, 5, 1031-1034.

Y. M. A. Yamada, K. Torii and Y. Uozumi, Beilstein J. Org. Chem., 2009, 5, 1-5.

M. Zanfir and A. Gavriilidis, Org. Process Res. Dev., 2007 11, 966-971.

L. Malet-Sanz and F. Susanne, J. Med. Chem., 2012, 55, 4062-4098.

M. Saber, J. M. Commenge and L. Falk, Chem. Eng. Sci., 2010, 65, 372-379.

M. Al-Rawashdeh, F. Yu, T. A. Nijhuis, E. V. Rebrov, V. Hessel and J. C. Schouten, Chem. Eng. J., 2012, 207-208, 645-655.

M. Al-Rawashdeh, J. Zalucky, C. Müller, T. A. Nijhuis, V. Hessel and J. C. Schouten, Ind. Eng. Chem. Res., 2013, 52, 11516-11526.

Y. Wada, M. A. Schmidt and K. F. Jensen, Ind. Eng. Chem. Res., 2006, 45, 8036-8042.

S. Hubier, U. Bentrup, U. Budde, K. Lovis, T. Dietrich, A. Freitag, L. Küpper and K. Jahnisch, Org. Process Res. Dev., 2009, 13, 952-960.

A. Yavorskyy, O. Shvydkiv, N. Hoffmann, K. Nolan and M. Oelgemöller, Org. Lett., 2012, 14, 4342-4345. 
339 N. Kockmann, M. Gottsponer and D. M. Roberge, Chem. Eng. J., 2011, 167, 718-726.

340 D. M. Roberge, M. Gottsponer, M. Eyholzer and N. Kockmann, Chim. Oggi, 2009, 27, 8-11.

341 N. Kockmann, Chemie-Ingenieur-Technik, 2012, 84, 646659.

342 N. Kockmann and D. M. Roberge, Chem. Eng. Process. Process Intensif., 2011, 50, 1017-1026.

343 G. S. Calabrese and S. Pissavini, AlChE J., 2011, 57, 828834.

344 M. J. Nieves-Remacha, A. A. Kulkarni and K. F. Jensen, Ind. Eng. Chem. Res., 2013, 52, 8996-9010.

345 Y. Zhang, S. C. Born and K. F. Jensen, Org. Process Res. Dev., 2014, 18, 1476-1481.

346 Q. Michaudel, Y. Ishihara and P. S. Baran, Acc. Chem. Res., 2015, 48, 712-721.

347 C. J. Welch, J. M. Hawkins and J. Tom, Org. Process Res. Dev., 2014, 18, 481-487. 


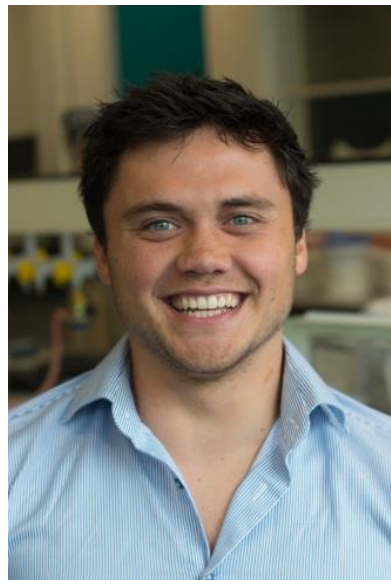

Hannes P. L. Gemoets was born in Ghent (1991), Belgium. He received a MSc degree (Industrial Chemical Engineering, cum laude) from the KaHo Sint-Lieven in 2013. Currently he is pursuing a PhD under supervision of Dr. Timothy Noel and Prof. Volker Hessel at the University of Technology Eindhoven (Netherlands). His research focuses on the development of novel continuous-flow methods for $\mathrm{C}-\mathrm{H}$ functionalization strategies.

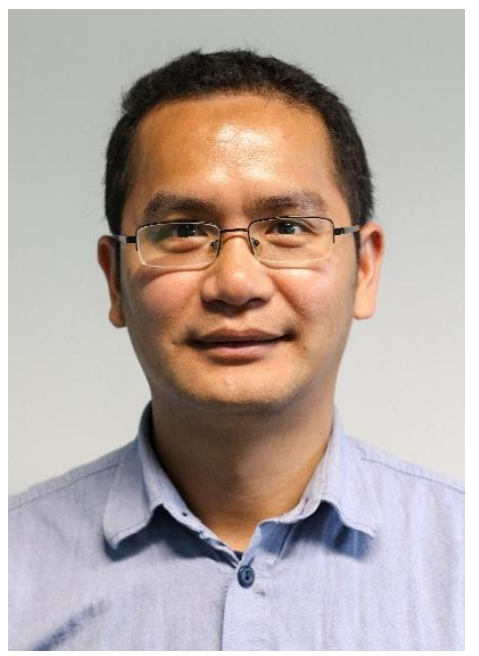

Yuanhai Su was born in China. He received B.E. from Tianjin University, and then Ph.D. degree from Dalian Institute of Chemical Physics with the supervision of Prof. Guangwen Chen and Prof. Quan Yuan, both in chemical engineering. He conducted his postdoc research with the support of the Alexander von Humboldt Foundation, with the host of Prof. Eugeny Kenig in Paderborn University, Germany. Currently, he is the recipient of the Marie Curie Actions fellowship (host: Assistant Prof. Timothy Noël), and works in Eindhoven University of Technology, the Netherlands. His research interests are in the areas of process intensification, microreactor technology and continuous-flow chemistry.

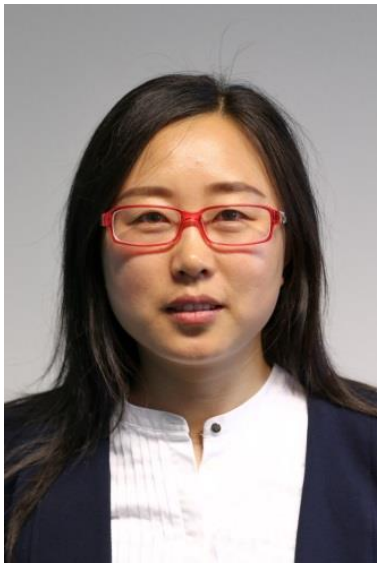

Minjing Shang was born in Shandong Province, China. She received B.E. and MSC degrees from Dalian University of Technology (China) in 2011, under the supervision of Prof. Yongchun Zhang, on the topic of $\mathrm{CO}_{2}$ hydrogenation to form methanol. Currently, she is a PhD candidate with the supervision of Dr. Timothy Noël and Prof. Volker Hessel at Eindhoven University of Technology (Netherlands). Her research interests focus on process intensification and continuous-flow Chemistry.

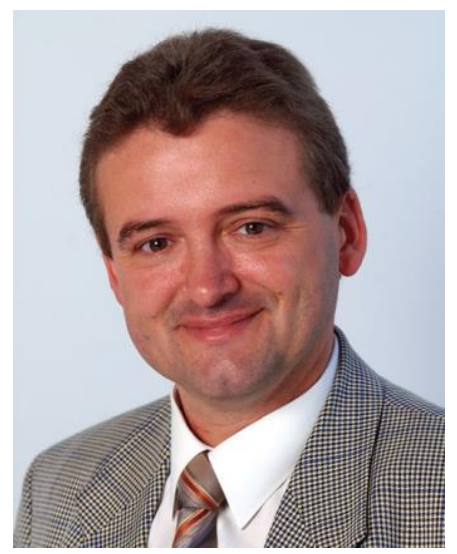

Prof. Dr. Volker Hessel studied chemistry at Mainz University. In 1999 he was appointed Head of the Microreaction Technology Department at Institut fur Mikrotechnik Mainz (IMM) GmbH. In 2002, he was appointed Vice Director and in 2007 he was appointed Director R\&D at IMM. In 2011 he was appointed full Professor for the chair of "Micro Flow Chemistry and Process Technology" at Eindhoven University of Technology. In 2009, he was appointed Honorary Professor at the Technical University of Darmstadt and is Fellow of their Cluster of Excellence "Smart Interfaces". He received the AIChE "Excellence in Process Development Research" award in 2007, and in 2010 he received the ERC Advanced Grant on "Novel Process Windows". 


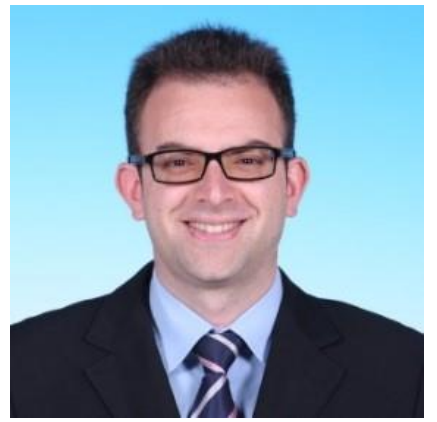

Rafael Luque has extensively published (>250 peer-reviewed publications) in the areas of (nano)materials science, heterogeneous (nano)catalysis, microwave and flow chemistry, biofuels and green chemical methods in synthetic organic chemistry, filed 3 patent applications and edited 8 books as well as numerous contributions to book chapters and invited, guest, keynote and plenary lectures in scientific events worldwide. Among recent awards, Rafael has received the TR35 Spain from Technology Review and MIT as one of the top 10 young entrepreneurs in Spain (2012) and the RSC Environment, Sustainability and Energy Early Career Award (2013) from the Royal Society of Chemistry UK.

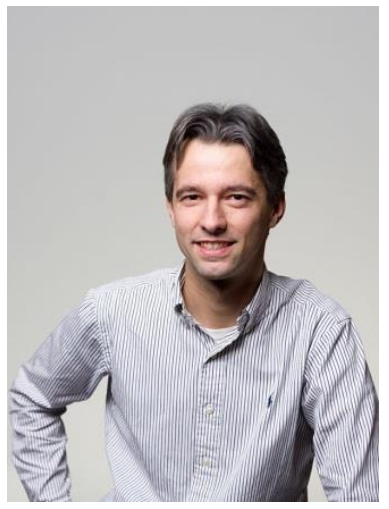

Timothy Noël obtained his M.Sc. (Industrial Chemical Engineering) in 2004. In 2009, he received his Ph.D. at the University of Ghent. He then moved to the Massachusetts Institute of Technology as a Fulbright Postdoctoral Fellow with Professor Stephen L. Buchwald (MIT-Novartis Center for Continuous Manufacturing). In 2012, he accepted a position as an assistant professor at Eindhoven University of Technology. In 2011, he received an Incentive Award for Young Researchers. In 2012, he received a Veni grant (NWO) and was nominated for the European Young Chemist Award. Since 2014, he has been serving as an associate editor of the Journal of Flow Chemistry. Recently, he received a prestigious VIDI grant (NWO) and he coordinates the Marie Skłodowska-Curie ETN program "Photo4Future". 